\title{
DIE ALTENGLISCHE GLOSSENHANDSCHRIFT PLAN'TINUS 32 (ANTWERPEN) UND ADDITIONAL 32246 (LONDON).
}

In Wright-Wülkers Anglo-Saxon and Old English Vocabularies (London 1884) sind an vierter und fünfter stelle (sp. 104-191) zwei lateinisch-altenglische sachglossare abgedruckt, die dort irrigerweise dem "erzbischof Elfric" zugeschrieben und in das 10. jahrhundert verlegt werden. ${ }^{1)}$ Sie haben indes weder mit dem erzbischofe Ælfric noch mit dem gleichnamigen abte irgendetwas $\mathrm{zu} \operatorname{tun}^{2}$ ) und stammen auch erst aus dem ende des 11. oder dem anfang des 12. jahrhunderts.

Wright und Wülker druckten die beiden glossare nach einer modernen abschrift (Junius Ms. 71; vgl. Wanley s. 96), welche von dem bekannten Franciscus Junius oder vielmehr François du Jon (1589-1677), dem in Holland aufgewachsenen bibliothekare des grafen Arundel, nach einer alten handschrift hergestellt war, die sich damals angeblich im besitz des Antwerpener malers Peter Paul Rubens $(\dagger 1640)$ befand. Lange zeit galt diese handschrift für verschollen. Aber im jahre 1884 erwarb das Britische museum von einem dr. Nolte ein manuskript-fragment von 24 blättern (jetzt Additional 32246), in welchem J. Zupitza bald darauf einen teil des gesuchten

1) Auch im 0xforder wörterbuche werden diese glossen unter Alfrics namen zitiert und um das jahr 1000 angesetzt.

2) Allerdings hat unser glossar mehrfach aus dem echt- Elfricschen glossare geschöpft. Das zeigt sich am stärksten in der liste der krankheitsadjektive (WW $161^{36}-162^{23}=$ unten $\mathrm{nr}$. 245-275), die sicher ans Elfric (ed. Znpitza $304^{15}-305^{9}$ ) stammt. 
Rubens-manuskriptes erkannte, ${ }^{1}$ ) nachdem schon E. M. Thompson in 'The Journal of the British Archæological Association', vol. XLI (1885) s. 144-152 auf die grofse ähnlichkeit der darin befindlichen glossen mit den von Junius abgeschriebenen hingewiesen hatte. Thompson wagte es nicht, das neue Londoner manuskript als die vorlage von Junius zu bezeichnen, weil sich manche abweichungen von Junius' abschrift zeigten und namentlich zwei grö (sere abschnitte darin gänzlich fehlten. ${ }^{2}$ ) Das letztere bedenken konnte 1887 Zupitza durch den hinweis ${ }^{3}$ ) heben, dafs die Londoner handschrift in wünschenswerter weise ergänzt werde durch eine handschrift des Musée PlantinMoretus zu Antwerpen, die auch die von Junius kopierten lateinischen verse auf den erzbischof Elfric sowie den gleichfalls von ihm mitgeteilten lateinischen brief an einen priester Elfric enthalte, also sicher die von Junius benutzte handschrift sei. Ebenso leicht entfällt der andere einwand, wenn man die allgemeine unzuverlässigkeit der Juniusschen abschriften in betracht zieht, auf die - im gegensatz zu Sweets lob (झlfred's Pastoral Care s. XIX) - schon mehrmals hingewiesen ist. ${ }^{4}$ Auch mir hat ein genaues studium der Antwerpener handschrift, das mir durch das freundliche entgegenkommen des herrn konservators Denucé in Antwerpen und die dankenswerten bemühungen des kaiserlich-deutschen generalgouverneurs in Belgien und des herrn geheimrats Boysen in Leipzig ermöglicht war, die überzeugung gebracht, daโs die Antwerpener handschrift, ergänzt durch die Londoner fragmente, die von Junius benutzte glossen-handschrift gewesen ist. Ein bericht über das ergebnis meiner unter-

1) Laut mitteilung in der Berliner Gesellschaft für das Studium der neueren Sprachen vom 29. März 1887 (vgl. Archiv f. n. Spr. LXXIX 88 f.).

2) In demselben sinne äufserte sich Fr. Kluge auläfslich seiner kollation der Londoner handschrift mit Wright-Wïlkers abdruck (Anglia VIII 448-452). Von E. Sievers auf ähnliche unstimınigkeiten in Junius' Tatiankopie hingewiesen, zog er allerdings später seinen einspruch zurück (Engl. Stud. X 130).

8) Zupitza, Archiv LXXIX 83 f.

4) von Zupitza in der Z. f. d. Altert. XXXI 2, von McLean in Anglia VI 448, von Breck in seiner Leipziger dissertation (1887) s. 15, von Logeman in seiner Rule of St. Benet (1888) s. XXXII und von einem anonymus in der Academy rom 27. Sept. 1890, s. 274. Das gleiche kann ich bestätigen auf grund der Junins-kopie (Jun. Ms. 45) des Cato-textes von Julins A II. 
suchungen wird daher schon jetzt den fachgenossen nicht unwillkommen sein.

Die Antwerpener handschrift trägt jetzt auf dem rücken des modernen schweinslederbandes die signatur nr. 32, sowie auf rotem leder in goldpressung die aufschrift: Excerptiones de Prisciano. Sie besteht aus 49 pergamentblättern und einem mittelst falzes eingefügten halbblatte, ${ }^{1}$ ) das in der modernen bleistiftzählung als fol. $19^{B}$ bezeichnet ist. Die gröIse der blätter beträgt durchschnittlich etwa $29 \times 22 \mathrm{~cm}$. Inhaltlich wie äufserlich erweist sich die handschrift als unvollständig. Denn fol. 2 und 3 bilden einen isolierten bogen, dessen beide blätter textlich nicht zusammenpassen, sondern beim übergang von fol. $2^{\mathrm{b}} \mathrm{zu} 3^{\mathrm{a}}$ eine gröIsere lücke zeigen. Beim übergang von fol. $3^{\mathrm{b}} \mathrm{zu} 4^{\mathrm{a}}$ ist abermals eine gröfsere textlücke. Aber von fol. 4 ab bietet die handschrift wenigstens lauter regelrechte lagen $\mathrm{zu}$ vier bogen: fol. $4-11$ bildet die lage $B$ ( - wenn wir das angeklebte blatt 1 und den bogen fol. 2-3 als $A$ bezeichnen dürfen - ), fol. 12-19 die lage $C$, fol. 20-27 die lage $D$, fol. 28-35 die lage $E$, fol. 36-43 die lage $F$ und fol. 44-49 die nur drei bogen umfassende schlufslage $G$. Diese lagen weisen in sich selbst textlich keine lücken auf, sind also vollständig. Dagegen stofsen wir auf eine textlücke zwischen fol. $19^{\mathrm{b}}$ und $20^{\mathrm{a}}$, also zwischen den lagen $C$ und $D$.

Es trifft sich nun gut, dafs in die genannten drei lücken der Antwerpener handschrift sich jedesmal teile des Londoner fragmentes Additional 32246 zwanglos einfügen. ${ }^{2}$ ) Die erste aus drei bogen ${ }^{3}$ ) bestehende lage der Londoner handschrift (= fol. 2-7), welcher nach Thompson der anfang des textes fehlt, fügt sich prächtig zwischen fol. 2 und 3 des Antwerpener codex ein, so dals das Antwerpener doppelblatt 2 und 3 den äufseren bogen einer regelrechten nunmehr vierbogigen lage bildet. Die zweite aus vier bogen bestehende lage der Londoner handschrift (fol. 8-15) füllt die textlücke hinter fol. 3 des Antwerpener codex aus. Und die dritte Londoner lage

1) Die ganze äufsere blatthălfte fehlt.

2) Ich kann mich dabei allerdings zur zeit nur anf die angaben von Zupitza und Thompson stützen, die aber für unsern zweck im grofsen und ganzen genẗgen.

8) fol. 1 ist ein einzelnes eingeheftetes blatt. 
(fol. 16-21, mit offenbar eingefalztem fünften halbbogen) gehört in die Antwerpener lücke nach fol. $19^{\vee}$, da das lateinische Colloquium Alfrici auf der Antwerpener fol. 19 verso mit dem satze qui nec saltem holeribus uestris dulciter sine me utimini (= Wright-Wülker $98^{8}$ ) schliefst $\left.{ }^{1}\right)$ und auf der Londoner fol. $16^{\text {recto }}$ mit $T u$ pistor, dic nobis (= Wright-Wülker $98^{\circ}$ ) sich unmittelbar anschliefsend fortsetzt. ${ }^{2}$ ) Die ursprüngliche zusammensetzung der Plantinschen handschrift mufs also die folgende gewesen sein:

$$
\begin{aligned}
& \text { Lage } A(\text { fol. } 1-10)=\left\{\begin{array}{l}
\text { Antwerpen fol. } 1 \\
\text { London fol. } 1 \\
\text { Antwerpen fol. } 2 \text { (jetzt lage A } 1 \text { ) } \\
\text { London fol. 2-7 (lage A) } \\
\text { Antwerpen fol. } \left.3 \text { (lage } A^{2}\right)
\end{array}\right. \\
& \text { "B (fol. 11-18) = London fol. 8-15 (lage B) } \\
& \text { "C (fol. 19-26) }=\text { Antwerpen fol. 4-11 (lage B) }{ }^{3} \text { ) } \\
& " \mathrm{D}(\text { fol. 27-34) }=\quad \text { fol. 12-19 (lage C) } \\
& \text { \# } \mathrm{E}(\text { fol. 35-43) = London fol. 16-24 (lage C) } \\
& " \quad \mathrm{~F}(\text { fol. } 44-52)=\text { Antwerpen fol. } 19^{\mathrm{B}}-27 \text { (lage D) } \\
& " G(\text { fol. 53-60) }=\quad \text { fol. 28-35 (lage E) } \\
& " \quad H(\text { fol. } 61-68)=\quad " \quad \text { fol. } 36-43 \text { (lage F) } \\
& " \quad I(\text { fol. } 69-74)=\quad " \quad \text { fol. 44-49 (lage G) }
\end{aligned}
$$

Wir erhalten so einen kodex von 74 pergamentblättern, die in neun lagen zu meist vier bogen zusammengefalst sind. Einzig die schlufslage hatte nur drei bogen, während die erste lage noch zwei vorgesetzte einzelblätter oder ein doppel-

1) Auf dem eingefalzten halbblatt fol. $19 \mathrm{~B}$ ist kein rand freigelassen, so dafs nichts vom Colloquium eingetragen werden konnte.

2) Das Antwerpener halbblatt $19 \mathrm{~B}$ ist jetzt an die Antwerpener lage $D$ angefalzt und mufs auch ursprünglich zn dieser lage gehört haben, da fol. 19 B verso mit Sciscitor schliefst und fol. 20 recto mit Sciscitaris beginnt.

3) Nach dieser anordnung hat Junius die altenglischen randglossen der Antwerpeuer fol. $4^{\text {a }}$ (= Wright-Wülker $161^{36}-162^{22}$ ) umgestellt, und zwar unter die krankheitsuamen, die mehr am ende des vokabulars standen, was sich nach ihrem inhalte leicht begreifen läfst. Verstehen läfst sich so auch, warum Junius die beiden ersten, in den neuen zusammenhang nicht passenden glossen von fol. 4 a fortgelassen hat.

Anglia. N. F. XXIX. 
blatt und die fünfte und sechste lage einen weiteren fünften halbbogen aufwies.

Über den inhalt des Plantinschen kodex lälst sich folgendes sagen, wobei ich mich, sofern nichts anderes angegeben, der blätterzählung der ursprünglichen vollständigen form der handschrift bediene.

(1) Den grundtext der ganzen handschrift bildet ein auszug aus der berühmten Lateingrammatik des spätrömischen grammatikers Priscianus, welcher unter dem titel Incipiunt excerptiones de Prisciano fol. $2^{a}-72^{b}$ (der ursprünglichen handschrift) umfalst. Dieser auszug ist gänzlich verschieden von dem, welcher unter des Hrabanus Maurus werken sich findet (z. b. Opera ed. Pamelius, Köln 1626, I 28-50). Er schliefst sich vielmehr eng im wortlaut an das original an und erreicht die kürzung mehr durch einfache auslassungen als durch zusammenziehende verarbeitung. Ein ähnlicher auszug ${ }^{1}$ ) hat dem abte Elfric bei der abfassung seiner altenglischen Lateingrammatik vorgelegen, die er selbst als luas excerptiones de Prisciano in der vorrede bezeichnet. Die gegenüberstellung des anfangskapitels mag dies zeigen:

Elfric ed. Zupitza (Berlin 1880) s. 4: Secundum Donatum omnis vox aut articulata est aut confusa. Articulata est, quae litteris conprehendi potest; confusa, quae scribi non potest. Stemn is geslagen lyft gefredendlic on hlyste, swa micel swa on Jcere heorcnunge is. Ic secge nu gewislicor, pat alc stemn byठ geworden of 万aes muðes clypunge and of Jare lyfte cnyssunge. Se muð drifð ut $\partial a$ clypunge, and seo lyft byð geslagen mid ¿are clypunge and gewyrd to stemne. AElc stemn is oðde andgytfullic oठde gemenged. Andgytfullic stemn is, pe mid andgyte bið geclypod, suasua ys 'arma uirumque cano' ic herige pa wrepnu and bone ver. Gemenged stemn is, pe bio butan andgyte, swoylc swa is hryjera gehlow and horsa hncegung, hunda gebeorc, treowa brastlung et cetera.

1) Nicht also das Prisciansche originalwerk selbst, wie Brandl, Altenglische Literatur (1908) 8. 1107 anzunehmen scheint ("eine übersetznng der damals sehr beliebten Institutiones grammaticae von Priscian"). Übrigens finden sich die erweiterungen, die Elfric dem Antwerpener auszug gegentiber anfweist, auch nicht in dem Priscianschen original. Dennoch glanbe ich nicht, dais nnser Antwerpener auszug Elfrics vorlage war, schon weil der doch jedenfalls ans der vorlage herübergenommene lateinische allfangssatz bei Alfric völlig anders lantet und confusa als gegensatz zu articulata in dem Antwerpener auszug, wie im Priscianschen originale, durch inarticulata vertreten ist. 
Antwerpen Ms. 32 fol. 2a: De uoce initium. Plilosophi definiunt uocem esse aerem tenuissimum ictum uel suum sensibile aurium, id est, quod proprie auribus accidit. Et est prior diffinitio a substantia sumpta, altera uero ab accidentibus. Accidit autem uoci auditus, quantum in ipsa est. Uocis autem differentie sunt quattuor: articulata, inarticulata, litterata, inlitterata. Articulata enin est, que coarctata, hoc est copulata cum

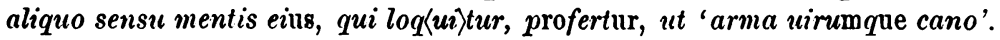
Inarticulata est contraria, que a nullo affectu proficiscitur mentis ut sibilus hominum et gemitus, quę scribi non possunt, intelleguntur tamen. Litterata enim est, que scribi potest sine sensu, ut 'coax', 'cra'. Inlitterata est, quę nec scribi nec intellegi potest, ut strepitus et mugitus et similia. Uox dicta est uel a uocando, ut rex a regendo, dux a ducendo, uel a sono, ut quibusdam placet.

Dieser grundtext ist in der hauptsache von zwei sich abwechselnden händen in fränkischer buchschrift der ersten hälfte des 11. jahrhunderts geschrieben und mehrfach in zierlicher schrift des ausgehenden 11. oder beginnenden 12. jahrhunderts mit lateinischen interlinearglossen und auch randbemerkungen versehen. Nur ganz vereinzelt begegnen altenglische interlinearglossen derselben späten zeit. Mir sind nur die folgenden aufgefallen:

putamen nucis, hula fol. $5^{\text {a }}$

ne quâ, nahweder fol. $33^{: ~}$

utro utroque, naper ancs. betwux tuam fol. $33^{\text {b }}$ identidem, eft-sona fol. $34^{\text {a }}$

5 sricti, faestlice fol. $34^{\text {" }}$ triiugus, on breo ze-yht $\left.{ }^{1}\right)$ fol. $46^{\text {: }}$

(2) Am rande des Priscian-textes finden wir nun folgende drei texte von anderen händen des beginnenden 11. jahrhunderts nachgetragen:

(a) Von fol. $3^{a}$ ab finden wir die ganze handschrift hindurch bis zum vorletzten blatte gelegentlich auf einzelnen seiten ein alphabetisches lateinisches glossar auf die äufseren ränder geschrieben, welches folgendermafsen beginnt:

1) Dies ze-yht steht doch wohl für zezyht und bedentet 'gejocht, angeschirrt' zu einem sonst nicht belegten *zyčan ( $\delta \bar{y}$ čan?) 'anjochen, anschirren', das ein altes kausativum zum stamme von ae. iuc 'joch' darstellen würde. Vgl. das an. eykt, welches ein urgm. *jaukian 'anschirren' voraussetzt. 
A. \& w...i. deus uoce Pelasga, sive Argina nel Graia, Mirmidona, uel Danaa seu Dora.

Anfractus .i. circuitus.

Ancisus. i. circumcisus.

Anquiro .i. circumquero.

Ambesus .i. inscius seu ignaurs, stultus.

Ambustus .i. exustus, corrosus.

Das glossar ist nicht zusammenhängend geschrieben, sondern über die ganze handschrift verteilt. Zwar ist jedesmal, was za ein und demselben buchstaben gehört, fortlaufend auf den rand gesetzt. Bevor ein neuer buchstabe aber beginnt, folgt eine mehr oder weniger grofse anzahl freigelassener ränder. Sieht man genauer $\left.z \mathfrak{u},{ }^{1}\right)$ so ergibt sich, dals der abstand von buchstabe zu buchstabe meist vier blätter beträgt. Der schreiber hat also offenbar für später nachzutragende glossen raum lassen wollen und deswegen sein glossar von acht $z \mathfrak{u}$ acht seiten auf die handschrift verteilt.

In diesem alphabetischen glossar finden sich nur vereinzelt auch altenglische glossen und zwar von derselben hand und als ursprünglicher bestandteil des glossars. Das glossar dürfte daher wohl in dieser form aus England stammen und auch dort in die handschrift eingetragen sein, wenn natürlich auch mit der möglichkeit zu rechnen ist, dals der schreiber ein in einem kontinentalen kloster ansässiger Angelsachse war. Junius hat bei seiner abschrift diese glossen, soweit er sie nicht ausliefs, unter das gleichzunennende lateinisch - altenglische sachglossar nach gutdünken verteilt. Mir sind in dem Antwerpener teile folgende 16 altenglische glossen aufgefallen, deren einreihung bei Junius aus den in klammern beigesetzten verweisungen auf Wright-Wülker zu ersehen ist.

[fol. $4^{\text {b }}$, auf dem äufseren rande links:]

Elisa mens .i. deiecta . forscrenct . W.-W. $162^{14}$

Elogium .i. dictio . saza .

1) Es stehen nämlich in dem Antwerpener teile die $\boldsymbol{A}$-glossen anf fol. 2a-b (- dann folgt die lücke, die durch die erste lage des Londoner fragmentes ansgefüllt wird - ), die $E$-glossen anf fol. $4^{\mathrm{a}-\mathrm{b}}$, die $F^{\prime}$-glossen auf fol. 8 a, die $G$-glossen anf fol. 12 a, die $H$-glossen auf fol. 16 a, die $L$ glossen auf fol. 20 a, die $M$-glossen auf fol. 24 a-b, die $N$-glossen auf fol. 28 a, die $O$-glossen anf fol. 32 a, die $P$-glossen auf fol. 36 a -37 a, die $Q$-glossen anf fol. 40 a und die $S$-glossen auf fol. 47 a -48 a. 
Empiria . manezra embe-smeazunza .

W.-W. $165^{28}$

10 Emunctoria . candel-twist. $165^{29}$ Enum 1) . cytel . [fehlt]

Emeritus .i. prouectus .zepunzen . W.-W. $165^{31}$ Emphimergides ${ }^{2}$ ) .i. numerus cotidianus .zerim . Eneruus ${ }^{3}$ ) . mazen-leas

15 Epitholamium ${ }^{4}$ ).i. carmen nubentium . zift-leod. ” $165^{32}$

[fol. $12^{\text {a }}$, auf dem oberen und rechten rande:] Gobio . genus est piscis . bloeze . W.-W. $180^{27}$ Glanx . glandis . picbred ${ }^{5}$ )

[fol. 16 ${ }^{\text {a }}$, auf dem rande rechts:]

18 Hilum .i. medulla penne . peopa . ${ }^{6}$ )

[fehlt]

[fol. $20^{\mathrm{a}}$ : auf dem oberen rande:]

Lolligo .i. piscis maritimi ${ }^{7}$ ) . uno anno piscis . alio auis . hoc est byrnete . ${ }^{8}$ )

1) D. i. aenum = 'eherner kessel'.

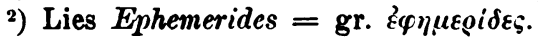

2) Lies Eneruis 'entnervt'. - Das $z$ in mazen ist aus $n$ gebessert.

4) Lies Epithalamium = griech. $\varepsilon \pi \iota \vartheta \alpha\rangle \dot{\alpha} \mu \iota \nu v$.

5) Glanx ist in glans zu bessern, wie Junins stillschweigend schreibt. - Die ae. glosse picbred ist schwer zu denten, da mit pic 'pech' und pic 'stachel' hier wenig anzufangen ist. Vielleicht trifft das 0xforder wörterbuch das richtige, wenn es (unter pig) ae. pic-bred als bicg-bread 'schweinemast' faist. Die schweinemast erfolgte ja das ganze mittelalter hindurch hanptsächlich durch eicheln, so dafs sachlich die glosse verständlich wäre. Formell läfst sich pic- statt * picg- rechtfertigen durch den hinweis auf belegtes bricbot für bricg-bol oder wiccraeft für wicg-craft; nnd wegen der monophthongierung von $e a z 11 e$ vergleiche das unten 8.103 anm. 1 gesagte. Der gebrauch des wortes breal 'brot' für tierfutter tindet sich ebenso in ae. beo-bread 'honigwabe'. (Tollers angabe, dals sich die glosse at the end of a list of names of trees befinde, trifft, wie man sieht, nur für Junius' abschrift za, nicht für die originalhandschrift.)

6) Ae. peopa ist die nur hier belegte form mit o-umlant für das häufige pipa 'mark'.

?) Lies maritimus.

s) Lat. lolligo bedeutet 'tintentisch'. Aber der zusatz uno ano piscis, alio auis 'in einem jahr ein fisch, im anderen ein vogel' weilst jedenfalls anf den mittelalterlichen, bis ins 17 . jahrhundert herrschenden volksglauben, dafs die meer- oder bernikelgänse nicht aus eiern, sondern aus den im meere lehenden, krebsähnlichen 'entenmuscheln' (Lepas anatifera) entständen, - eiue anschaunng, die dadurch anfgekommen war, dafs die 
[fol. $32^{a}$ : auf dem äufseren rande reclits:]

20 Offendiculum .i. scandalum . ruma .

[fehlt]

[fol. $47^{\mathrm{b}}$ : auf dem äufseren rande links:]

Sutura . seam . custure . 1 )

Siligo .i. genus frumenti. vize.2)

(b) Offenbar nachdem das alphabetische Lateinglossar schon eingetragen war, hat ein anderer, etwas später und weniger sorgfältig schreibender kopist, den wir also in das ende des 11., wenn nicht gar den anfang des 12. jahrhunderts

gattung der bernikelgänse $n$ im winter an den küsten der nordsee erscheint, aber in kälteren, nördlicheren gegenden brïtet; vgl. Zohar II 156; Giraldus Cambrensis ( $\dagger$ 1123), Topographia Hibernica c. 11; Gervasins r. Tilbury ( $\dagger$ ca. 1220), Otia imperialia III c. 123; Jacobus de Vitriaco ( $\dagger$ 1240), Historia Hierosolimitana; Vincenz v. Beauvais ( $\dagger$ 1224); Albertns Magnus ( $†$ 1280); Neckham; Trevisa; Maundeville ed. Halliwell s. 264; Turner, Avium historia (1544); Gesner, Avium natura (1555); Holinshed; Seb. Münster, Cosmographia 1550 s. 59; Gerardus de Vera, Diarium nauticum, Amsterdam 1598, fol. 15, Gerard, Herbal.1597, s. 1391 ; Hector Boece, Croniclis of Scotland; Hall, Virgid.IV 2; Marston, Malcontent III 1, 49; Shakespeare, Tempest IV 249; Drayton, Polyolbion XXVII 305; C. Schott, Physicae cnriosa IX c. 22; Aldrovandus, Ornithologia 1603; Mich. Maier, De volucri arborea 1619; G. Funck, De avis Britannicae, vulgo anseris arborei, ortu et generatione 1689; Hering, De ortu avis Britannicae 1665 u. m.; dazu Max Müller, Lectures on the Sc. of Langnage ' II $583-604$; J. V. Carus, Geschichte der Zoologie (1872) 8. 191-195; Revue archéologique 3e Série, XXVI 2-12; Campbell, Popular Tales I s. X; Dania II 347; Suolahti s. 417 ff. Demzufolge meint auch sicherlich die ae. glosse byrnete dasselbe, wie das ne. barnacle, nämlich 1. die 'entenmuschel' (Lepas anatifera), 2. die 'bernikelgans', d. i. entweder Bernicla leucopsis 'nonnengans' oder Bernicla torquata 'ringelgans'. Lautlich stellt sich dies bymete $\mathrm{zu}$ den mittellateinischen $\boldsymbol{t}$-formen bei Gervasius von Tilbury (barneta) und im Promptorium Parvulorum (ed. Mayhew s. 31: barnites und bernutta). Wie sich die $t$-formen aber zu den romanischen (Meyer-Lübke nr. 1047), mittelenglischen (NED) nnd keltischen (Pedersen I 280; II 663) $c$-formen stellen, ist bei der etymologischen undurchsichtigkeit des wortes nicht anszumachen. Doch dürfen wir in unserem byrnete wohl den ältesten beleg für das wort sehen, wie die davor stehende lateinische erlänterung auch wohl der älteste beleg für den volksglauben ist; denn die meist als ältester beleg angeführte stelle aus Petrus Damianus ( $f$ 1072) spricht nur von 'baumgänsen' (ut ex arborum ramis volucres prodeant Opera 1783 III 631).

1) custure ist altfranzösisch und entspricht dem nfrz. couture 'naht'.

2) Lat. siligo bedentet eine art 'winterweizen', das ae. ry-ge aber 'roggen'. 
setzen dürfen,1) mit heller, blasser tinte ein lateinisch-altenglisches sachglossar auf frei gebliebene ränder gesetzt. Da wo der äufsere rand schon durch das erste glossar besetzt war, ist nun auch der innere rand der seiten herangezogen. Anfang und schlufs des glossars, sowie ïberhaupt der gröfste teil desselben finden sich in dem Londoner fragment, was fast den anschein erweckt, als ob es nicht reiner zufall gewesen sei, daIs gerade jene teile aus der handschrift entfernt wurden und in London zum verkauf kamen. In dem Antwerpener manuskriptteile sind nur zwei bruchstuicke ${ }^{2}$ ) verblieben: fol. $3^{\mathrm{a}-\mathrm{b}}=$ Wright-Wülker $129^{26}-135^{11}$ und fol. $4^{\mathrm{a}}=$ WrightWülker $161^{36}-162^{22}$. Diese teile mögen hier im abdruck folgen. Ich habe dabei eine erklürung der lemmata und glossierungen versucht, so wie sie mir für die dringend erforderliche neuausgabe der altenglischen glossentexte wünschenswert erscheint. ${ }^{3}$ ) Namentlich bin ich auch mehrfach auf die sach-

1) $\mathrm{Zu}$ dieser späten datierung um 1100 stimmt auch die sprache der glosse. Es befinden sich bereits zwei französische lehnworte, nämlich custure 21 und capun 156. Die volleren endrokale zeigen schon mehrfach reduktion zu $e$ : so haben wir $e$ für $a$ in fuzeles (plur.) 162, doppe 98, se mare 131, lame 253 und ebenso $e$ für $u$ in cuce 61 , wule 180.184 .223 , mede-royrt 225 , zeolev-earte 146, swalewe 157, oder a für $u$ in niht-scada 232 . Monophthongierung eines ea erscheint in harpe 34.35 , starn 129, zacruwe 185, eines $e o$ in ardlinz 155; nmgekehrt ea geschrieben für $c$ in scyl-eazede 252 und sūr-ëazede 25t. Fin $c$ steht für $e$ in -abbunz 165 und napte 175, umgekehrt $e$ fïr $a$ in (h)remn 123.124. (Ich möchte diese späte datierung auch deswegen besonders betonen, weil das Oxforder wörterbuch die glossen noch um das jahr 1000 ansetzt.) Lemma und glosse stinmen nicht genau zusammen in $91,97,112,116,117,121,126,130,138,142,146,152,158$, 227, 228, 234, 268, 269.

2) Das exstere umfangreiche bruchstïck (fol. 3) hängt äufserlich mit dem anfang des Priscian zusammen, liefs sich also nicht gut entfernen, ohne anch gewissermalsen das titelblatt des kodex mit fortzunehmen.

$\left.{ }^{3}\right)$ Nur vorläufiges vermochte ich zu bieten bei der behandlung der pflanzennamen, die noch ganz im argen liegt, zumal wir ïber die bedeutung der lateinischen lemmata auf diesem gebiete nicht sicher orientiert sind. Eine einigermafsen zuffriedenstellende deutung der altenglischen pflanzennamen wird erst möglich sein an der band von kritischen neuausgaben der botauischen und medizinischen texte der Angelsachsen samt ihrer abbildungen. Und diese werden kaum zu unternehmen sein ohne herbeiziehung der reichen lateinischen pflanzenkundlichen literatur des inittelalters, deren älteste und wichtigste stücke, wie der Leydener Codex Voss. lat. Q. 9 (7. jh.), St. Gallen M. 751 (9. jh.), Breslan Un. Bibl. III. F. 19 (9. jh.), St. Galleu M. 217 (9. jh.), St. Gallen M. 752 (10. jh.), Cassel Phys. et hist. uat. fol. 10 
und kulturgeschichtliche bedeutung einzelner glossen eingegangen, die mir die bisherige glossenforschung nicht genügend berücksichtigt $\mathrm{zu}$ haben scheint.

[fol. $3^{\mathrm{a}}$ ]

[auf dem inneren rande links:]

Ymnus . lofsanz

Bicinium . twezra sanz.

W.-W. $129^{28}$

25 Chorus . sinzende heap.

Chorea . hluddra sanz .1)

Matutinum officium . uht-zebed $l$ penunz .2)

$\begin{array}{lcc} & \text { W.-W. } 129^{28} \\ & 129^{28} \\ & " & 129^{30} \\ \text { penunz . } 2) & " & 129^{31} \\ \text { tpeowdom . } & 2) & 129^{32} \\ & " & 129^{34} \\ & 129^{36} \\ & " & 129^{37} \\ & 129^{38} \\ & " & 129^{39}\end{array}$

30 Lectio . radinz.

Diaphonia . unzesweze sanz.

Canticum . samsweze sanz . 4)

(10. jh.), Harleian 4986 (12. jh.), Laur. Plut. 73.16 (13. jh.) u. a. m. in vollständigen photographien in dem hiesigen institut für geschichte der medizin zugänglich sind.

1) hluddra sanz 'lanterer gesang' ist eine recht unvollkommene erklärung von lat.-griech. chorea, xookia 'reigentanz', aber ein beweis, dafs man im englischen mittelalter wie anch in der renaissance beim volkstümlichen reigentanz (Shakespeares round) den rhythmus durch chorgesang und nicht durch instrumentalmusik markieren liefs.

2) benung erscheint häufig für konkrete gottesdienstliche funktionen gebraucht, während beozodom in mehr allgemeinerem, abstrakteren sinne 'gottesdienst' bezeichnet. In obigen glossen sind indes beide völlig synonym verwendet, um die gottesdienstlichen funktionen (psalmen-rezitation, lektion, responsorien, gebete und freie gesänge) bei dem gemeinsamen horendienste der mönche zu bezeichnen.

3) responsorium ist die ganze oder teilweise wiederholung eines rom vorsănger gesungenen textes in gemeinsamem chorgesang.

4) So liest die hs., nicht sum swegesang, wie Wright-Wülker bieten. Samswëze sanz 'znsammenklingender, harmonischer sang' ist der gegensatz zu dem vorhergehenden unzeswëze sanz 'disharmonischer sang', and so

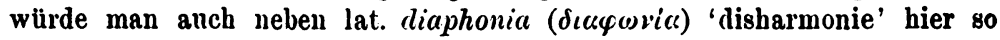

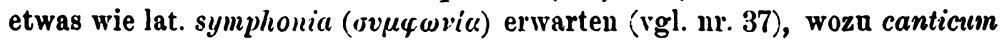
'lied' ein erklärender zusatz gewesen sein könnte. Auch die folgenden lemmata 33-35 scheinen nicht ganz in ordnung zu sein. - Das nur hier belegte adjektiv samsweze ist in den wörterbiichern nachzutragen; doch findet es sich (allerdings ohne beleg) in der neuausgabe von J. Hall, A Concise Anglo-Saron Dictionary (Cambridge 1916). 
Psalmus proprie . hearpsanz .

W.-W. $129^{4 \theta}$

Canticum psalmi .1) after harpan sanz .

35 Psalmus . ar hcerpan sanz.

Armonia . zehwoere ${ }^{2}$ ) sanz.

Simphonia . answeze sanz.

Fertum . messelac .

12942

Offertorium . laacsanz.$^{3}$ )

40 Oblatio . ofrunz.

Dano . sawlsceat 4$) \ngtr$ syndriz zodeslac

Dedicat . zode zesyld .

12943

12944

Officium . penunz . ${ }^{5}$ )

Consecrat . zode zehal.zap . ${ }^{6}$ )

45 Immolatio . onsazunz.

Sacrificium . offrung . ${ }^{7}$ )

Mactatio . sniðunz .

Holocaustum . ealoffrunz $\cdot^{8}$ )

Libatio . wintifer . ${ }^{9}$ )

1) So (psalmi), nicht psalm (WW), liest die handschrift. Es handelt sich demnach um ein lateinisches wort, das zu canticum gehört.

2) Lies zepwaere, wie Junius stillschweigend schreibt. Über hw fiur pw vgl. Napier, OEGl. I 66; auch Horn, Ne. Grammatik (1908) I § 199.

2) So liest dentlich die handschrift, nicht lanesang (WW). - Unter offertorium versteht man den liturgischen gesang, der die darbringung der opfergaben während der messe begleitet. Daher die ae. deutung läc-sanz 'opfersang'.

4) Säwol-sceat 'seelenschatz' ist ein drittel des beweglichen nachlasses, welcher bei der beerdigung zum seelenheil des toten der kirche fällig war (Liebermann). - Duno ist verlerbt, vielleicht fïr Donum (?) oder Pro anima (?).

5) V'gl. oben z. 27.

6) Das $b$ sehr undeutlich über dem $a$.

7) Vgl. oben z. 40.

8) Eall-offrunz, eigtl. 'ganz-opferung', ist eine künstliche nachbildung

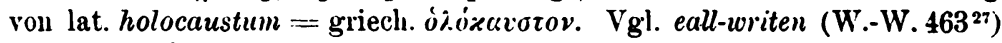

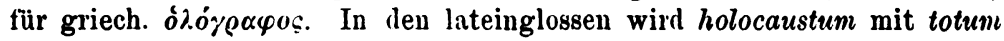
combustum oder incensum wiedergegeben (Goetz, Corp. gloss. V $208^{23} ; 229^{8}$; IV $\left.244^{51}\right)$.

9) Da der begriff des trankopfers (libatio) dem germanischen religionskultus fremd war, schuf der glossartor ein ad hoc zusammengestelltes kompositum win-tifer. 'wein-opfer'. Dies zeigt zugleich, dais ihm die alte beleutung des wortes tijer, uämlich 'opfertier', nicht mehr bekannt war. (Das bei den simplex mehrmals belegte $-b$-, welches Hall ${ }^{2}$ u. a. falschlich als normalform fassen, ist untürlich nnr archaische schreibnng für - $f$-). 
50 Omelia . folclic lar. $\left.{ }^{1}\right)$

W.-W. $130^{14}$

Cerimonie $\bar{z} \cdot{ }^{2}$ ) orgia $\cdot$ zeld-lice ealhalzunz $\cdot{ }^{3}$ ), $130^{15}$

Meratum uinum . zehlyttrad 4) win.

Mirratums) uinum . zemenzed mid myrran.

Sacrificium . husel . ${ }^{6}$ )

1) Die kirche unterscheidet seit dem 5. jahrhundert die einfachere, lediglich auf schrifterklärung und -anwendnng abzielende os $\mu$ i ice von dem kunstvolleren, einen bestimmten gedanken durchführenden $\lambda \dot{o}$ yos (lat. sermo). Die homilie galt als die besser für die breiteren volkskreise geeignete predigtform, weshalb z. b. Angnstin das wort homilia direkt mit tractatus popularis erklärte. Vgl. die lateinglosse: Omilia 'popularis tractatus' (Goetz, Corp. gl. IV 264"1).

2) 3 ist die häufig in unserem glossar vorkommende und auch sonst in der glossenliteratur wohl bekannte abkürzung für graece.

3) So, und nicht geldhaealhalgung (W.-W.), licst die handschrift; ealhaljunz beginnt die neue zeile des sehr schmalen inneren randes. Zur erklärung ist heranzuziehen die im Londoner teile der handschrift vorkommende glosse: cerimonia uel orgia, $\ddot{z}$. 'zelddazas, part sind halize [sc. dazas]' (W.-W.107 ${ }^{22}$ ) sowie die Aldhelm-glosse: lupercalia 'cet pain zylde' (Napier 11, 184). Das ae. zeld hat überall hier die auch fürs Altsächsische und Althochdeutsche gesicherte, abgeleitete bedentung 'opfer', oder noch besser die daraus erweiterte bedentung 'kultus'. Das in unseren wörterbüchern (aufser Hall ${ }^{2}$ ) nachzutragende ae. zeld-dlazas bedeutet daher 'kulttage', 'festtage' - nicht 'guild-days' (Hall ${ }^{2}$ ) - , und das adjektivum zeldlic 'kultisch' und nicht 'of a guild', wie Hall ${ }^{2}$ ansetzt. (Wie das lat. abstrakte caerimonia 'heilige verehrung, kultus' in das koukrete 'kultheiligtum' überging, so hat auch das ae. abstrakte zyld 'kultus' die konkrete bedeutung 'kultidol' entwickelt, wobei sicherlich an jene heidnisch-germanischen holzidole zu denken ist, die jetzt K. Helm, Altgerman. Religionsgeschichte I 214-228 uns trefflich vorgeführt hat). - Das zweite wort unserer obigen glosse, eall-hālzunz 'allheiligung', ist mit dem von Latein abweichenden eall-hāliz 'allheilig' des Pariser Psalters 131, 8 zusammenzuhalten.

4) Das lat. meratum oder meracum vinum bedeutet 'reinen, unverfälschten wein', während das ae. zehlpttrad vielmehr einen 'geklärten' d. h. von seinen abfallprodukten wie hefe, weinstein $\mathfrak{u}$. a. gut gelänterten wein bezeichnet. Vgl. in Elfrics glossar (ed. Zupitza 2227): liquo ['hell machen, klären, seihen') ' $i c$ hlyttrize'. Liegt sonach eine ungenaue übersetzung des glossators vor, oder dürfen wir daraus folgern, dals weinfälschung den Angelsachsen unbekannt war? Über angelsächsischen weinbau siehe die literatur bei Liebermann, Ags. Gesetze II 731.

5) Lies myrrhatum. Mit myrrhenharz wurde der wein jedenfalls zu konservierungszwecken vermischt. Die Angelsachsen kannten die myrrhe aber wohl nur aus literarischen quellen.

c) Sacrificium bedentet in der mittelalterlichen kirchensprache nicht nur den eucharistischen opferakt der messe, die 'kommunion', sondern 


\section{[auf dem oberen rande:]}

55 Monodia . z . latersicinium . quasi solicinium .

Munus . $\nmid$ Zenia $\left.{ }^{2}\right) z$. lac

pæt is anessones ${ }^{1}$ ) W.-W. $129^{26}$

Elemosina . ł Agapis . ${ }^{3}$ ) celnıesse .

$130^{16}$

Donum . Datum . ł Donatum . zifu .

Pretiun . warp .

b0 Deptiatus . $\left.{ }^{4}\right)$ urdleas.

Uiuus . euce .

$\begin{array}{ll}" & 130^{16} \\ " & 130^{17} \\ " & 130^{18} \\ " & 130^{19} \\ " & 130^{20} \\ " & 130^{29} .\end{array}$

speziell auch das dabei genossene geweihte brot, die 'hostie'. In beiden bedentungen erscheint anch das ae. hüsl; nur dafs hier 'hostie' die ältere und 'kommunion' die jüngere bedentung ist. Denn ae. hüsl, gt. hunsl ist meiner meinung nach nicht mit den slavisch-iranischen wörtern für 'heilig' zusammenzustellen, sondern eine konkretbildung mit den suffix -slo zu dem urgerm. stamme *\%unp-, *\%und- 'erjagen' (gt. luunps, ae. hüp, ahd. hunda 'bente'; ae. hunta 'jüger'), der weiterhin wohl zu griech. xaiv' «ízovc 'töten' gehüren mag (Brugmann, Grundr.: II 1, 372). Die bedentung des urgerm. *aunslo- wäre dann wohl ursprünglich 'opferung von kriegsgefangenen', was vermutlich die älteste form des heidnisch-germanischen opferkultes gewesen ist (K. Helm, Religionsgeschichte I $292 \mathrm{ffi}$.).

1) Sachlich gehört die ganze glosse unter die musikausdriticke (z. 2326), die den linken rand begiunen. Junius hat die glosse daher vor Hymnus 23 gestellt. Und da dieselbe wirklich anf dem oberen rand in der höhe der Hymunus-glosse steht, könnte man denken, dafs der glossator eine solche oder ähuliche einreihung beabsichtigt hätte. Tatsächlich sind aber die auf dem oberen rande stehenden, mit Monodia beginnenden glossen so augenfällig von denen des linken randes abgetrennt, dals eine solche vermutung an der überlieferung keinerlei anhalt findet und daher abzulehuen ist. - Das latersiciniun des lemmas ist offenbar zu ändern in: latine sicinium oder (älter?) sincinium. Vgl. die glose: Sicinium dicitur quasi singularis cantilenae cox, id est, cum unus canit, quod a Graecis monodia dicitur (Ducange). Das folgende solicinium 'einzelgesang' scheint sonst nicht belegt. Doch bietet Ducange ein solicanus. - Das ae. anessones (so die handschrift) ist sicherlich in ancs sones zn zerlegen. Bei Sones könnte man an verderbnis aus sōn 'musik' denken. Besser palst aber eine besserung in sonz, da anes sonz genauer dem Lateinischen entspricht. (Sonz mit $o$ statt des sonst ihm geläufigen sanz müfste der kopist aus seiner vorlage beibehalten haben.)

2) Für Xenia (ร́ćvıv); vgl. Goetz IV $197^{11}$ : venia 'munera, dona'.

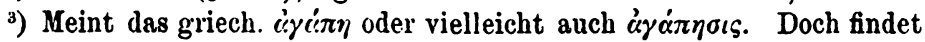
sich die form agapis auch sonst: acapis 'caritas' (Goetz IV 202 ${ }^{23}$ ) und Agape elemosyna, ....; nain agapi(s) est dilectio (Goetz II s. XIII).

4) Lies (mit abkürzungsstrich) Dep̄tiatus d. i. depretiatus (80 belegt bei Goetz IV $50^{8}, 504^{\circ}$; V $449^{53}$ : depretiatus 'vilis effectus'). 
Rediuius . ze-ed-cuced.

W.-W. $130^{30}$

Mortuus . deað .1)

Defunctus . forøfaren .

65 Defungitur . fordfarp .

Longeuus . langlife .

[auf dem äufseren rande rechts:]

Nobilis . Ingenuus . apelboren .

Ignobilis . $¥$ plebeius . uncepelboren .

[fehlt]

[fehlt]

Uilis . waclic .

W.-W. $130^{26}$

70 Carus . leof.

$130^{27}$

Opere pretium.

Odiosus . purhlað .

Care ualet . pretiosum est . deor ${ }^{2}$ ) hit is .

W.-W. $130^{28}$

$73^{\text {b }}$ Uile ualet . undeore hit is .

13021

Care uendidit . deore he hit bohte .i. sealde . ${ }^{3}$ ), $130^{23}$

75 Uile uendidit . undeore he bohte.

$130^{25}$

Capillamenta . ruwe oðठ drisne . ${ }^{4}$ )

1) Lies dead, wie Junius stillschweigend bessert.

2) Lies deore.

3) Bycgan hat im Ae. noch die allgemeine bedentung 'durch kauf austauschen', kann also ebensowohl für 'einkaufen' wie für 'verkaufen' stehen. Da das lat. vendidit aber nur das letztere bedentet, setzt der glossator noch ein verdeutlichendes sealde 'übergab, verkanfte' hinzn.

4) Die handschrift bietet deutlich ruce 'haarig, struppig', nicht rupe, wie Junius las. Und damit ist anch der weg bereitet zu dem bisher unverständlichen folgenden drisne. Es wird gleich ritwe ein adjektiv im nom. plur. sein und sich ebenso zu dem adjektiv on-drysne 'schrecklich' verhalten wie das gleichbedeutende, im Londoner teil der handschrift begegnende drystic 'terribilis' $z u$ dem oft belegten on-drystic (für *on-drysnlic?). Wir werden daher nuserem wörterbuch ein adjektiv drysne 'schrecklich' einverleiben dürfeu. (Einen anderen weg der erklärung schlägt Toller im supplement ein, indem er zu dreosan 'fallen' ein adjektivisches drysne 'herabfallend' annimmt.) - Die beiden adjektiv-plurale rūue und drysne passen nnu nicht sonderlich zu dem substantivischen lemma capillamenta 'haare'. Ich möchte daher vermuten, dais capillamenta verderbt ist aus capillati 'haarig'. Die gleiche glosse findet sich übrigens auch in dem alphabetischen glossar von Harleian 3376 (Wr.-W. 1998): Capillamenta, 'racce [lies ruwe], drisne'. Ein "drisn f.? false hair? hairy roots of plants?", wie es noch bei Hall in der zweiten auflage anf grund unserer glosse zn finden ist, dürfen wir aber jedenfalls endgültig aus unseren wörterbüchern streichen. - Obiges oðঠ, eine reduktionsform, die auch sonst in späten handschriften begegnet (z. b. Archiv CXXIX 43 a. 3), meint natürlich oore 'oder'. 
Polio . ic smepie.

W.-W. $130^{36}$

Deuoto . 1) ic voyrze.

Plano . ¥ leuigo . ic zeznide .

80 Compensatio . edleanunz .

Deuotatio . werznes $ł$ ze-hat . ${ }^{2}$ )

Commolio . ic zrinde . ${ }^{3}$ )

Conficio .4) ic zemenze.

Commolitus . zezrunde.$^{3}$ )

85 Conualeo . ic awyrpe. ${ }^{5}$

\section{NOMINA AUIUM.6)}

Cignus . \& cicinus . ${ }^{7}$ ) ylfete .

Onocratulus . ${ }^{8}$ )

Pauo . pauus pawe .

1) Lat. devotare, eigtl. 'den unterirdischen göttern als opfer weihen', bedentet bei den kirchenvätern (z. b. Augustin) 'verfluchen'. Vgl. anch die Lateinglossen devotat 'maledicit' (Goetz IV 330 ${ }^{27}$ ) und devotare 'exprobrare, maledicere' (Goetz V 567'). Ein gleiches gilt von dem substantiv devotatio, das in der kirchensprache (Augnstin) 'verwünschung' heifst; vgl. dazn Goetz V $189^{27}$ : devotatio 'per furorem maledictio', sowie die obige glosse 81: devotatio 'werznes $l$ zehat', wo $l$ zehat möglicherweise verderbt ist aus einem per furorem entsprechenden ausdruck wie etwa on zehāte. Allerdings könnte der glossator anch devotatio mit devotio 'gelübde' verwechselt haben und im hinblick auf letzteres eine $z$ weite erklärung mit zehāt 'gelübde' hinzugefügt haben.

2) Vgl. die vorhergehende anmerkung.

3) Der glossator hatte offenbar das lat. commolo 'zermahlen' in sinne, während das lemma Commolio wohl das lat. commollio 'zerweichen' meinte.

') Vgl. die glossen Confic 'zemengan' (Corpus ed. Hessels C 674), Confici 'zemenge' (Cleopatra ed. W.W. $365^{18}$ ) sowie C'onfictio oivgrols (Goetz II $446^{25}$ ).

5) Während sonst âwoyrpan in der bedeutung von 'abwerfen' belegt ist, heifst es hier so viel wie 'sich erholen, genesen'. In der gleichen bedeutung erscheint es auch bei Elfric, Homil. I $534^{28}$ : $\delta a$ fartice âroyrpte se ädliga cniht.

๑) Für die erklärung der ae. vogelnamen bietet mancherlei H. Suolahti, Die dentschen Vogelnamen (Stra/sburg 1909). Die völlig unkritische arbeit von Ch. H. Whitman, The Birds of Old English literature (= Journal of Germanic Philology II 149-198) bedarf dringend einer erneuerung.

7) Eine mlat. nebenform zu cycnus (gr. xíxvos); $\mathrm{ggl}$. Cycinus 'ollo' [d. i. olor] Goetz IV $318^{16}$ u. 0 .

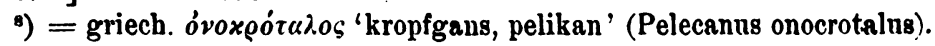


Aquila . Ethon . z . carn .

4) Ein mlat. vogelname beacita erscheint auch sonst in angelsächsischen glossaren (Ep.-Erf.-Corp. 125; Brüssel WW 286 ${ }^{7}$; Cleopatra WW 260 's, $358^{1}$ ), aber seine bedeutung ist unbekaunt. Es ist in allen fällen mit ae. stearno, stearn (WW $285^{\circ}$ dafür verschrieben tearn) oder stęn glossiert, das man (z. b. Klnge) wegen seines vermeintlichen etymologischen zusammenhanges mit lat. sturmus 'staar' und ngrm. *staro 'staar' (ae. star, *stara, me., ne. stāre, and. star, stara, mnd. star, ahd. star, stara, an. stari) mit 'staar' übersetzt hat. Und dieser deutung scheint unsere obige glosse durch den (sonst fehlenden) zusatz vel sturnus entgegen zu kommen. Dagegen spricht aber, 1. daIs andrerseits ae. stearn im zusammenhängenden text des 'Seefahrers' als isigfeðera 'eisbefiedert' bezeichnet wird, was nur auf einen an külte gewöhnten meeresvogel paist, nicht aber zu dem im winter gen süden ziehenden staar, und 2. dafs dasselbe altenglische wort anch als glosse zn lat. gavia erscheint (Erf. 1116: gavia qui dicitur 'stern' saxonice), was einen nicht näher bestimmbaren, gefrä fsigen meeresvogel, etwa die 'möwe', bedeuten soll. Auf einen meeresvogel und $z$ war die 'seeschwalbe' weisen auch drei neuenglische belege: noch gegen ende des 19. jahrhanderts hiels die 'gemeine seeschwalbe' (Sterna hirundo) im dialekt von Dorset starn und die 'trauerseeschwalbe' (Sterna nigra) stern (Swainson, Provincial Names and Folk Lore of British Birds 1885, 8. 202, 204); nnd dieselbe bezeichnung kannte im 16. jahrhundert der naturwissenschaftler William Turner, der in seinem buche 'Avium, quarum apud Plininm et Aristotelem mentio est Historia' (1544) bei der seeschwalbe hinzufügt: nostrati lingua 'sterna' appellata d. h. entlatinisiert and der falschen orthographie des 16. jahrhnnderts entkleidet ne. starm. Endlich finden wir auch anfserhalb Englands verwandte formen mit der gleichen bedentung: nämlich (1) ostfries. steern (L. Häpke, Volkstümliche Tiernamen im nordwestlichen Deutschland 8. 307), westfries. stirn (bei C. Gesner, Historia animalinm, 1555, 8. 564: Frisii hanc avem 'stirn' appellant; wegen ar $>$ er $>$ ir s. Siebs, Grdr. § 11, $1 \mathrm{c} ; 20,4)$, neuwestfries. sterns, stirns, Ameländisch starns [deminutiv], neunordfries. sternk [demin.] 'seeschwalbe' (J. Schmidt-Petersen, Wörterbuch und Sprachlehre der Nordfriesischen Sprache, Husum 1912); (2) die rom 8-losen stamme gebildete nordische sippe für 'seeschwalbe': an. perna, nschwed. tärma, nnorw., ndän. terne [daraus ne. tern, seit 1678 belegt]; sowie (3) auf balto-slavischem boden das altpreufsische starnite 'seeschwalbe'. Sonach kann es für mich keinem zweifel unterliegen, dafs wir fürs Altenglische ein wort stearn 'seeschwalbe' anzusetzen haben, das Sweet und Hall $^{2}$ nur mit fragezeichen bieten, während Bosworth-Toller anf eine angabe der vogelart überhaupt verzichtet. - Andererseits fehlt es nicht an belegen, dafs das wort stearn fruh in England auch auf den 'staar' (Sternus vulgaris), eigentlich ae. stcer; *stara (wegen me. stāre), übertragen ist, was bei der ähnlichkeit der altenglischen namen wohl begreiflich ist. Denn aufser obiger zassmmenstellung mit lat. sturnus findet sich anch ein ne. starm und sein deminutiv starnel für 'starr' gebrancht: ersteres (starn) 
Herodios . 1) $\bar{z}$. swan .

W.-W. $131^{12}$

Ardea . hrazra.

$131^{14}$

Diomedia $\left.{ }^{2}\right) ~ \Varangle$ olor . swan .

$131^{13}$

Ficedula . swertlinz $\cdot^{3}$ )

$131^{15}$

Strix . ł Cauanna . ule 4 ) . ł Noctua . $ł$ ulula . "

$131^{16}$

Luscinia . $¥$ philomella $\left.{ }^{5}\right)$. nihtezale.$\nmid$ Acredula . "

Mergus . scealfi.$^{6}$ )

13118

Mergulus . fuzeldoppe .i)

13120

erscheint dialektisch sowohl in Somerset wie in Shetland für 'staar' belegt, letzteres (starnel) in einem grolsen, zusammenhängenden dialektgebiete in Nord- und Mittelengland (York - Derby - Nottingham - Lincoln - Leicester - Northampton - Worcester). Angesichts dieser recht starken verbreitung im Neuenglischen werden wir nnserer obigen glosse grö fsere glaubwürdigkeit beilegen und die übertragung des wortes ae. stearn, ne. starn anf den 'staar' schon in die angelsächsische zeit zurückdatieren dürfen. Der eintrag ins wörterbuch wird also lauten müssen: ae. stearn, stearna, 1. 'seeschwalbe', 2. 'staar' (?).

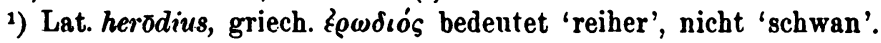

2) Lies Diomedea, wie Junius stillschweigend bessert. Diomedeae aves hiefsen die reiher, weil des Diomedes' Gefährten in übermäfsiger trauer über sein verschwinden in reiher verwandelt waren. Diomedea pafst also weder zum lat. olor noch zum ae. sucan; aber auch z. 91 ist das

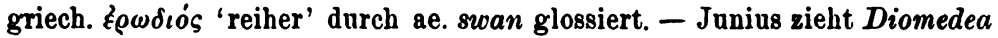
zur vorhergehenden glosse; und tatsächlich steht das wort in der handschrift hinter hrazra. Aber das von Junius übersehene, die nächste zeile beginnende vel lehrt, dafs das wort zur nächsten glosse zu zieben ist.

3) Lat. ficedula meint sicherlich denselben vogel, wie das heutige ital. becafico, der nach Whitman, bald der 'gartengrasmücke', bald der 'kohlmeise' gleichgesetzt wirl. Ae. swertling hängt qweifellos mit sweart 'schwarz' zusammen und meint daher irgend einen vogel, der mindestens teilweise dunkles gefieder hat. Dem würle sowohl die oberseits bräunlichaschgrane 'gartengrasmücke' entsprechen als auch die 'kohlmeise' mit ihrem gelben bauch.

4) Junius stellt ule ans ende der zeile. Statt des femininums cavanna finde ich sonst nur das maskulinum cavannus 'nachteule' belegt.

5) Lies Philomela ( $\varphi(\lambda . o \mu \dot{\eta} \lambda(c)$, wie Junius stillschweigend bessert. Incinia bei W.-W. ist blofs druckfehler. - Der zusatz vel Acredula fehlt bei Junius. Welcher vogel mit dem schon bei Cicero belegten acredula gemeint ist (käuzchen? grille?), ist nicht klar.

6) Lat. mergus bedentet den 'taucher', ae. scealfor aber, wie md. skalver und die verwandten westfries. skolfer, nnl. scholver, mnd. scholver, den 'kormoran' oder 'scharbe' (Graculus carbo); s. Suolahti s. $393 \mathrm{ft}$. Danach ist der Bedentungsansatz bei Bosworth-Toller, Hall ${ }^{2}$ und Kluge ${ }^{8}$ zu ändern.

7) Ein kompositum fuzel-doppe 'taucher', eigtl. 'vogeltaucher' nimmt sich semantisch sonderbar aus. Deshalb schlägt Suolahti a. 207 eine 
Aucarius .1) zoschafuc .

W.-W. $131^{22}$

100 Auca . zos .

Achalentida 2) . nihtezale . 13121

Anser . zanra . ${ }^{3}$ ) [fehlt]

Ornithia 4) . $\bar{z}$ fuzelas .

W.-W. $131^{23}$

Anatis ${ }^{5}$. ened .

[fehlt]

W.-W. 13124

105 Ornithogonia ") $\cdot \bar{z}$ fuzelas .

[fehlt]

Ciconia . storc .

W.-W. $131^{25}$

Rubisca . rudduc . $\left.{ }^{6}\right)$

" 13120

trennung in fuzel doppe 'vogel tancher' vor, unter hinweis auf den neuschwedischen vogelnamen dopping 'taucher' und das ae. kompositum $d \bar{u}$ fedoppa 'taucher' (Lamb. Ps. 101,7; me. doue-doppe, diue-dap, ne. dial. divedop). Für die existenz eines simplex doppa 'taucher' - zu ae. *doppian, was anf grund von me. doppen, ne. dop 'tanchen' (= aschwed.nschwed. doppa, nnorw. doppa) neben ae. dyppan anzusetzen ist, wie umgekehrt ae. hoppian, ne. hop (dazu ae. gaers-hoppa 'grashüpfer') neben anzusetzendem ae. *hyppan, me. hippen, ne. hip steht - spricht anch das allerdings nur einmal belegte me. doppe 'tanchente' (King Alisannder). Dasselbe wort finden wir als ersten teil eines kompositums mit der lautgesetzlichen verkürznng (Bülbring $\$ 397 \mathrm{~b}$ ) in ae. dop-fuzel 'taucher' WW $258^{14}, 284^{8}$; St. Gallen 913 s. 140 [Anglia 36, 390; Klnge, Lesebuch * s. 12]; Parisin. 2685 bei Suolahti s. 443) und in dopp-enid 'wasserhuhn' (Ep.-Erf.-Corp. 419; Plantinus 141). Allerdings ist die hinzusetznng des allgemeinbegriffs fuzel in unserer obigen glosse anffallend und mir sonst aus glossen nicht bekannt. Vielleicht kam der glossator aber dadurch dazn, dafs er an das synonyme dop-fuzel dachte. - Die obige glossenform doppe kann sehr wohl für doppa stehen, da auch sonst nnser text bereits solch späte reduktionsformen hat; vgl. s. 103, anm. 1. Allerdings kaun man anch aus dem dufe-doppan westennes des Lambeth-psalters die ursprüngliche form des nominativs nicht feststellen.

1) Die bildung aucarius 'habicht' zu auca 'gans' erscheint anch in den Brüsseler vogelglossen W.-W. $285^{2}$.

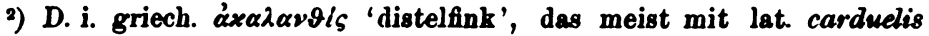

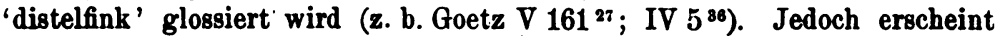
die gleiche deutung als 'nachtigall' in Epinal-Erfurt-Corpus 26: Achalantis vel luscinia vel roscinia 'nectigalae' sowie in dem Brtisseler vögelglossar W.-W. 285 ".

3) ae. gan(d)ra 'gänserich', ne. gander, jst eine maskulinerweiterung wie nhd. dial. ganr, gander, gânrt, nndl. gander (Suolahti s. 413).

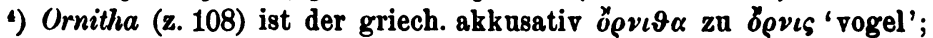

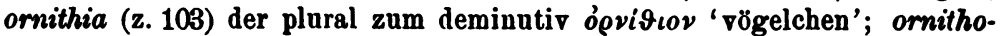
gonia (z. 105), griech. ó vvıo-yovia 'erzengung der vögel', ein büchertitel, den der glossator nicht verstanden hat.

5) Junins schreibt dafür den nominativ Anas.

') Mat. rubisca 'rotkelchen' begegnet auch sonst in ae. glossaren (Corp. ed. Hessels R 2506, 259; Faustina A. X zu Elfric ed. Zupitza 307; 
Ornitha 4) . 3 . hem . 1)

[fehlt]

Auricinctus . $\left.{ }^{2}\right)$ zoldfinc .

W.-W. $131^{2 i}$

110 Alauda . lauerce . ${ }^{3}$ )

13128

Bugium . hoefenbloete . ${ }^{4}$ )

13129

Alcedo . 1 alcion .5) mcew .

$131^{30}$

Columba . culfer .b)

Palumba . uvudeculfie .

115 Palumbes . cusceote .i)

Brüssel W.-W. 286" ; Cleopatra W.-W. 26017. - Ne. ruddock bzw. reddock erscheint noch heute dialektisch in vielen teilen Englands (Schottland, York, Warwick, Worcester, Suffolk, Kent, Wiltshire, Devon, Somerset, Cornwall).

1) Statt hem lies henn; rgl. Brüssel W.-W. $286^{33}$ f.: Gallina . 'hoen' . Ornitha $\overline{\bar{s}}$, wo über ornitha von späterer band nochmals haenn übergeschrieben ist [so nach der photographie des Brüsseler sachglossares in dem Leipziger forschungsinstitut für nenere sprachen].

2) Den vogelnamen auricinctus fiude ich nur noch in dem alphabetischen Cleopatra-glossar W.-W. 356"2. Gemeint ist er auch wohl in dem weiter unten als ur. 150 folgenden Cintus $l$ frugelus 'goldfinc'. Vyl. auch die glosse $\mathrm{nr}$. 145. Der name auricinctus erklärt sich ans den rotgelben flecken auf den flügeln des gold- oder distelfinken.

3) Über die etymologie von ae. läverce 'lerche' vgl. Suolahti s. $97 \mathrm{f}$.

4) Das unklare lat. bugium erscheint als vogelname auch im Brüsseler sachglossar (WW $287^{\text {'8}}$ : scorellus 'clodhammer 7 feldefare' [so!, nicht feldeware, wie W.-W. drucken] $l$ bugium) sowie im alphabetischen Cleopatraglossar (WW 361 17: Bugium 'haferbloete'). - Das handschriftliche haefenblcete ist sicher verschrieben für hofer-bløte, welches die 'sumpfschnepfe' (Gallinago scolopacina) bezeichnet (Z. f. d. Wortf. 14, 154; Suolahti s. 276f.). Es ist dies eine bildung zu ae. hafer 'bock' und blatan 'blöken' und entspricht also inhaltlich dem nd. havoer-blair, welches ebenfulls eigentlich 'bockmeckerer' (za nd. blarren 'blöken') bedeutet und ebenfall» ein name fïr die sumpfschnepfe ist. Vergleiche dazu andere ähnliche benennungen für den vogel bei Snolahti s. $277 \mathrm{f}$.

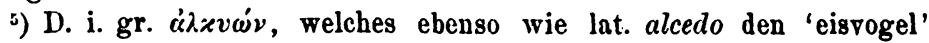
bedentet, während der angelsachse dafür die heimische 'möwe' (ae. måv Suolahti s. 397 ff.) substituiert hat.

B) Lies culfre (Snolahti s. 207f.) wie z. 114. Dialektisch gilt ne. culver bezw. kilver oder couver noch heute im südwesten (Dorset, Somerset, Devon), südosten (Sussex), mittellande (Lincoln, Derby, Ostanglien) und in Nordengland (Lancashire).

') Ae. $c \bar{u}$-sceote 'holz-oder ringeltaube' (Columba palumbus) ist noch hente dialektisch erhalten als ne. cushat, conshat oder cushy in Schottland, Nordengland (Northumberland, Cumberland, Westmoreland, Durham, York) und dem mittellande (Cheshire, Derby, Worcester, Suffolk, Buckingham, Berkshire). Zum zweiten bestandteil vergleicht Suolahti s. 208 dän. dial.

Anglia. N. F. XXIX. 
Bitorius . 7 pintorus . vorenna . 1)

W.-W. 131 ss

Cicada . Uicetula . hezesuzze ${ }^{2}$ )

118 Cicada . hilhama . ${ }^{3}$ )

Turdus . scric . ${ }^{4}$ )

skuda (Bornholm) und schwed. skuta (Farö) 'holztaube' sowie ae. sceotan 'sich rasch bewegen'. - Im klassischen Latein heifst der rogel palumbes (oben z. 115); die mlat. form palumba (z. 114) findet sich aber mehrfach in glossen (Goetz III $257^{60}, 435^{42}$; V 318 " palumba ' columba silvestris grandis').

1) Dieselbe glosse im Brüsseler sachglossar: Bitorius . vorcenna $l$ pintorus (W.-W. $286^{16}$ ). Mlat. bitorius = butorius, zu kl.-lat. butio, bezeichnet, wie das alte simplex, 'die rohrdommel', ae. vrenna (ne. wren; Suolahti 8. 80) dagegen den 'zaunkönig'. Ein mlat. pintorus vermag ich sonst nicht nachzuweisen.

2) Ae. heze-suzze ist me. heisugge, heysoke (mit anlehnung an to suck 'saugen'), ne. dial. haysuck (in Worcester, Gloncester, Somerset, Devon) und bedeutet sicherlich, wie die me. und ne. fortsetzungen, den gemeinen 'feldsperling'. - Uicetula ist gleich lat. ficetula, ficedula 'grasmincke', das mehrmals mit ae. suzza glossiert ist, doch einmal auch mit hoez-sugga (ZfdA. XXXIII $241^{\text {s}}$ ). Freilich palst weder lat. ficetula 'grasmücke' noch lat. cicada 'baumgrille' der bedeutung nach recht $\mathrm{zu}$ ae. heze-sugge. Das Cicada ist möglicherweise irrtümlich ans der folgenden zeile heraufgenommen.

3) Vgl. Cidada 'hyllehama oððe garstapa' (Cleop. W.-W. 3787). Ae. hylle-hüma, eigtl. 'hügel-heimchen', soll wohl - zur wiedergabe des lat. cicada 'baumgrille' - die 'feldgrille' im gegensatz zur 'hansgrille' (ae. hāma) bezeichnen. Ich vermag also der erkiärung von J. van Zandt Cortelyon, Die ae. Namen der Insekten (Heidelberg 1906) 8. 95 nicht beiznstimmen, der in dem ersten bestandteil ein ae. *hyll 'hülle' sieht, das sonst im Englischen nicht belegt ist und anch sachlich kein unterscheidnngsmerkmal für eine besondere grillenart abgeben würde, da alle grillen bei ihrer sommer-häntung ihre hullle abwerfen. Ae. hyll 'hügel' dagegen ist nicht blols ein ganz gewöhnliches wort, sondern wird auch bis heutigen tages als nnterscheidungsmerkmal bei tiernamen gebraucht. So gibt es nach dem Oxforder wörterbuch, um nur rögel zu nenven, hill-partridge, hill-star, hill-tit und hill-woren, dialektisch auch noch (nach Wright) ein hill-bird, hill-chack, hill-hooter, hill-linty, hill-plover und hill-spairow.

4) Ae. scric bedeutet, wie lat. turdus, sicherlich die durch ihren schnarrenden ton anffallende 'misteldrossel' (Turdns viscivorns), nicht aber, wie Sweet, Klnge und Hall wegen ne. shrike 'würger' annehmen, diese letztere raubvogelart. Die misteldrossel heifst noch hente dialektisch in Cumberland und Wiltshire shrike, shrike-bird, shrike-cock oder shrike-pie; nnd damit stimmt überein, dafs man in Deutschland (Westfalen) dafür die dialektische bezeichnung der schrik hat (Suolahti s. 64). Anf die laute stimme der misteldrossel nehmen auch andere deutsche dialektnamen bezng, wie schnarver, schnarz, schnarrezer, fries. snarlier (Helgoland) und oberd. zerrer, zarrer (Suolahti s. 60). Zum teil gelten diese namen allerdings auch von dem ebenfalls auffallig schnarrenden 'wiesenknarrer' (Ortygometra 
120 Cornix . 7 coruina . crawe . $\left.{ }^{1}\right)$

W.-W. $131^{3 i}$

Butio . cyta . ${ }^{2}$ )

Turtur . turtle . ${ }^{3}$ )

Coruus . 7 corax . remn .4)

Nicticorax ${ }^{5}$ ) . nihtremn . 4)

125 Gracula . ł monetula . ceo .6)

Gaia . $ł$ catanus . hizere . $\left.{ }^{\top}\right)$

crex). So scheint auch das germ. *skrtk- für verschiedene vogelarten gebrancht zu sein, die durch ihre stimme auffielen; so heifst mnd. schrik, nnd. (westfäl.) schrik 'krammetsvogel', nhd. va. schryck, screek 'wiesenknarrer', schwed. skvika, norw. skrike 'eichelhäher' (Suolahti s. 295). [Im Leydener glossar 213 ist natürlich scriic statt Sweets scruc zn lesen; andere beispiele für doppeltes $i$ siehe Archiv 125,55 A. 5].

1) Das (ron Junins übergangene) corvina bedentet hier wohl 'zur rabengattung gehörig'; vgl. Goetz, Corpus glossariorum latinorum, II, $574^{16}$ : Cornix . comıs. Über ac. crāwe s. Snolahti s. $179 \mathrm{f}$.

2) Lat. buteo, eine falkenart, etwa 'bussard' - es glossiert z. b. griech.

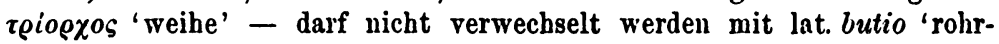
dommel'. - Ae. cyta bezeichnet den 'weihe'.

3) Über ae. turtle s. Snolahti s. $216 \mathrm{f}$.

4) D. i. hremn, hrefn 'rabe' und niht-hremn 'naclitrabe'. Über ae. hrofn s. Suolahti s. $174 \mathrm{ff}$.

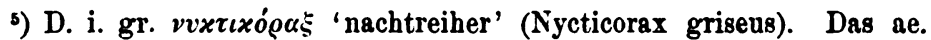
niht-hrafn ist nach Suolahti s. 380, ebenso wie ahd. naht-ram nnd an. $n \bar{a} t$-hrafn, ein gelehrtes literaturwort.

') Lies monedula ['dohle'], wie Junins stillschweigend schreibt. Über ae. cco 'doble' s. Suolahti s. 189.

') Über das vlat. gaia 'häher' (Corvus glandarius), welches das Etymon fïr afrz. jai (ne.jay), prov. gai, span. gayo, ital. gazza usw. ist, siehe die literatur bei Körting nr. 1482 und Meyer-Lübke nr. 3640. - Das dann folgende, sonst nicht nachweisbare catanus steht wohl für gaianus. welches seinerseits eine abteilung zu gaius 'elster' wäre, falls es nicht direkt fïr das letztere verschrieben ist. (Mit diesem catanus dürfte auch irgendwie zusammenhängen das unrerständliche cicuanus, welches sowohl im Corpus-glossar ed. Hessels C 438 wie im Cleopatra-glossar WW $364^{10}$ als lemma zu hi亏ore vorkommt). - Das ae. hizora (mnd. heger) ist etymologisch mit ald. hehara, nhd. häher verwandt und bezeichnet denselben rogel wie letzteres, nämlich den 'eichelhäher' (Corvus glandarius); s. Snolahti s. 198f. Ausschlaggebend für diese gleichsetzung ist die einzige stelle, wo das wort aufserhalb der glossen erscheint, nämlich das 22. rätsel (el. Trautmann 1915 , s. 86 ; ed. Wyatt s. 82 ), wo ein vogel damit bezeichnet wird, der leicht fremde laute nachahmt und wie der hund bellen, wie die geis blöken und wie gans, habicht, adler, möwe oder weihe kreischen kann, was nach freundlicher auskunft meines zoologischen kollegen prof. Meisenheimer wort fuir wort auf den eichelhäher, aber nur auf diesen 
[auf dem unteren rande:]

\author{
Scurnus . Fulix . ${ }^{2}$ ) \\ Stronus . stoern. ${ }^{3}$ ) \\ 130 Turdus . star .4) \\ Turdella . se mare star..$\left.^{5}\right)$ \\ Coturnix . $¥$ ortigametra $\left.{ }^{6}\right)$. arschen .7$)$
}

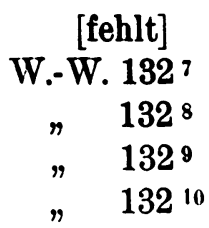

palist. Daher sind die anderen dentungen des ae. hizore, wie sie BosworthToller, Sweet, Hall, Whitman, Tupper nnd Wyatt mit 'specht', 'olster' oder 'dohle' bieten, abzulehnen.

1) Die beiden wörter ciculus und tucus sind von Junius übergangen. Das erstere ist eine auch sonst vorkommende (Ahd. Gl. IV 27), wohl verderbte form für lat. cuculus 'kucknck'. Ein tucus 'kuckuck' erscheint öfter in glossen (z. b. Goetz V 624; Ahd. Gloss. IV 27, III 17), wohl zurückgehend auf Isidor, Etym. XII 7, 67: Tucus, quem Spani cuculum vocant, a voce propria nominatus. - Dieselbe ae. glosse wie oben haben wir anch im Brüsseler glossar (WW 286 ${ }^{25}$ ): Cuculus . 'geac' . $l$ ciculus . Tucos. Über ae. geac 'kuckuck' s. Suolahti s. 5.

2) Die bei Junius fehlende glosse ist schwer $z$ denten. Lat. fulix ist das 'wasserhuhn', aber das nur hier belegte scurnus vermag ich nicht zu erklären. Es könnte für sturnus 'star' verschrieben sein, wozu allerdings die glosse fulix inhaltlich kanm passen wirde. Doch ist zn beachten, dafs anch nnter $\mathrm{nr} .90$ oben nnser glossar das wort sturnus in sehr freier weise mit der 'seeschwalbe' zusammenstellt'. Wäre die korrektur in sturnus richtig, so würden 128 und 129 wohl in eine glosse zusammenzuziehen sein.

8) Auch ein lat. stronus ist nur hier belegt. In hinblick auf die vorher erscheinende 90. glosse Beacita . I sturnus 'stearn', ist es wohl in sturnus zu bessern. - Ae. staern ist jedenfalls nur eine späte, monophtongierte form für stearn 1. 'seeschwalbe', 2. 'star' (vgl. oben s. 110 a. 1 n. s. 103 a. 1). In staern eine nebenform von staer 'star' $z u$ sehen, wie Whitman, Jonrnal of Germanic Philology II (1898) 153 will, ist lantlich unmöglich. (Das stęrn des Corpus-glossars ist eine archaische, die brechung graphisch noch nicht ausdrückende schreibnng für stearn).

4) Lat. turdus bezeichnet die 'drossel', das ae. stcer dagegen den 'star'. Also haben wir anch hier wieder eine ungenaue glossierung, wie in z. 121, 126 usw. (s. s. 103 a. 1).

5) Lat. turdella ist die 'kleine drossel'. Sonach wird der glossator irrtümlich se māre [lies se māra] 'der grölsere' für se lassa 'der kleinere' geschrieben haben. Wegen der reduktion der endung -a $2 \mathrm{a}-e$ vgl. 8. 103 a.1.

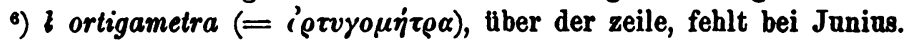

7) Der erste bestandteil von cersc-hen oder ersc-hen (Elfric ed. Zupitsa $307^{\circ}$; WW 287 ${ }^{12}, 460^{2}$ ) ist offenbar ae. ersc oder arsc, 'das mehrfach in flurnamen begegnet' (Middendorff) nnd jedenfalls, wie seine nenengliache 
Pica . azu . 1)

W.-W. $132^{11}$

Pluuialis . hulfestre . ${ }^{2}$ )

$132^{12}$

135 Bubo . uf. ${ }^{3}$ )

$"$

$132^{13}$

Upupa .

Picus . fina ${ }^{4}$ )

[fehlt]

Cracculus . $¥$ Garrulus . hroc . ${ }^{5}$ )

W.-W. $132^{14}$

Miluus . zlida . ${ }^{6}$ )

140 Ibin . zeolna . ${ }^{\top}$ )

fortsetzung dial. ersh, arrish (NED und Wright) die bedentung 'stoppelfeld' oder vielleicht blofs 'feld' haben wird. Ae. ersc-hen whirde danach soviel wie 'feldhuln' bedenten. Ob ans diesem rein etymologischen grunde aber der vogel, der damit gemeint ist, wie Suolahti 8. 256 annimmt, das von uns sogenannte 'feldhuhn' oder 'rebhuhn' (Perdix cinerea) gewesen sein mufs, scheint mir doch sehr zweifelhaft. Es ist überall mit lat. coturnix oder griech. ó 'wachtel' bedenten; und, da anch die wachtel im tiefen ährenfeld verborgen lebt, wülste ich keinel grund, warum nicht auch ae. ersc-hen die 'wachtel' (Coturnix communis) meinen sollte.

1) Über ae. azu 'elster' (Corvus pica) 8. Suolahti s. $192 \mathrm{f}$.

2) Ein 1t. pluvialis im sinne von 'regenpfeifer' scheint sonst nicht belegt. Doch wird ein vlat. *pluviarius 'regenpfeifer' (Meyer-Luibke nr. 6622) von ital. piviere, afrz. plouvier usw. vorausgesetzt. - Das ae. hulfestre ist nur noch ein zweites mal belegt, nämlich im Brüsseler glossar WW $287^{14}$, wo es allerdings ein unverständliches Ciuprella glossiert. Der bedentungsansatz 'regenpfeifer' stützt sich nicht nur auf das lemma der Plantinus-glosse, sondern auch anf das lautlich verwandte westfries. wilster (Dijkstra). Verwandt ist das wort mit der westgermanischen bezeichnung für regenpfeifer (Suolahti 8. 269): ae. hwilpe oder hwoilpa (aus dem gen. huilpan des 'Seefahrers' 21), westfries. wilp (Dijkstra), ostfries. regen-wilp, mnl. nnl. voulp, ud. voilp, wolp, auch water-volp. (Ein "nl. wilp", wie es Grein, Klnge, Halle ${ }^{2}$, Suolahti anführen, ist zwar als altere form für nl. voulp anzunehmen, scheint aber nirgend wo belegt zu sein).

3) Über ae. if 'uhu' (Bubo maximus) 8. Suolahti s. $309 \mathrm{f}$.

') Über ae. fina 'specht' (Picus) s. Suolahti 8. 28.

5) Lat. graculus bezeichnet die 'dohle' (Corvus mouedula), das ae. hroc dagegen, ebenso wie ne. rook, fries. nl. roek, mnd. rok, ahd. lruoh, an. hrökr, schwed. råka, dän. raage, die ähnlich aussehende 'saatkrähe' (Corvus frugilegus); s. Snolahti s. 183.

6) Das ae. zlida hezeichnet, wie me. glede, ne. glede, glead und die damit verwandten an. gleða, dän. dial. glede nisl. gleða, sowie nisl. gleơra, schwed. dial. glära (Hellquist, Etymol. Bemerkungen, 1893, s. WII), den 'weihe', d. h. in erster linie wohl den 'königsmilan' (Milvus regalis). Vielleicht sind aber anch allerhand andere falkenähnliche raubvögel, wie die 'kornweihe' n. a., darin einbegriffen gewesen.

') Ein Angelsachse konnte nattirlich nicht den weifsen ägyptischen ibis gesehen haben, sondern höchsteus die braune ibisart des 'sichlers' 
Fulica . dopenid .1)

W.-W. 13218

Uultur . earnzeap ${ }^{2}$ )

13210

Aceia . snite . \ wude-cocc. ${ }^{3}$ )

13220

Grus . cran . $\left.{ }^{4}\right)$

145 Florentius . zoldfinc . ${ }^{5}$ )

Luscinus . zeolewearte . $\left.{ }^{6}\right)$

(Ibis falcinellus), der gelegentlich in Eugland erscheint. Vielleicht ist daher zeolna verschrieben fiir archaisches zeoluc d. i. zeolwa 'der gelbe', wie allenfalls der sichler bezeiøhnet werden könnte. Sonst ist lat. $i b i s$ (gr. i $\beta \iota \varsigma$ ) glossiert mit ae. vindeclifre (WW $427^{29}$ ) 'kleiber oder blanspecht' (Sitta caesia; vgl. Archiv 119, 433; Suolathi s. 161, der frühnhd. rinnenkläber vergleicht) und mit ae. scrcef (St. Gallen 918 s. $143^{3}$ ed. Anglia 36, 392) 'scharbe oder kormoran' (Graculus carbo; Suolahti s. 393 vergleicht mit Falk-Torp an. skarfr, dän. skart, schwed. dial. skavf, ahd. scarva, scarba 'scharbe').

1) Ae. dopp-enid, über dessen etymologie die anmerkung zu ae. doppa 'taucher' (glosse 98) zu vergleichen ist, bezeichnet irgend einen tanchenden wasservogel, auf grund des lat. lemmas und des nhd. dial. duckente (Suolahti s. 306) am ehesten wohl das 'blälshuhn oder wasserhuhn' (Fulica atra), obschon der ausdruck 'duckente' (Snolahti s. 444) anch für den gemeinen tancher oder 'steifsfnfs' (Colymbns) gebrancht wird.

2) Das lat. vultur bezeichnet den 'geier', dagegen das ae. earn-géap den 'seeadler' (Haliaëtus albicilla). Über' das nebeneinander von ae. earngeap und ae. earn-geat, -geot, ahd. erin-geoz, an. gjбðr 'seeadler' s. Suolahti s. $349 \mathrm{f}$. und kaum richtig Holthausen in Anglia Beibl. 19, 164; vgl. anch Kralik, Göttinger gel. Anz. 1914, $158 \mathrm{ff}$.

s) So, nicht aceta (Junius), liest die handschrift. Zu lat. acceia 'schnepfe' vgl. Meyer-Lübke, Wtb. ur. 66. - Ae. snite entspricht dem me. ne. snite 'schnepfe' (Suolahti s. 274), und das ae. wridu-cocc dem ne. woodcock 'waldschnepfe' (Scolopax rusticula), neben welchem im Altenglischen auch das kompositum voudu-snite erscheint.

') Über ae. cran 'kranich' (ne. crane, nl. kraan, mud. krān, nud. krane, ahd. crano) neben ae. cranoc (nud. kränek, mud. kranek, ahd. kranıh) s. Snolahti s. $291 \mathrm{f}$.

5) Vgl. in einem alphabetischen glossar des 15. Jhs. in Trinity College, Cambridge (WW 583 ${ }^{47}$ ): Florencius 'a goldfynche'. Sonst vermag ich diesen lateinischen namen für den goldfink nicht weiter nachznweisen. Doch ist damit $\mathbf{z a}$ vergleichen der zweimal dafür belegte name florulus WW $260^{85}, 405^{10}$ (woraus das unverständliche fronulus 'linetwize' WW $404^{7}$ wahrscheinlich verderbt ist). - Wie in Deutchland, so versteht man auch in England unter 'goldfink' (ne. goldfinch) zumeist den 'distelfiuk' oder 'stieglitz' (Fringilla carduelis), und diese finkenart wird anch wohl hier gemeint sein (Suolahti s. 115ff). Vgl. anch die glossen 99 und 150.

-) Luscinus, das auch sonst in glossen (z. b. Goetz II 125 24, 55048, III $90^{3}$; WW $132^{23}, 477^{3}$ ) als vogelname erscheint - nicht zu verwechseln mit lat. luscinus 'geblendet' -, steht doch wohl für klass.-lat. luscinius 
'nachtigall'. - Das nur hier belegte ae. zeolewearte wird wohl sicher irgendwie mit zeolu 'gelb' zusammengehören und also einen vogel bezeichnen, der irgend etwas gelbes an sich hat. Als zweiten bestandteil des kompositums trennt man in der regel ae. vearte 'warze' ab, ohne dais es gelingen will, diesen begriff in irgend einem anderen vogelnamen nachznweisen. Neuerdings hat daher Suolahti s. 94 das wort mit dem an. ertla 'bachstelze' (schwed. ärla, dän. erle, norweg. erla) verglichen und eine zerlegung in zeolew-earte befürwortet. Dann würde das wort für älteres zeolu-earte stehen (vgl. ae. bealu-inwit), indem der erste bestandteil sein $w$ aus den oblikeu kasus bezogen bätte, wie in den belegten formen smeoruzo und meluw (Sievers \$249 a. 2). Ae. carte 'bachstelze' entspricht genau dem an. arta, dessen bedeutung allerdings meist als 'knäkente' (Anas querquednla) angegeben wird, doch nur weil das entsprechende nschwed. årta diesen vogel bezeichnet. Die ursprüngliche Bedleutung von an. arta kann dies schwerlich gewesen sein, weil der davon abgeleitete vogelname an. ertla bis heute die 'bachstelze' (Motacilla) bezeichnet. Ae. zeolu-earte wïrde danach die 'gelbe bachstelze' (Motacilla flava) sein. Vogelnamen, die mit gelb- zusammengesetzt sind, sind wenigstens im Deutschen sehr häufig (Suolahti s. 480).

1) Die glosse parrax 'rorenna' erscheint auch bei fllfric ed. Zupitza $307^{12}$. Die form des lnt. wortes sowie die bedeutung 'zaunkönig' ist nur an diesen beiden stellen belegt. Doch ist parrax, ebenso wie parrix (Diefenbach), offenbar cine nebenform zu klass.-lat. parra oder parrus, dessen bedeutung bei den alten (Plautus, Plinins, Horaz u. a.) unsicher ist, das jedoch in lateinischen glossen für verschiedene kleinere singrogel

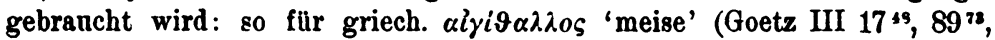

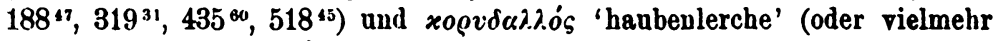

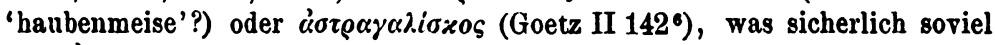
wie $\alpha \sigma \tau \rho \alpha \gamma \alpha \lambda . i v o \varsigma$, nämlich 'distelfink', ist. Zu letzterer bedeutung wïrde passen die zweite ae. glosse hice-māse, welches nach auswois seines zweiten bestandteiles eine meisenart bezeichnen mufs. Gewöhulich falst man hicemāse als 'blaumeise' (Parus caeruleus), wohl aber nur, weil das dialektische ne. Tickmall (Cornwall) 'blaumeise' daran anklingt. Auch das simplex hice erscheint als 'meise', worauf W. Lehman (Archiv 119, 434) aufmerksam gemacht hat: par'uca 'hicue' Corp. P176 und parruca 'yce' Cleop. WW $468^{22}$. Und dafs es sich hier wirklich um ein selbständiges wort, nicht ein nur halbausgeschriebenes hicemase handelt, dafür spricht das mnl. hijken, hiken 'parus maior' (d. i. 'kohlmeise'), welches zugleich anch die länge des $\bar{\imath}$ beweist. Ae. hīce-māse wäre dann ein tautologisches kompositum wie ahd. lindwourm, deren mehrere E. Koeppel in der Furnivall-Festschrift 8. 201-204 fiirs Altenglische znsammengestellt bat. Eine etymologische anknüpfung dieses hīce wülste ich nur, wenn es sich zu mnd. hicken 'mit dem schnabel hacken', mnl. hicken 'stechen' stellte, das einem ae. *hiccian neben haccion hacken' entspräche. (Auch die dial. ne. nebenform hack-mal 'blanmeise', neben hick-mal [Wright, EDD unter hack-mal] legt anlehnung an ne. hack 'hacken' nahe. Vielleicht könnte dasselbe *hick 'hacken' anch in ne. 
Merula . \& plara . prosle .1)

W.-W. $132^{25}$

Accipiter . $¥$ Raptor . spearhafoc . $\left.{ }^{2}\right)$

$132^{26}$

150 Cintus . \& Frugelus . zoldfinc . ${ }^{3}$ )

9

" $1322^{27}$

Hirundo . swalewe.

Carduelis . linetwize . ${ }^{4}$ )
13228

$132^{29}$

[fol. $3^{\mathrm{b}}$ ]

[auf dem oberen rande:]

Rapariolus . fiscere . ${ }^{5}$ )

hickwall 'grünspecht' [NED] vorliegen.) - Das lat. simplex parra (= Meyer-Lübke nr. 6251) erscheint im Altenglischen als 'kohlmeise' (colmāse W-W $286^{14}$, vgl. ne. coal-mouse; wegen ae. cum-māse W-W $260^{1:}$ vgl. Angl. Beibl. 17. 297) glossiert, und das deminutivum parrula sowohl als 'kohlmeise' (col-māse W-W 26020, ZfdA. 33, 241 ${ }^{46}$; spic-māse W-IW $286^{15}$, vgl. nhd. speckmeise, an. spiki, norw. spiklie 'kohlmeise') wie einfach als 'meise' (māse Ep.-Er.-Corp. 806, Ld. 202, W-W 468 ${ }^{16}$ ), wozn noch die glosse

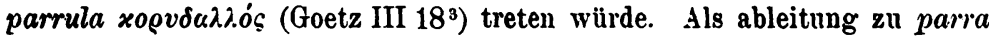
ist jedenfalls auch das obenerwähnte lat. parruca zu ziehen.

1) Das sonst nicht nachzuweisende plava wird wohl verderbt sein. Wegen ae. prostle 'drossel' s. Suolahti s. 52. - Junius liest fälschlich uel statt $d$.

2) Raptor 'räuber' als vogelname begegnet soust nirgends. - Ae. spear-hafoc 'sperber' (vgl. an. spprr-haukv und abd. sparw-āri, as. sparowari mnd. sparuer, mnl. sparuare) ist me. sparhauk, ne. ra. sparhawk, welches durch einsetzen der volleren form (ae. spearwa) zu me. sparowhauke (15. Jh.), sparrow-hazok erweitert ist, wozu der gleiche vorgang in schwed. sparthök, dän. spurvehog, norw. dial. sporvehauk za vergleichen ist.

$\left.{ }^{3}\right)$ Lat. cintus erscheint nur noch im alphabetischen Cleopatra-glossar (WW 380'7) mit der glosse 'finc'. Vermutlich ist es verderbt aus dem vogelnamen auricinctus 'goldfink', über den oben unter $\mathrm{nr} .109 \mathrm{zu}$ vergleichen ist. - Das lat. frugelus - und ebenso das in zwei glossaren des 15. Jh. auftretende lat. frugella 'a rook' (W-W $585^{3}, 640^{80}$ ) - könnte die latinisierung

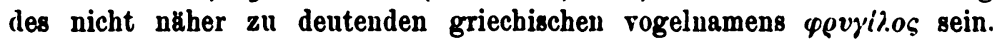
Vielleicht sind die formen aber nur verschrieben für lat. firingillus, firingilla, die mehrfach in altenglischen glossen erscheinen: nämlich als fringilla WW $286^{12}$ und fringella W-W $23^{13}, 404^{14}$ mit der bedeutung 'fink', und als frigellus W-W $584^{88}$ mit der bedentung 'rotkehlchen'.

-) Auch hier stimmen lemma und glosse nicht genan: lat. carduelis ist der 'distelfink', ae. tinne-twige (vgl. ne. lintıchite) aber der 'hänfling' (Fringilla cannabina). Wegen des -twige vergleiche ae. Distel-twige 'distelfink' und ahd. distil-zwigil zu ahd. zwigon 'zupfen' (neben mhd. zzoicken, ac. twiccian 'rupfen'; Angl. Beibl. 17, 298; Suolahti s. 115).

s) Der lat. vogelname rapariolus für den 'eisvogel' (Alcedo ispida), den das volk wegen seiner gefrä[sigkeit auch 'kënigsfischer' nennt, begegnet nur hier. Ein gleiches gilt für ae. fiscere als vogelname, wofïr im Ne. seit dem 15. Jh. king's fisher oder (jetzt meist) kingfisher gilt. 
Pullus . cicen . 1)

W.-W. $132^{35}$

155 Tanticus . cerðlinz. ${ }^{2}$ )

$132^{31}$

Capo . capun . ${ }^{3}$ )

Gallus . coc .

$1322^{32}$

Gallinacius . capun ${ }^{3}$.)

13233

Falco . $¥$ capus . a capiendo . wealhhafoc .4)

1) Über ae. ìyc̀en 'küken' s. Suolahti s. 234.

2) Ti. [oder Te.] Tanticus die hdschr. - Das lat. tanticus, das allerdings anch in dem Brïsseler und in dem Cleopatra-glossar (WW 286 ${ }^{28}$, $361^{14)}$ als lemma zu eoroling, yroling vorkommt, ist vermutlich verderbt aus lat. tantalum, das bei Isidor, Etym. XII 7, 21 als name für 'reiher' erscheint; vgl. auch Goetz V 1580.29: tantalum 'avdea avis', Corpns ed. Hessels Intr. 325: tantalus 'aelbitu' [d. i. 'schwan']. - Ae. cerðling, was woll mit monophthongierung für eoroling steht, entspricht jedenfalls lautlich wie inhaltlich dem nhd. irdling 'bachstelze' (Z. f. d. Wortf. 4, 191; Archiv f. n. Spr. 119, 434). Es liegt darin dieselbe bedentnngstibertragung von 'ackersmann' anf den vogel vor, die wir auch in dem dentschen namen für die verbreiteste bachstelzenart, die 'weifse bachstelze' (Motacilla alba), Laben, die gewöhnlich 'ackermünnchen' (auch 'ackermann') genannt wird (vgl. Archiv 119, 434 anm. 2), weil sie in den fuisstapfen des ackermanns folgt, um in der aufgepfligten furche würmer za sammeln (Snolahti s. 91).

s) Das zweimalige capūn liefse sich in unseren glossen als französisches lehwwort (agln. capīn aus lat. capponem) auffassen, da ein sicher französisches custure 'naht' darin (als $\mathrm{nr}$. 21) begegnet. Und ein gleiches gilt von dem mit unserem text sicherlich in beziehnng stehendem Brtisseler glossar, wo ein $i$. capın in jüngerer land (anf. 12. Jh.?) nachträglich über die glosse Gallinacius . capo (danach ist $\mathrm{W}^{\top} \mathrm{W} 286^{32} \mathrm{zu}$ bessern) geschrieben ist. Damit wäre die schwierigkeit beseitigt, daโs bei jüngeren ae. entlehnungen aus dem Lateinischen sonst stets lat. $\delta$ als $\delta$ erscheint (vgl. ae. non, son, Romware), während hier sich $i t$ zeigt. Sonach wäre Suolahti s. 238 zu indern. - Die glossierung ist in $\mathrm{nr} .158$ wiederum nicht sonderlich genau, da lat. gallinaceus einfach den 'haushalun', nicht aber den 'kapphabu bezeichnet. (Wright-Wülker drucken fälschlich Gallinaccus).

4) Ein lat. capus 'falke' erscheint auch sonst: Isidor XII, 7, 57, Goety $V 175^{12}, 493^{51}, 563^{65}, 56 t^{31}$, Elfric ed. Znpitza $307^{11}$; Ahd. Gl. WI $87^{34}$. Ae. weall - hafoc, wie das vielleicht auf altenglische vorlagen zurïckgehende ahd. walh-habuh, ist doch wohl trotz Suolahtis einspruch (8. 331) der 'wanderfalke' (Falco peregrinus), nicht der 'wälsche falke', obgleich wir wissen, dals könig Eðelstan jagdvögel aus Nordwales bezog (Roeder in Hoops' Reallexikon I 218, II 8). Auch in der altenglischen dichtnng heifst der jagdfalke 'der fremdling', se wølisca (Menschen-Geschick 90). Vgl. auch an. valr 'falke' (eigtl. 'der fremde') und das allerdings sehr unklare nkymr. gualch 'falke' (T'hurneysen, Keltoromanisches 8. 59; Loth, Les mots latins dans les langues brittoniques, 1892, s. 94 f.; Windisch, Das keltische Britannien, 1912, s. 172), das eiu älteres *walk- roraussetzt, wie es lateinische 
konzilienhandschriften in der schreibung walcones (MGL, Conc. II ${ }^{1} 3,15$ und 47,20 ) erhalten haben. (Ob die altkeltischen namen abret. Uualc-moel und mkymr. Gualchmei, nkymr. Gucalchmai etwas damit zu tun haben, ist trotz Rhys, Welsh Pilology s. 402 und Loth, Chrestomathie bretonne, 1890, s. $171 \mathrm{zum}$ mindesten $\mathrm{zweifelhaft.} \mathrm{Akorn.} \mathrm{falluun} \mathrm{[hs.} \mathrm{falbun]} \mathrm{und} \mathrm{nbret.}$ falc'hun 'falke' sind aber lehnwörter ans aglfrz. falcīn).

1) Dieselbe glosse wie im Brüsseler glossar (WW 287 $)$ : Soricarius [darüber von späterer hand, um 1100] 'bleria pyttel'. Sicherlich ist das obige unverständliche scoricarius mit der Briisseler handschrift in soricarius zu bessern, welches, zu lat. sorex 'spitzmaus' gehörend, ursprünglich 'die mans betreffend' bedeutet haben muls, hier aber eincn mäuse-jagenden raubrogel bezeichnet. Letzteres würde nun auf eine ganze reihe von kleineren falkenähnlichen raubvögeln, wie edelfalken, bussarde, milane, habichte, sperber a. a., sowie auf alle eulenarten zutreffen. Indes ist in der mebrzahl der fälle mit analogen volkssprachlichen bildungen doch der 'mäusebnssard' (Buteo vulgaris) gemeint: so bezeichnen diesen vogel ae. mūsere (St. Gallen 918, ed. Anglia 36, 392), and. ahd. mūsāri, mnd. mūser, mhd. mūsscere, uhd. dial. mauser, stock-müser, meuss-ar; mause-falck, mause-geyer, müse-bickeler, mūse-kibbese mnd. mūse-biter, (vgl. Suolahti s. 352 ff.), westfries. mūze-biter, mul. muusbiter, nnl. muisvalk, aschwed. mūsa-vaker, nschwed. müsvcik, ndän. musvaag. [Eine andere bedentung haben nisl. müsar-rindill 'zannkönig' nnd mud.mūs-hunt, mnl. munshont, unl. muishond (daraus ne. mouse-hunt) für 'wiesel' und 'katze']. Für irgend eine falkenart, etwa den 'mäusebussard: (Buteo vulgaris) oder den 'turmfalken' (Falco tinnunculus), spricht auch die glossierung von lat. soricarius mit mits-hafoc (Corp. S 438; WW 25910, $285^{6}$; Elfric ed. Zupitza 307 var.; ZfdA. 33, 240 ${ }^{17}$ ), welches einem ne. mouse-hauk entopricht, das in Amerika jetzt den 'rauchfufsbnssard' (Archibuteo lagopus), in England aber die 'zwergohreule' (Asio brachyotus) bezeichnet. Nach der gleichen richtung weist eine romanische fortsetzung des mlat. soricarius, nämlich das katalanische sorigé 'turmfalke' (MeyerLübke nr. 8100). Eine falkenart wird anch unsere obige glosse bleripittel oder bleri pittel - beide lesungen lälst die handschrift zn - meinen. Formell betrachtet wird bleri, wie die Brilsseler parallelform bleria, jedenfalls mit dem adjektiv ae. blere 'kahl' zusammengehören. Und wir dïrfen dafiir sicherlich auch dieselbe bedeutung ansetzeu wie für blere, nämlich 'kahl'. Was kann aber der begriff 'kahl' bei vögeln besagen wollen? Dafs es sich nicht um eigentliche haarlosigkeit handeln kanu, lehrt die naturgeschichte. Die analoge verwendung des synonymen ne. bald in volkstümlichen vogelnamen zeigt uns aber, dafs bald bei allerhand vögeln mit einem weifsen flecken am kopfe, einer blässe, verwendet wird nnd also hier die alte bedeutung 'weilsfleckig, blässig' hat. So heilst das 'wasserhuhn' (nhd. auch blä/shuhn; vgl. Suolahti s. 302 ff.) wegen seiner weifsen stirnplatte ne. ball-coot bezw. in den dialekten (nach Swainson und Wright) bald-duck (Somerset), bald foul oder bald pont (Northumberland, Lothian), die 'weifsstirnige gans' (Anser albifrons) in Schottland balk goose, die 'pfeif- oder blälsente' bald-pate, der 'weifsköpfige seeadler' 
(Haliaëtus lencocephalus) bald eagle und der weifsköpfige 'fischadler' (nhd. auch veifskopf; vgl. Suolahti s. 365) sowie die 'kornweihe' mit ihren weifsen genickstreifen bald buzzard. Endlich wird nach Swainson s. 132 aus mir nicht ganz klarem grunde anch der 'mänsebnssard' (Bnteo vulgaris) seit älterer zeit in England als bald buzzard und bald kite bezeichnet. Und dies ist ja gerade die rogelart, welche durch die glossierung müs-hafoc, wie wir vorher saheu, für das lat. soricarius an anderen stellen erwiesen wird. Wir dïrfen daher anch für unser obiges bleri pyttel die bedeutung 'mäusebussard' in auspruch nehmen, zumal anch der zweite bestandteil der ae. glosse, ae. pyttel 'bussard' oder 'weihe' (= me. pittel, ne. dial. dunpidlle in Dorset), sich mit einem anderen ne. dialektnamen für eine bussardart, den 'wespenbussard' (Pernis apirorus), nämlich puttock (Dumfries, Antrim, Suffolk, Essex, Sussex), etymologisch verbinden läfst (s. NED). Damit ist auch der weg frei gemacht für die bisher nicht erkanute etymologie von ae. blere: dieses aljektiv stellt sich offenbar zu mnl. blaer, blaerde 1. 'einen weifsen fleck (blässe) habend', 2. 'kahl', nnl. blaar 1. 'blässig', 2. 'weifser stirnfleck', mud. blare 'bläfskuh', norweg. blarand 'bläfshuhn', und ist also eine $i$ - oder io-ableitung zu dem nrgerm. stamme *blaz-, *blas-, dessen verbreitung aus den etymologischen wörterbüchern unter nhd. blässe, blass, nl. bles, schwed. bläs, däı. blis, ne. blaze, anch frz. blaire 'blä (shuhn' (Meyer-Lübke Mr. 1144), zu ersehen ist ( $\mathrm{vgl}$. bes. die vogelnamen uhd. blä/shuhn, dial. blüssente, blässhenne, blässling, blässel, mhd. blazze und die tieruamen ahd. blasros, mnd. blasenhengst, ul. blespaard, westfries. bleshynder, nordfries. bleskiet, dän. Ulisset fiur 'pferd mit blässe'). Durch diese etymologie ist die kürze des stammvokales festgelegt. Endlich ist die frage noch zu erörtern, wie sich die form bleri in unserer Antwerpener glosse und das bleria des Brïsseler glossars, denen sich noch ein nrkundenbeleg aus dem 10. jahrh. (on Allfstanes pys blerian [zewitnesse] Thorpe's Dipl. s. 174) anschliefst, in ihrer stammbildung zn dem jo-stamm blere stellen. Bisher nimmt man an, dafs bleri für blerig verschrieben sei, so dais wir dieselbe doppelbildung hätten wie hei ae. reppig neben repe, westiz neben weste, wyrpiz neben wyrpe, mepiz neben mepe, lïpiz noben lïpe u. a. m. Indes ist zu beachten, dafs statt bleri pyttel die andere hardschrift bleria pyttel hat und dafs also vielleicht bleri für bleria verschrieben ist. Ein bleria liefse sich aber sehr wohl als eine schwache form mit erhaltenem $j$ (vgl. ëciu C. Past. $299^{10}$ ) zum adjektiv blere auffassen. Und diese aufassung scheint sich sogar zu empfehlen für las bleria der urkunde (von 901-924), da diese sonst überall schreibungen wie Tyssebyriz, äznizean, cunnizan, žeendizan bietet. Die existenz einer ableitung bleriz mufs daher als sehr zweifelhaft erscheinen, und wir werden uns wohl im wörterbuch begnügen dürfen mit dem ansatz: blere, schwach Uleria 1. 'mit weifsem fleck (blässe) versehen', 2. 'kahl'.

1) Bardioriolus 'colmase' erscheint auch im alphabetischen Cleopatraglossar (WW 361 ${ }^{15}$ ). Das sonst unbelegte lat. bardioriolus vermag ich jedoch nicht zu erklären. Ob es entstellt ist ans *berbicariolus 'bachstelze', welches als birbicariolus WW 260"31, $358^{\prime \prime}$, Corp. B 136, birbicaliolus WW 
Oscines aues . wizule fuzeles . 1)

W-.W. $133^{2}$

Amenus locus . luffendlic stede . 2)

Oceanus . zarsecz .

165 Sinus . sae-abbunz $\cdot^{3}$ )

Promunctorium 4 ) . clif .

[auf dem linken äu[seren rande:]

NOMINA HERBARUM.

Lilium . lilie .

Fafida . leomuc .5)

Colochintida . wylde cyrfet. ")

$\Rightarrow \quad 133^{6}$
$" \quad 133^{7}$
,$\quad 133^{5}$

$286^{28}$ oder berbigarulus WW $361^{14}$ belegt ist? Zur bildung des letzteren wăre heranzuziehen das mlat. berbecarius 'schafhirte' (Ahd. Gloss. III 350 ${ }^{32}$ ), von dem das Französische den vogelnamen bergerette, bergeronnette 'bachstelze' (Meyer-Lübke nr. 9267) abgeleitet hat, und zum bedentungsübergang das nhd. dial. schroienhirt 'bachstelze'. Über ae. colmāse 'kohlmeise' (Parns maior), mhd. kolmeis vgl. Suolahti 8. 154.

1) Lat. oscen ist ein terminus der antiken Augursprache und bezeichnet einen vogel, aus dessen stimme die Auguren weissagten; vgl. Goetz IV $266^{12}$ : oscines aues quae cantando auspicia faciunt. Daher die ae. glusse: vizule fuzeles 'weissagerische vögel'. Man beachte den plural fuzeles mit reduktion der flexionssilbe -as (vgl. oben 8. 103 a. 1).

2) Luffendlic (statt lufiendlic) ist wohl weniger schreibfehler als vielmehr eine späte, auf dialektischer (anglischer) grundlage beruhende und die mittelenglischen verhältnisse vorausnehmende form.

3) Ae. sa-ebbunz, das ans rhythmischen gründen ich als kompositum, nicht als genetirgruppe auffassen möchte, kann nnr bedenten soviel wie 'das zuruicktreten des meeres'. Wie das mit dem lat. sinus in einklang gebracht werden kann, ist nicht ohne weiteres klar. Doch mufs man bedenken, dafs lat. sinus nicht nur den 'meerbusen', sondern auch eine (in gewissem sinne durch das zurticktreten gebildete) 'landspitze' bedenten kann. Vielleicht lag also der altenglischen glosse eine ähnliche dentung «u grnnde, wie wir sie bei Goetz IV $172^{\text {ar }}$ (sinus . excesum fluctibus aut flexura maris siue amnis inclusum) finden, die natürlich dann im Altenglischen verstümmelt wiedergegeben sein mülste.

') Junius setzt stillschweigend Promuntorium.

5) Dieselbe glosse im Cleopatra-glossar WW 411 ${ }^{27}$ : Faficla 'hleomoc', und me. WW $556^{18}$ : Fauida $i$. 'fauede' $i$. 'leomeke'. Aber fafida scheint verderbt, - vielleicht aus fabaria, welches bei Simon Bartholomeus und Alphita das me. lemoke 'quell-ehrenpreis' (Veronica Beccabunga) glossiert; vgl. dazu me. brok-lemke, ne. brooklime 'ehrenpreis'.

6) Griech. xoגoxvv $\forall$ is ist die koloquintenpflanze und ihre apfel-oder gurkenahnliche frucht (Cucumis colocynthis). Daher wurde sie bei den Römern frỉh als 'wilder kürbis', cucurbita siluatica, bezeichnet, woraus sich mehrfache lateinglossen, wie coloquintida $i$. e. curcubita agrestis (Goetz III $537^{12}$; ăhnlich III $\left.631^{37}, 559^{2}\right)$, und auch die obige altenglische glossie- 
rung mit wilde cyrfet erklären. Es ist mir daher zweifelhaft, ob bei voilde cyrfet mit Hoops, Waldbänme s. 602 wirklich an eine wildwachsende art des 'flaschenkürbis' (Cucurbita lagenaria) zu denken ist.

1) Das lat. labrusca bedentet 'wilde rebe', wie aus zahlreichen glossen bei Goetz hervorgeht (uitis siluestris V 214 ${ }^{39}, 306^{45}$; uitis agrestis V $462^{23}$, $370^{\circ}, 505^{4}$ nsw.). Obiges ae. winzerd steht daher nicht für win-zeard 'weingarten', sondern für ws. wīn-zyrd 'weinrebe', welches allerdings nur durch obige glosse gesichert ist. In späterer zeit sind allerdings beide wörter mit einander vermengt, in der weise, dals nun wīn-zeard für 'weinrebe' eintritt, wie vereinzelt anch das simplex zeard (Ae. Ann. $852 \mathrm{E}$ ) für zyrd und cyne-zeard (WW 155 ${ }^{12}$ ) fïr cyne-zerd 'scepter' (WW 110'-2) vorkommt. In der Junius-abschrift steht vor obiger glosse eine andere, Brionia uel ampelos leuce $\bar{z}$. 'hwit wilde winzeard' WW $133^{10}$ ), die in dem Antwerpener teil der handschrift sich nicht findet, also wohl im Londoner fragment steht.

2) Butanicum ist $\mathbf{z u}$ bessern in botanicum, wie Junins stillschweigend schreibt. Botanicum bedeutet nicht 'kräuterbuch', wie Georges fälschlich

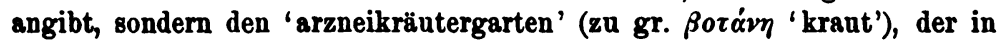
der klostersprache auch herbarium genannt wird. Viridiarium - so liest die handschrift - heifst dagegen im mittelalter der 'gemüsegarten'. Wăhrend bei gröfseren klöstern, wie dem St. Gallener klosterplane des 9. jahrhunderts (F. Keller, Der Bauplan von St. Gallen, Zürich 1844), beide gärten getrennte anlagen bildeten, sind sie bei kleineren wohl zn einem einzigen nutzgarten vereinigt, weshalb der Angelsachse für beide nur eine glosse bietet, nämlich wyrt-tūn, d. i. 'kräntergarten'. Vgl. M. Heyne, Hansaltertümer II 89; M. Gothein, Geschichte der Gartenkunst (Jena 1914) I 182 ff.; Hoops' Reallexikon II $113 \mathrm{ff}$. - Junius liest fälschlich voyrttun.

s) Ae. mazba und mazope ist genügend für verschiedene kamillenarten - in erster linie wohl Anthenis arvensis und nobilis sowie Matricaria chamomilla - bezengt. Ein gleiches gilt von dem daraus entstandenen me. maipe - so ist WW $557^{2}$ statt maiwe $z$ lesen - und ne. maythe, maythen und maidweed (NED). Wenn weiter unten in nr. 237 mazpa mit herba putrida glossiert ist, so wird eine starkriechende Anthemis-art, wie z. b. Anthemis cotula, gemeint sein. - Das nnverständliche lat. caluna mufs verderbt sein: vielleicht aus camomilla (=gr. $\chi \alpha \mu \alpha i \mu \eta \lambda o v)$ 'römische kamille' (Anthemis nobilis), womit das ae. wort Iseechdoms I 120 und WW $296^{29}$ identifiziert erscheint, oder auch aus buphthalmon (= gr. $\beta o v \dot{\varphi} \vartheta \alpha \lambda \mu o v),-$ einer bei Dioskurides und Plinins vorkommenden pflanze, die nach v. Fischer-Benzon, Altdeutsche Gartenflora s. 42, die 'goldblume' (Chrysanthemum coronarium) bezeichnet - , woraus die Brüsseler glossen Bucstalmum . 'hwit mazere' (WW 297') and Obtalmon . 'mazere' (WW $\left.300^{11}\right)$ verderbt sein dürten. 
175 Nepita . napte .1)

W.-W. $133^{19}$

Adriatica . zalluc . $\$$ malum terrę .2)

n 13320

1) Lies nepeta 'katzenminze'. - Im Englischen heifst die pflanze sonst ae. nepte, me. nepte, ne. nept, nep, amerik. catnip. Also steht hier $a$ ebenso fur $e$, wie in abbunz 165 .

2) Dieselbe glosse im Durhamer pflanzenglossar (Lchd. III 299: Adriatica 'zalluc') und ähnlich bei Elfric (ed. Zupitza 31014: adriaca . 'zalluc') nowie in Bata's Colloquium (Napier, OEG, 56, 388: Adriaca 'zalluc'). Sonst vermag ich weder adriatica noch adriaca, die wohl für Hadriatica bezw. Hadriaca stehen, als pflanzennamen uachzuweisen. Im Brüsseler glossar erscheint als lemma zu zalloc das lat. sinfitum (WW $299^{20}$ ), d. i. Symphytum officinale, die 'schwarzwurzel oder wallwurz'. Und diese pflanze ist auch sicher gemeint in einem ags. rezepte (Leechdoms III $6^{10}$ ), da dort ausdrücklich von der wurzelrübe der pflanze (zalluces moran) die rede ist. Die griechische benennung $\sigma \dot{v} \mu \varphi v \tau o v$ erklärt sich aus der heilkräftigen wirkung der pflanze, die das zuwachsen und zuheilen von wnnden befördert; und so wird auch der ae. name z(e)alloc von ae. zealla 'hautwunde' abzuleiten sein; vgl. nhd. schadheil für dieselbe pflanze sowie nhd. voundwourzel für Valeriana officinalis, wundklee für Anthyllis, wundkraut für Actaea spicata, Digitalis lntea, Sedum Anacampseros und Veronica officinalis, wundlattich für Hieracium muroram und Hypochoeris macnlata, wundschwamm für Lycoperdon bovista, und ähnlich ne. woundwort für Laserpitium und Liabium Brownei (W. Ulrich, Internat. Worterbuch der Pflanzennamen, Lpz. 1875). - Wenn anderseits zalloc im Corpus-glossar G 7 (nnd darans anch WW $298^{1}$ und $412^{28}$ ) das lat. galla 'gallapfel' glossiert, so ist schwer zu sagen, ob das eine durch die ähnlichkeit des wortklanges veranlafste fehlübersetzung ist, oder ob der glossator in vollem verständnis fïr die bedentung des lateinischen wortes eine anglisierung desselben mittelst des ae. suffixes -oc wählte. Recht unwahrscheinlich ist das letztere aber deswegen, weil man nicht einsieht, warum man bei der herübernahme des fremdwortes sich nicht, wie in andern fällen, mit dem simplex begnügt, sondern noch ein germanisches suffix angefügt haben sollte. Zudem spricht alles andere dafür, daIs das me. ne. gall 'gallapfel', ebenso wie das nhd. gallapfel, enst im spătmittelalter ans dem Französischen entlehnt ist. (Die abweichende darstellung bei Klnge, Hirt und Walde beachtet nicht ae. zalla, mhd. mnd. galle und an. galli 'hautwunde', ae. zallede 'wund', sowie das mnl. gāle 'hautausschlag'; das richtige bei Falk-Torp nnd Franck-Wijk.) Sonach wird wohl ein zalloc 'gallapfel' ans den wörterbüchern zn streichen sein. Wer aber der autorität des Corpus-glossars folgen zu sollen glanbt, mufs zwei etymologisch und inhaltlich getrennte wörter fürs Altenglische ansetzen: 1. zalloc 'schwrazwurz', 2. zalloc 'gallapfel' (ans dem lat. galla entlehnt). - Der zweite lat. pflanzenname (malum terrae), welcher vou Junins stillschweigend vor die ae. glosse gestellt ist, findet sich als lemma zu zalloc auch im Cleopatra-glossar (WW $451^{7}$ ). In lateinischen glossaren bezeichnet er alle möglichen pflanzen, wic osterluzei (Goetz II 584 ${ }^{89}, 502{ }^{39}$, $614^{2}, 547^{\circ 2}$, III $633^{\circ}$ ), erdscheibe (III $578^{30}, 544^{\circ}, 581^{22}, 581^{52}, 584^{5}, 595^{85}$, $610^{\star 8}, 629^{\circ 2}$ ) oder minze (III $584^{54}$ ). 
Costus . cost .1)

W.-W. $133^{21}$

Trifolium . zeacessure $¥$ prilefe.$^{2}$ )

13322

Uaccinium . brunwyrt .3)

180 Aprotanum . superne wude .4)

$133^{23}$

Lubestica . lufestice .5)

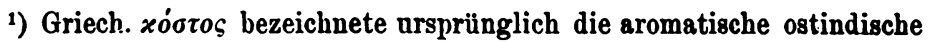
kostuswurzel (Costus speciosus). Im mittelalter wird costus aber früh auf die 'frauenminze' (Tanacetnm balsamita) übertragen ( $\nabla$. Fischer-Benzon s. 73), und so mag anch das ae. cost diese ehemals sehr beliebte pflanze bezeichnen. Ne. cost nnd costmary gelten sowohl für 'frauenminze' wie für 'rainfarn' (Tanacetum vulgare).

2) Während das lat. trifolium schlechthin den 'klee' bezeichnet, meint das ae. zéaces-sūre jedenfalls den 'sauerklee' (0xalis acetosella), welcher auch im Nhd. 'kuckucksklee', 'kuckucksbrot' oder 'gauchampfer' (Ulrich) heifst und im Ne. cuckioo-meat oder cuckoo-sorvel. - Das nur hier erscheinende pri-ly/e ist vermutlich nur eine gelehrte nachbildung von lat. trifolium, nach analogie ron ae. pri-fete 'dreifülsig', ori-fingre 'dreifingrig', Ori-flere 'dreistöckig', pri-hyrme 'dreihörnig', pri-scyte 'dreieckig', pristrenğe 'dreisaitig' u. a. Wie alle diese wörter, ist also pri-lyfe als iobildung (zu leaf 'blatt') anzusehen nnd demnach stammvokal und endnng anders zu beurteilen, als es bei Bosworth-Toller geschieht.

s) Junius schreibt fälschlich branwyrt, weil das $u$, wie oft in unseren glossen, eine dem $a$ sehr ähnliche form hat. Das nur anf dieser falschen lesung beruhende ae. "branwyrt" ist danach aus unseren wörterbüchern (Bosworth-Toller, Sweet, Hall ${ }^{2}$ ) zn streichen. - Vaccinium ist jetzt der botanische name für 'heidelbeere'. Was man aber im altertum darnnter verstand, ist ebenso unklar, wie die botanische bedentung seiner griechischen vorlage $\dot{v} \dot{\alpha} x \iota v \vartheta 0$ s. In mittelalterlichen glossaren findet sich vaccinium für sehr verschiedene blumen, wie reilchen (Goetz II $332^{38}, 332^{88}$, V $527^{32}$ ), anemone (II $225^{51}, 266^{37}$ ), safran (IV $188^{19}, 576^{44}$ ), schlüsselblume (WW $\left.618^{24}, 644^{14}\right)$. Dieselbe glosse wie oben erscheint aber in Durhamer pflanzenglossar (Leechd. III 305): Vaccinium 'brun-ryyrt'. Ae. brin-acyrt wird, wie noch heute ne. brownvort und nhd. braunuurz, eine scrophularia-art, bezeichnen.

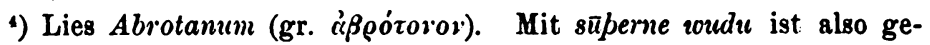
meint die aus Sïdenropa importierte 'eberraute' (Artemisia abrotanum), die anch heute noch im Ne. southernnoood heifst. Dieselbe glosse ist gemeint im Brüsseler glossar mit Abrotomum. Scedrenewouda (WW 301 ${ }^{33}$ ).

5) Genau dieselbe glosse in Elfrics glossar (ed. Zupitza 3108), im Brüsseler glossar (WW 301 ${ }^{35}$ ) und im Durhamer pflanzenglossar (Leechd. III $303^{18}$ ). Die vulgär-lateinische form lubestica d. i. luvestica, die die vorlage des ae. lufestice 'liebstückel' (Levisticum officinale) ist, erscheint nur an diesen drei stellen, jedoch ein den gleichen lautstand meinendes luvisticum in einem Leidener glossar (Ahd. Gl. III 605'). Meist finden wir dafür formen mit $e$ oder $i$, levisticum, livisticum, die ihrerseits offenbar vulgärlateinische 


\section{Solsequium . \& Heliotropium . solsece 1}

Astula regia . wuderofe.$^{3}$ )

$$
\text { sizelhwerpe .2) " } 133{ }^{28}
$$

umgestaltungen des unidentifizierbaren klass.-lat. pflanzennamens ligusticum sind (das vermntlich von dem adjektiv Ligusticus 'Ligurisch' abzuleiten ist) und die grundlage für afrz. levesche (darans me. levish, nl. levesche, lavas), nfrz. livèche und ital. levistico (Meyer-Lübke 5038) bilden. Die bisherige forschung nimmt nun vlat. levisticum auch zur grundlage der altgermanischen lehnformen, die aber in ihrer ältesten gestalt überall $u$ statt e aufweisen: ae. lufestice, as. lubesteko, lubistekul, mnd. lubbestock, mnl. lubbestoc, lubbestekel, logestikel, ahd. lubistechal, lubistecco, mhd. lübesteckke, lubstickel. (Die nordischen formen, dän. lovstikke, lostilk, schwed. libsticka, sind ebenso wie die slavischen [Berneker unter $\left.l^{\prime} u b i s t o k\right]$ ans dem Dentschen entlehnt.) Und dieses germ. $u$ gegenüber vlat. $e$ pflegt man dann durch volksetymologische anlehnung an ae. lufu, ahd. luba, as. luba 'liebe' zu erklären. Nun wird zwar nicht zu leugnen sein, dafs der Germane bald innerlich diese verknüpfung vollzogen hat, wie er auch den zweiten teil an die germ. wörter für 'stock' anlehnte; vgl. mhd. liebstuckel, nhd. liebstöckel. Indes scheint mir der ursprung dieses $u$ dennoch in dem vlt. substrat, der nebenform luvisticum neben livisticum (vgl. lubet, libet usw.); zu liegen. Denn das bestehen einer vlt. $u$-form wird anch für das Romanische durch afrz. luvesche (darans me. lovache, ne. lovage) und aital. rovistico erwiesen. Und so wird man auch die germanischen lehnformen aus dieser nebenform abzuleiten haben. - Man beachte anch hier die spate reduktionsform -voude für voudu (s. 103 a. 1).

1) ('neowhole ist vermutlich ein schreibfehler fïr cneow-holen (Corp. $\mathrm{R} 245, \mathrm{WW} 269^{22}, 300^{12}, 300^{21}, 448^{80}$ ), kaum schon die me. reduktionsform kne-hole. Inhaltlich ist ae. cneoro-holen sicherlich dasselbe wie me. kne-holë und ne. knee-holly, nämlich 'mäusedorn' (Ruscus aculeatus). - Das nur hier vorkommende lemma sinpatus ( $\mathrm{ob}=\sigma \dot{v} \mu \varphi v \tau o v$ ?) vermag ich nicht $\mathrm{zn}$ deuten.

2) Sizelhwerpe ist schreibfehler für sizelhwerfe (älter sizel-hweorfa), wie Junins stillschweigend bessert. Die hentzntage als 'heliotrop' be-

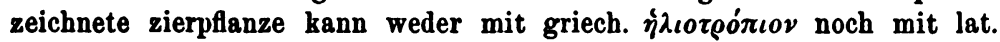
solsequium oder ae. solsece und sizelhweorfe oder mit afrz. solsecle (daraus me. solsecle) gemeint sein, da diese pflanze erst im 16. jahrh. von Peru nach Europa gekommen ist. Welche pflanze die alten so bezeichneten, scheint nicht festzustehen. Im mittelalter ist solsequium für verschiedene blumen gebrancht, wie namentlich cichorie und ringelblume (v. FischerBenzon s. 106 f.; Goetz III 585 ${ }^{\circ}$ ); und auch die modernen romanischen fortsetzungen (Meyer-Lübke 8078), wie nfrz. souci, verstehen darunter die 'ringelblnme' (Calendula officinalis). Die 'ringelblume' wird daher höchstwahrscheinlich auch mit den ae. und me. ausdrücken gemeint sein.

8) Vgl. Dresdner glosse (Angl. 24, 433): astula regia 'woude-rove'. Das lat. hastula regia wird in glossaren oft mit gr. do $\sigma o ́ \delta \varepsilon \lambda o s$ zusammengestellt (Goetz III 535 44, 549 49) und bezeichnet jedenfalls eine knollenreiche 
Mille-folitm . $\nmid$ mirifilon.$z \cdot z \ll r u w e ~ ł$ centefolia.1) W.-W. $133^{31}$

Tanaceta . helde .2)

$133^{33}$

Samum . hyluourt . ${ }^{3}$ )

n $133^{34}$

Herba . zoers . ł wyrt .

Butunus . heope .4)

190 Apium . merce . ${ }^{5}$ )

liliacee, wie das heutige Aphodelus ramosus oder 'affodill'. In später zeit - sicher schon im 14. jahrhundert (Leechl. II 412) - verstand man unter hastula regia etwas ganz anderes, den 'waldmeister' (Asperula ordorata). Diesen selben bedeutungswandel hat das englische wort mitgemacht. Denn obschon das me. wude-rove, ne. woodroof, woodroff, woodruff nur noch den 'waldmeister' bedeutet, scheint das ae. wudu-rofe, älter (?) wudu-lvrofe, ein knollengewächs (Leechd. I 18, 132, 156) zu bezeichnen, also vermutlich gleichfalls den 'affodill'. Im Durhamer pflanzenglossar (Lchd. III 299)

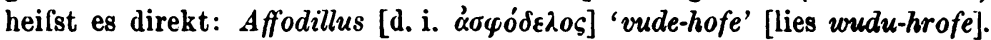
(Diese lateinform auf englischem boden lehrt übrigens, dafs das dentsche affodill, spätmhd. affodille, sein $f f$ für sph nicht erst durch anlehnung an nhd. affe bekommen hat [Hirt], sondern dals hier schon vulg.-lat. assimilation vorliegt.)

1) Mirifilon, wie mehrmals in glossen zu lesen steht (Corp. M. 204,

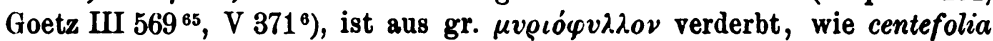

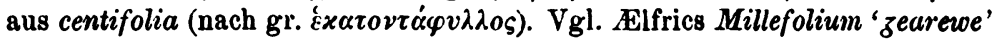
(ed. Zupitza 311'). - Ae. zaeruwe statt zearuwe 'schafgarbe' (Achillea millefolium; vgl. nhd. tausendblatt, afrz. milfueil, ne. milfoil) zeigt dieselbe späte monophthongierung wie in stcern 129 u. a. (vgl. oben s. 103 anm. 1).

2) Das oft belegte mlat. tanacetum (Elfric ed. Zupitza 311 ${ }^{1}:$ tanicetum 'helde') meint jedenfalls den ehemals sehr beliebten 'rainfarn' (Tanacetum vulgare); und diese pflanze wird auch mit dem (etymologisch allerdings unklaren) ae. helde gemeint sein. Vgl. v. Fischer-Benzon s. 74 sowie 70, 73; NED unter tansy; Meyer-Lübke M. 8555 .

8) Das nur hier vorkommende Samum ist mir unverständlich. - Ae. hyl-wort ist, wie ne. hillwort, wohl der 'polei' (Mentha pulegium); vgl. Elfric ed. Zupitza $311^{11}$ : pollegia 'hylwoyrt'.

4) Vgl. Durhamer glossar (Lchd. III 300): Betunus 'heope' und WW $556^{7}$ : Butunus i. 'hoepe' (13. jh.). Das sonst nicht weiter belegte Butunus sieht aus wie eine latinisierung des aglfz. butun-s (vlat. *bottonem) 'knospe, knopf'. Tatsächlich kommt auch das we. button noch im sinne von kelchröhre der rose oder 'hagebutte' vor (s. NED unter button 2). Ae. heope entspricht ne. hep, hip 'hagebutte' und as. hiopo, ahd. hiafo, nhd. hiefe, aschwed. hiupon, nschwed. nypan, ndän. hyben, dän. dial. hjupa, norw. nype. Vgl. R. Loewe, Germanische Pflanzennamen (Heidelberg 1913) \&. 43.

5) Lat. apium (daraus mnd. mnl. nnl. eppe, ahd. epfi, mhd. epfe und mit suffix ahd. epfih, nd. nhd. eppich) und ae. merece (me. merche, ne. va. march; as. merk, merka, mnd. merk, mschwed. märke, dän. merke) bedeuten

Angliu. N. F. XXIX. 
Uenenifuga . atterlape .1)

Febrefugia . Febrifuga . feferfuze . ${ }^{2}$ )

Ruta . rude.

WW. $1333^{38}$

Blitum . \& lappa . clate . ł clyfioyrt . $\left.{ }^{3}\right)$

195 Simphoniaca . hennebelle .4)

Gersussa . biscopioyrt .5)

'eppich' oder wilden 'sellerie' (Apinm graveolens); vgl. v. Fischer-Benzon, s. $119 \mathrm{f}$.

1) Ae. ätor-lābe sieht aus wie eine nachbildung des allerdings nur hier belegten mlat. veneni-fuga, das man mit 'gegengift' übersetzen könnte. Welche pflanze hier gemeint, kann nicht gesagt werden. Sonst erscheint ätor-läpe für 'betonie' (WW 358 ${ }^{\circ}$ ), 'hirsengras' (Lchd. I 22, 148), 'borstengras' (Lchd. II 110) u. a.

2) Lat. febrifugia - so die älteste form bei psendo-Apuleius - entspricht semantisch dem nhd. fieberkraut. $\mathrm{Da}$ aber viele pflanzen im mittelalter als fiebermittel gelten, wird auch febrifugia für die verschiedensten pflanzenarten, wie beifnfs, tausendgüldenkraut, erdgalle, aurin, mutterkraut n. a., gebrancht. Am hänfigsten erscheint es in don glossaren für das 'mntterkraut' (Matricaria parthenium), für welches auch bei uns mundartlich der name fieberkraut gilt. Und da auch das ne. feverfew, welches übrigens ans agln. *feırefuë stammt, gleichfalls diese pflanze bedentet, mag schon das ans dem Latein entlehnte ae. feferfüze in erster linie an dieselbe pflanze denken.

8) Die handschrift liest blitum \& [nicht vel, wie Junins bietet] lappa. Tatsächlich handelt es sich auch um zwei verschiedene pflanzen: lat. blitum

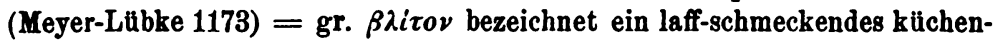
gewächs wie etwa 'melde' (anders v. Fischer-Benzon s. 129 f.), lat. lappa dagegen die 'klette'. Allerdings findet sich auch lat. blitum mit ae. clāte glossiert (Corp. B 142; WW $358^{18}$ ), welches sowohl die gewöhnliche 'klette' (Arctinm lappa) wie andere klettenähnliche gewächse, wie labkraut (Galinm aparine), kropfklette (Xanthium), huflattich (Tussilago) u. a., bezeichnet;

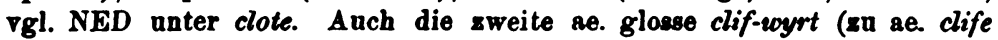
'klette', as. kliba, mnd. klive, ahd. chliba; vgl. ne. cleavers, clivers) bedeutet sowohl 'klette' wie 'labkraut' (Leechd. II 376). Vgl. Elfric ed. Zupitza 311': lappa 'clate odre clifwyrt'. In den Dresdner glossen bezeichnet cluf-

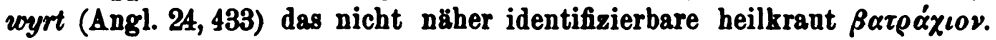
(Th. Wright's deutung von clifroyrt als 'fingerhut' [WW 134 anm. 1], die auch Hall ${ }^{2}$ bietet, ist abzulehnen.)

c) Ae. henne-belle bedentet das 'bilsenkraut' (Hyoscyamus), das anch im Deutschen als hühnerlockkraut (Ulrich) bezeichnet wird. Dieselbe bedeutung hat lat. symphoniaca.

5) Ae. bisceop-royrt bezeichnet, wo es eindentig glossiert ist (Corp.

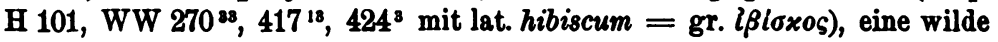
malvenart, 'eibisch' (Althaea officinalis). Andererseits tibersetst biscoproyrt im Herbarinm Apulei (Leechd. I 2) nnd in Elfrics glossar (ed. Zupitza 310 15: 
Ramusium . ramesan .1)

W.-W. $134^{\mathrm{T}}$

Dilla . \& acrocerium . docce .2)

seo lässe bisceopwyrt) das lat. betonica, d. i. 'zehrkraut' (Betonica officinalis), welches auch im deutschen volksmunde als pfaffenblümchen erscheint. Ne. bishop's-weed und bishop's-wort bezeichnen wesentlich andere pflanzen, wie geifsfu\{s, wassermünze und kapuzinerkraut. Dasselbe gilt von den deutschen pflanzennamen bischofshut, bischofsmütze and bischofsmützenblume (Ulrich). - Das nur hier anftretende lat. lemma gersussa hängt

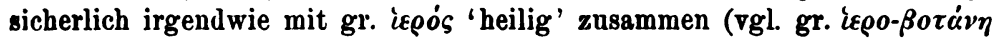

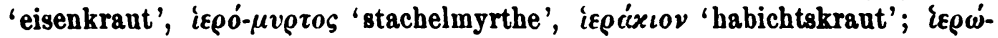
ovvos 'priesterlich'); vielleicht ist es $\mathrm{nnr}$ verderbt für mlt. gerobotana (= gr. 'є£oßotc่ $v \eta$ 'eisenkraut'), welches weiter unten (nr. 228) mit ae. biscop-2oyrtil glossiert ist. (Unverständlich ist mir die Dresdner glosse: radix andre 'bisceopwirt' Angl. 24, 432.)

1) Vgl. im Durhamer pflanzenglossar (Leechd. III 304): Ramuscium 'hrameson'. Sonst vermag ich ein lat. ramus(c)ium nicht nachznweisen. Das ae. hramesa (mnd. ramese, remese, nhd. dial. rams, ramsen, dän. schwed. norweg. rams) bedentet wohl nicht 'zwiebel' oder 'knoblauch' (Kluge), sondern, wie ne. rams und ramson, dän. rams, ramsleg und die nrverwandten lit. kermìszè, russ. čeremı̌a, slov. črę̧mờ, poln. trzemucha (Bernecker), den wilden 'bärenlauch' (Allium ursinum). Vermutlich ist also ramusium eine latinisierung des germanischen wortes.

2) Die hdschr. liest dentlich acrocerium (nicht mit Junius: acrocorium). Allerdings vermag ich das wort ebensowenig zu erklären - wenn auch ein gr. پ̌xpos 'spitz' drin stecken mag - wie das vorhergehende lat. dilla, das auch bei Elfric (dilla 'docca', ed. Zupitza 310'), sowie in Bata's Colloquium (Napier, OEG 56, 370: Dilla 'docce') und im Durhamer pflanzenglossar (Dilla 'docc' Leechd. III 302) erscheint. Das oft belegte ae. docce bedentet, ebenso wie me. dokke, ne. dock (vgl. mnl. docke, adän. -dokke), 'ampfer' (Rumex).

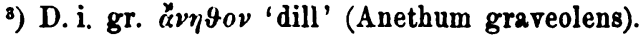

4) Ein analogischer nominativ cucumer statt klass.-lat. cucumis erscheint auch sonst in glossaren (z. b. Goetz III $588^{71}$, V $59^{30}$; WW $576^{45}$, $786^{89}$; vgl. auch v. Fischer-Benzon 8. 93). - Ob das öfter belegte ae. hwerlhwette 'gurke' zu ae. hwer 'kessel' (an. hverr, ahd. hwer) und ae. hwettan 'wetzen' gehört ( $\nabla g l$. nhd. wetzsteinkraut für Ononis repens), ist sehr zweifelhaft. Vielleicht assoziierte der Angelsachse lat. cucumis 'gurke' mit lat. cucuma 'kessel'.

3) Lies feldwyrt, wie Elfric (ed. Zupitza 310 ${ }^{10}$ : auadonia 'feltwyrt'; dazu Napier, OEG 56, 376 : auadona 'feltwyrt') und das Durbamer pflanzenglossar (Leechd. III 300: Auadonia 'feld-vyrt'). Was das nun hier belegte lat. avadonia - bei WW $134^{11}$ verdruckt als Anadonia - bedentet, kann 
ich nicht sagen. Sonst erscheint ae. feld-wyrt als glosse zu lat. gentiana (Leechd. I 12; WW 298 ${ }^{28}, 416^{16}$ ) und bedentet daher vermntlich eine enzianart, vielleicht den 'wiesenenzian' (Gentiana campestris). - Die verschreibung -wyrd statt -wyrt lässt wieder einmal ahnen, wie stark die das germanische religionsempfinden völlig beherrschende vorstellung der wyrd, des unabwendbaren schicksals, noch die psyche des mönchischen schreibers erfullte.

1) Das klassische Latein kennt nur ein femininum gladiola als pflanzennamen, jedoch bieten die glossare sowohl gladiolus wie gladiolum (Goetz III $\left.539^{55}, 561^{14}, 580^{24}\right)$. Das lat. wort bezeichnete verschiedene iridaceen (v. Fischer-Benzon s. $43 \mathrm{ff}$.), während das ae. zladene vermutlich, wie das me. gladene, ne. gladdon, die 'schwertlilie', und zwar wahrscheinlich die 'wasserschwertlilie' (Iris pseudacorus), meint.

2) Die lat. lemmata bezeichnen drei verschiedene pflanzen: Cynoglossa (für kl.-lat. cynoglossus, gr. $x v v o ́ y \lambda \omega \sigma \sigma o v)$ die 'hundszunge' (Cynoglossum officinale), plantago den 'wegerich' und lapathium (demin. von lapathum, gr. $\lambda \dot{\alpha} \pi(\alpha \vartheta o v)$ eine ampferart. Der Angelsachse hat sich also an den leichstverständlichen mittleren begriff gehalten. Denn ae. wez-brade (neben wezbrāde) bezeichnet, wie ne. voaybread (neben dial. vay-broad), den 'wegerich' (Plantago), der auch im Deutschen den namen wegebreit führt (ahd. wegabreita, as. weg-breda, mnd. wege-brede, mnl. weghe-bredde, nnl. weegbree, wfries. weibre; dän. veibred ist deutsches lehnwort).

3) Ae. mučž-wyjrt, me. ne. mugwort (zn wgm. *muggjo- 'mücke', ae. myčy, ne. midge) bedentet, wie lat. artemisia (nach der göttin "A den 'beifufs' (Artemisia vulgaris), der auch im deutschen volksmunde 'jungfernkraut' and 'weiberkraut' heifst und in England früher (14.-17. jh.) mit motherwort bezeichnet wurde. (Mit mückenkraut meint der Dentsche andere pflanzen, wie Conyza squarrosa, Inula dysenterica oder Polygonum hydropiper.) Das lat. matrum herba wird daher nicht, wie man nach Goetz, Corp. gloss. VI 98, glauben sollte, in mater herbarum zu bessern sein, zumal auch die lateinischen glossare Artemisia mit Dianaria herba (Goetz V $496^{52}$ ) and parthenion (Goetz III 573 ${ }^{67}$ ) erklären; vgl. v. Fischer-Benzon s. 75 f. und die Dresdner glosse (Angl. 24, 429): matrem herbarum que dicitur mugrourt.

4) Ähnlich im Durhamer glossar (Leechd. III 299): Annuosa 'eascthrote'. An beiden stellen ist annuosa offenbar verderbt aus ancusa d.i.

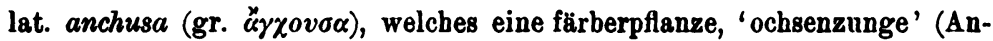
chusa tinctoria), bezeichnete. Sonst glossiert ae. aesc-protu meist das lat. ferula (Corp. F 138; WW $236^{40}, 298^{20}, 402^{35}, 409^{28}$; Leechd. III 302), d. i. 'ruthenkraut', eine in England nicht heimische pflanze, so dafs vielleicht mit einer namensubstitution $z u$ rechnen ist. Endlich erscheint drittens noch die gleichsetzung von aschrotu mit lat. verbena 'eisenkrant' (Leechd. II 368): Auch ist begrifflich der ae. name ('äschen-kropf' '?) nicht leicht 
Amorfolia . clate .1)

$\begin{array}{cc}\text { W.-W. } 134^{18} \\ " \quad 134^{13} \\ " & 134^{20} \\ " & 134^{21} \\ " & 134^{22} \\ " & 134^{23}\end{array}$

210 Auris leporis . halswyrt.5)

Ebulum . walwyrt . ${ }^{6}$ )

Cepe . onnelec .2)

Saxifraga . sundcorn .3)

13420

Philantropian 4) . lappa . clate .

13421

$134^{23}$

zu deuten - trotz ae. cofor-protu 'eberwurz' (Carlina acaulis) und uhd. taubenkropf und kellkraut, kropfwurz, kropflilie, kropfklette (Ulrich).

1) Ebenso im Durhamer glossar (Lchd. III 299): Amorfolia 'clate'.

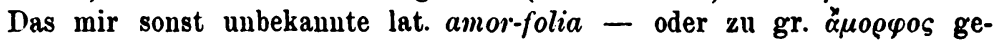
hörend? - erinnert an das gr. $\varphi \iota \lambda \dot{c} \iota \nu \vartheta \omega \pi 0 \varsigma$ 'menschenliebend', das im Herbarium Apulei (Lchd. I 306) mit ae. cläle 'klette' gleichgesetzt ist. Vgl. unten nr. 209.

2) Lat. cepe ist eine ältere form für das sonst übliche cēpa. - Ae. enne-léac ist entlehnt aus lat. ūnio 1. 'perle', 2. 'zwiebel', mit angefügtem ae. leac 'lauch' (wie bei por-leac 'porre' aus lat. porrus).

3) Mit ae. sund-corn ist offenbar die häufigste europäische saxifragaart gemeint, der 'körnersteinbrech' (Saxifraga granulata). Vielleicht heifst diese auch auf wiesen vorkommende art deswegen im Ae. sund-corn d.i. eigtl. 'wasser-, sumpf-korn', weil die andren saxifragaceen steinigen boden verlangen.

) So, nicht Philantropium (Junius), liest die handschrift; jedoch ist Philantropian wohl in Philantropion zu bessern. Die nur hier erscheinende wortform eutspricht dem in Herb. Apulei (Lchd. I 306) belegten pflanzennamen philantropos (gr. $\varphi \iota \dot{\lambda} \dot{\alpha} \nu \vartheta \rho \omega \pi \circ \varsigma$ 'menschenliebend'), der dort wie hier 'klette' bedeutet. Vgl. nr. 206 und v. Fischer-Benzon s. 60 anm. 1.

3) Nach dem lateinischen lemma zu urteilen (vgl. Durhamer glossar Lchd. III 300 und auricula leporis Goetz III $546^{34}, 560^{27}, 592^{14}, 613^{33}, 625^{\text {s0 }}$ ), bezeichnet hier ae. heals-wyjt wohl das 'hasenohr' (Bupleurum), das auch neuenglisch noch als hare's ear erscheint. An anderen stellen (Lchd. II 390) scheinen allerdings mehrere andere pflanzen damit gemeint zu sein, wie auch nhd. halswurz (vgl. ul. halskruid) die verschiedensten pflanzen, wie Campanula glomerata oder trachelium, Prunella vulgaris, Ruscus hypoglossum und Trachelium, bezeichnen kaun und ebenso adän. halzyrt für Inula Helenium und ne. throatwort für Cervicaria, Scrophularia nodosa, Liatris spicata und Campanula trachelium, glomerata oder latifolia steht. Keine hilfe bietet Elfrics glossierung (ed. Zupitza $311^{1}$ ) von healswyrt mit unklarem epicurium (zu żıxov́ gahell grece 'halswurt' Angl. 24, 430).

6) Lt. ebulum bedentet den 'attich' oder 'zwerghollunder' (Sambucus ebulus); und denselben stranch meint hier und an anderen stellen (Corp. E 11, Leyd. 121, WW $391^{19}$, Napier OEG 26, 57 ; me. WW $555^{10}, 579^{38}$ ) offenbar das ae. weal-wyrt. Für dieselbe bedentung spricht die gleichsetzung von weal-wyrt mit ae. ellen-wyrt (zu ae. ellen 'hollunder') im Herbarium Apulei cap. XCIII (Leechd. I 202: wael-voyrt [walhourt B] vel ellen-2oyrt) 
Allia .1) zarleac.

und im Durhamer pflanzenglossar (Leechd. III 302: Ebule $l$ eobulum [lies ebulum] 'veal-vyrt $l$ ellenvyrt'). Anch im Neuenglischen bezeichnet mundartlich (Shropshire und Edinburgh) wall-wort noch den 'zwerghollunder'. In der regel - und so auch bei Hoops, Waldbänme s. 265 - wird nuu obiges weal-wyrt mit dem in den ältesten glossen belegten ae. wealh-wyrt d. i. eigtl. 'welschkraut', gleichgesetzt, was lautlich natürlich sehr wohl möglich wäre. Indes erscheint hier als lemma eine ganz andere pflanze, nämlich "intula" (Epin. 518, Corp. I 147 und daraus WW 299 ${ }^{8}, 428^{23}$ ), was, wenn es ubberhaupt einen sinn haben soll, für lat. inula (v. FischerBenzon s. 63; Archiv CVII $377 \mathrm{ff}$.) stehen muls. Lat. inula bedeutet aber 'alant' oder 'helenenkrant' (Inula Heleninm), eine tatsächlich aus Sẗdeuropa stammende und nach England eingeführte pflanze, so dafs hierfür der name wealh-wyrt sehr gut passen würde. Ein altes wealh-wyrt sollte im 9. jahrhundert zu weal-wyrt werden; und so ist es verständlich, daIs die jüngeren glossare (WW 299 ${ }^{\circ}, 428^{28}$, Leechd. III 303) diese form für 'alant' (inula) bieten. Dagegen mufs es sehr auffallen, wenn ein 80 altertümliches um nicht zu sagen das altertïmlichste - glossar wie das Leydener uns das wort ohne $h$ bietet (ualuyrt 121), während doch sonst dort noch elha für ěola 'elch', salhas für sěalas 'weiden' und ualchefuc für wealh-hafoc 'wanderfalke' erscheint, - um von formen wie mihes, rihum, scoehere und scyhend ganz zu schweigen. Die form ualuyrt des Leydener glossars kann daher nicht von wealh- abgeleitet werden und mufs sich zu ae. weall 'wall' stellen. Und in der tat sehen wir, dafs die Leydener glosse gar nicht den 'alant' meint, sondern als lemma ein unverständliches elleus hat, das sicher fïr das oben schon erwähnte ebulus bzw. ebulum - beide formen sind alt verschrieben ist, so dafs also das ualuyrt des Leydener glossars den 'krauthollunder' meint. [Anders, aber kaum richtig Engl. Stnd. 50, 330.] "WallWurz" ist aber eine im Deutschen häufig vorkommende pflanzenbezeichnung (z. b. für Pulmonaria officinalis oder Symphytum offinale), and ich sehe keinen grund, warum nicht der name auch für den jetzt noch häufig für hecken verwendeten 'krauthollunder', unser $u$ eal-wyyrt, gebrancht werden sollte, - selbst wenn der 'krauthollunder' in prähistorischer zeit in England noch nicht nachweisbar ist. Bei dieser sachlage werden wir nicht unhinkönnen, für das Altenglische zwei ursprünglich gesonderte pflanzennamen anzunehmen: 1. ae. weall-wyrt 'krauthollunder' (Sambucns ebulus), 2. ae. wealh-woyrt, jünger wealioyrt 'alant' (Inula Heleninm). Gegen diese sonderung spricht nicht, dafs ein einziges Mal eine vermischung der beiden wörter durch einen schreiber eingetreten ist, nämlich in der Erfurter glosse 393: ebulum 'uualhuyrt' [lies uualuyrt, wie im Leydener gloss.].

1) Allia ist die ans dem kollektivem plural herïbergenommene, neue vulg.-lat. singularform zu kl.-lat. allium 'knoblauch'.

2) Das schwerzudentende ae. $z \bar{y} b$-corn ist nach Hoops, Waldbänme s. 616 die 'wolfsmilch' (Euphorbia lathyris), deren samenkörner als purgiermittel verwendet wurden (v. Fischer-Benzon s. 58). Daher WW 557? 
Poleus . hwitleac .1)

W.-W. $134^{26}$

215 Melleuna . medewyrt .2)

(13. jh.): Spurgia $i$. [frz.] spurge $i$. [me.] gupcorn [bei WW verlesen als guweorn]. - Das sonst nicht belegbare Herba munda wird wohl auch mit der purgierenden wirkung etwas zn tun haben; vielleicht ist daher Herba mundatoria 'purgierendes krant' zu lesen.

1) Poleus (und nicht Poletis, wie Junius schreibt) liest deutlich die handschrift, obschon der erste $u$-strich reichlich hoch einsetzt. Dies Poleus

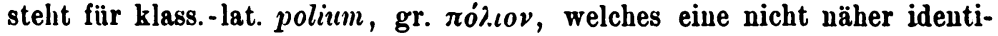
fizierbare pflanze bezeichnet. Jedenfalls hängt es etymologisch mit gr. $\pi o^{\prime}$. s $_{\text {' }}$ 'weifs' zusammen; und so ist es verständlich, dafs der Angelsachse das wort mit hwit-leac, eigtl. 'weils-lanch', wiedergibt. Offenbar bezeichnet also ae. hwìt-léac eine weilsblühende lanchart, wie porre, zwiebel oder knoblauch. Fïr die bedeutung 'zwiebel' (Allium cepa) würden zwei andere glossenbelege sprechen, nämlich die Cleopatra-glosse Alba cipa 'Invite leac' (WW 353') und die me. Laud-glosse Alba cepa 'witleac' (Leechd. III 335).

2) Vgl. Cleopatra-glossar (WW 451'): Melleuna 'meodowyrt' und Durhamer pflauzenglossar (Leechd. III 30t'): Mellauna 'meode-vyrt'. Das obige melleuna, für welches Junius fälschlieh melletina schreibt, wird aus klass.-lat. melittaena (gr. $\mu \varepsilon \lambda . i \tau \tau u \iota v \alpha$ ) 'bienenkrant' entstellt sein, welches im altertum als geschätztes bienenfutter galt (v. Fischer-Benzon s. 137). Es wird sich also hier um eine melissenart handeln, entweder wohl Melissa officinalis, die 'balsammelisse' oder 'honigblnme', oder Melissa sylvestris, die 'waldmelisse' oder 'honigblatt', die beide im volksmunde als 'bienenkraut, bezeichnet werden. Es steht nichts entgegen, diese bedeutung auch für das ae. meodo-voyrt auzunehmen, zumal die etymologie ('met-wurz') gut dazu stimmt. Das Oxforder wörterbuch allerdings identifiziert ae. meodo-wyrt mit 'wurmkrant' oder 'wiesenkönigin' (Spiraea ulmaria), aber wohl nur, weil das etymologisch entsprechende udän. mjodurt, uschwd. mjödört, nisl. mjað(ar)jurt sowie me. medwurt, ne. meadwort diese bedeutung anfweisen. Ich will nicht leugnen, dafs danach eine gewisse wahrscheinlichkeit besteht, dals die Angelsachsen auch 'wurmkraut' unter meodu-wyrt verstanden haben. Aber wir müssen auch hier mit der möglichkeit rechnen, da्s für die beiden gänzlich verschiedenen pflanzen ursprünglich anch zwei verschiedene bezeichunngen im Altenglischen galten, uämlich 1. ae. meodu-wyrt 'bienenkraut' (Melissa officinalis oder sylvestris) und 2. ae. *mad-wyıt, angl. *med-xyrt, (zu ae. med 'wiese'), me. medwoyrt, ne. meadwort 'wiesenkönigin' (Spiraea ulmaria), wofür im deutschen volksmund auch mädesü/s (= me. med-sucete, ne. meadsweet, meadousweet) vorkommt. Sicher gehörte zn letzterem die Harleian-glosse (WW $555^{8}$ ) Regina [d. i. regina prati] i. reine i. medwourt; vielleicht auch die Bata-glosse (Napier, OEG 56, 40) Rubia 'médewoyrt' (- falls dies nicht mit Schlntter Angl. 30, 249 in madre-wyrt zu ändern ist, was mir wenig wahrscheinlich ist -), obgleich lat. rubia eine andere Rosacee als Spiraea bezeichnet, näılich die 'färberröte' (Rubia tinctorum). 
Porrus . porleac .

W.-W. $134^{28}$

Cameleon . $\bar{z}$. wulfescamb . ${ }^{1}$ )

Cenocephaleon . heortclaefre .2)

$134^{29}$

Electrum . elehtre . ${ }^{3}$ )

220 Ficus . wicwyrt .4)

1) Cameleon steht für chamaeleon (gr. $\chi \alpha \mu \alpha \iota-\lambda, \hat{\varepsilon} \omega \nu$ ), das bei den alten 'eberwurz' bedenten soll, aber in den glossaren auch für andere pflanzen vorkommt, z. b. für carduus albus (Goetz III 537 ${ }^{57}$ ). Dasselbe wort ist gemeint mit dem camelleon des Herb. Apul. CLVI und dem camellea mehrerer glossare Ep.-gl. 183, Corp. C 27, WW $296^{10}, 362^{7}$. Das ae. vulfescamb wird eine distelart bezeichnen, wahrscheinlich, wie ae. wulfes-tøesl (Leechd. I 282; vgl. ne. teasel 'kardendistel'), die 'kardendistel' (Dipsacus silvestris).

2) Ebenso im Durhamer glossar (Leechd. III 301): Cenocephaleon 'heort-cleaure'. Das sonst mir nicht bekannte lat. cenocephaleon - so und nicht cynocephaleon (Junins) schreibt die handschrift - ist gleich gr. $x v v o-x \varepsilon \varphi \dot{\alpha} \lambda \iota o v$, dessen pflanzenart sich nicht näher bestimmen läfst. Ae. heor(o)t-cløfre bedeutet, nach dem zweiten kompositionsgliede (ne. clover) zu urteilen, sicher irgend eine kleeart. Welche, wird sich aber schwer sagen lassen. Ne. hart-clover, hart's clover bedentet den 'steinklee' (Melilotus officinalis), und so mag auch schon das ae. heort-clafre diese kleeart bezeichnet haben. Doch scheint anch hier wieder der ae. name fiir mehrere płlanzenarten gebraucht worden zu sein. Der dentsche volksmund versteht unter 'hirschklee' sowohl Trigonella (Melilotus) caerulea d. i. 'bockshornklee' wie Eupatorium cannabinum d. i. 'wasserhanf'.

s) Als pflanzenname begegnet electrum schon in den ältesten altenglischen glossaren (Erf. 386, Corp. E 116; ebenso Elfric ed. Zupitza 310 ${ }^{11}$, WW 322 ${ }^{7}$, Durhamer gloss. Lchd. III 302, Land-gl. Lchd. III 324: electrum vel lupinus), indem wohl die gelbe farbe des bernsteins auf die lupine (Lupinus) übertragen ist. So werden wir auch ae. elehtre (im Erfurter glossar verschrieben als elothr für elohtr) als 'lupine' fassen diirfen.

4) Die handschrift liest deutlich wicwyrt und nicht ficwyrt, wie Junius bietet. Die dentung der glosse ist schwierig, weil anch das Lateinische nicht eindeutig ist. Der gebrauch des wyrt-kompositums zeigt, dal's der Angelsachse jedenfalls nicht an lat. ficus 'feigenbaun' gelacht hat, sondern irgendeine krautart im sinue hatte, worauf auch die nachbarschaft der übrigen lateinischen pflanzennamen hinweist. Dafs lat. ficus als krant vorkommt, vermag ich nicht nachzuweisen. Jedoch erscheint

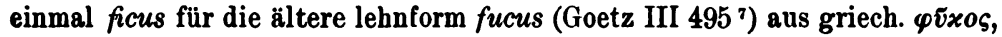
welches 'seegras' bedeutet. Möglich, dafs dies wort hier gemeint ist. Oder ist ficus verschrieben für ficaria (Goetz III $592^{52}, 614^{11}, 626^{29}$ ), welches ein angeblich feigenwarzen vertreibendes kraut, etwa die 'feigenwurz' (Ranunculus ficaria), darstellt. - Ein ae. wic-wyrt liefse sich etymologisch betrachtet mit ae. wīc 'wohnsitz' und wicg 'rofs', allenfalls auch mit ae. wice 'bergulme' und wicce 'hexe' in verbindung bringen. Aber irgendwelche möglichkeit einer botanischen bestimmung scheint sich, soviel ich 
Papauer . popiz ,

W.-W. $134^{33}$

Saliunca . wilde popiz . 1)

Apiaster . wude-merce .2)

Petrosilion . stanmerce . ${ }^{3}$ )

[auf dem unteren rande:]

225 Menta . minte .

sehe, daraus nicht zul ergeben. So ist es am ende doch noch am gerateusten eine verschreibung für fīc-wyrt anzunehmen, und dieses als 'feigenwurz' zu deuten, sei es, dal's man, wie im Deutschen und Englischen (ue. figwort), Ranunculus ficaria darunter versteht, welches ehemals als heilmittel viel gebraucht wurde (v. Fischer-Benzon s. 62), oder auch an Scrophularia nodosa denkt, die im dentschen volksmunde 'feigenwarzenkraut' und im englischen fig-wort heifst. Man wird aber daran festhalten miissen, dals das sonst nicht vorkommende ae. fic-wyrt lediglich auf konjektur beruht.

1) Lat. saliunca bedentet eine baldrianart, vermutlich Valeriana celtica. Der Angelsachse scheint aber das lateinische wort nicht verstanden zu haben und setzt als verlegenheitserklärung dafür 'wilder mohn', d. i. wohl Papaver dubium 'ackermohn'.

2) Vgl. im Cleopatra-glossar ( $\left.\mathrm{W} W \mathrm{~W} 30^{8}\right)$ : Apiaster 'swines mearce' [lies merce], im Brüsseler glossar (WW 297 10): Apis siluatica 'voudumerce' nnd im Durhamer pflanzenglossar (Leechd. III 299): Apiastum 'vude-merce'. Die lateinischen lemmata apiastum, apiaster und apis siluatica sind jedenfalls verderbt aus lat. apiastrum, das im klass:schen Latein die 'melisse' (Melissa officinalis) bezeichnet und daher im Corpus-glossar A 672 und WW $267^{19}, 352^{2}$ richtig mit ae. beo-royrt glossiert ist, aber in mittelalterlichen glossaren, mit apium 'eppich' zusammengebracht, auch für eine

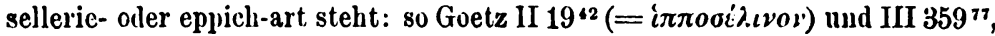

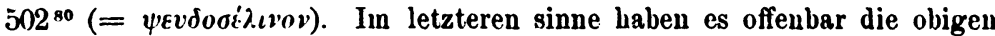
glossen gemeint, wie der zweite teil ler glosse, ae. mereče 'eppich' (vgl. oben nr. 190), zeigt. Ich sehe daher keinen grund, warum wir ac. wudumerece nicht als 'wilde sellerie' fassen sollew. Dafs mittelenglische glossen des 12. und 13. jahrhunderts (Leechd. III 4 anm. 4 und WW 554 ${ }^{8}$ ) wullemerche mit mlat. sanicula, also mit einer ganz anderen pflanze ('sanikel'), identifizieren, spricht dagegen nicht.

s) Petrosilion und petrosilium (WW 322 ${ }^{17}$ ) sind vulgärlateinische

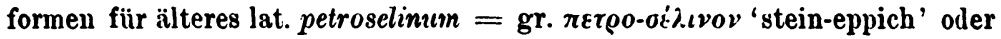
'petersilie' (Apium petroselinum). Ein vulg.-lat. petrosilium wird überdies sowohl von prov. peiresilh, frz. persil wie von ahd. pedarsilli, mhd. nhd. petersilie, mnd. petersilie, mnl. nnl. peterselie, ae. petresilie as etymon verlangt. Das daueben vorkommende mlat. petrosillum (WW 556 ${ }^{11}, 643^{22}, 710^{14}, 786^{3}$ ) ist vorlage für ital. petrosello. - Ae. stān-merče 'petersilie', das auch in Brüsseler glossar vorkommt (Sigsonte 'stan-merce' WW $299{ }^{27}$ ), ist in me: stanmarche (Prompt. Parv.) fortgesetzt, ist also wohl mehr als gelehrte übersetzung. 


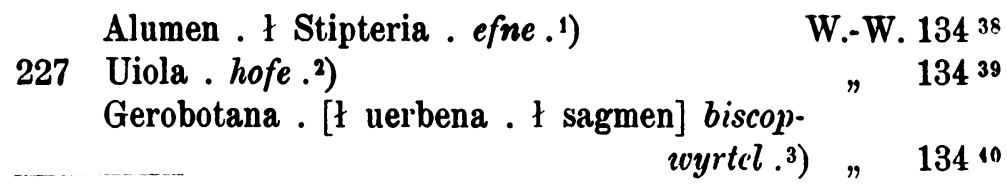

1) Vgl. im Londoner teil der Plantinns-glossen (WW 146 ${ }^{21}$ ): Alumen 'cfne'. So sehr es uns auch auffallen mufs, unter all den pflanzennamen plötzlich ein salz zu finden, so kann doch lt. alumen wie mlt. stipteria

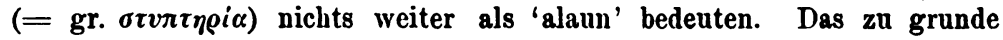
liegende urglossar mag allerdings lat. älum 1. 'wallwurz', 2. 'knoblanch' geboten habell. - Das nur in den beiden Plantinus-glossen belegte efne 'alaun' halte ich fïr verderbt, da Schlutters erklärungsversuch (Engl. Stud. $42,168)$ mich nicht befriedigt. Da ich trotz Schlutters einspruch der rätselhaften Epinal-glosse alumnis 'aelifnae' [beides genetiv] immer noch ein ae. *elefn 'alaun' entnehmen zu dïrfen glaube, halte ich obiges efne für verschrieben statt *elefne oder allenfalls *elfne. Ae. aelifn könnte vielleicht aus akymr. *ahifn (nkymr. elyf) entlehnt sein, das, wie kymr. llafn aus lat. lämina, kymr. colofn aus lat. columna, kym. ysgafn aus lat. scamnum und kymr. $\operatorname{terf}(y) n$ aus lat. terminus übernommen ist, lautgesetzlich anf den lat. plural alīmina (zn alīmen) zurückgehen könnte. Nur mülsten wir eine frühe entlehnung aus dem Lateinischen annehmen, damit das lat. $\pi$ den übergang des brit. $\bar{u}$ in $\bar{\imath}$ mitmachte (J. M. Jones, Welsh Grammar $\S 73$ ). Mkymr. elyf gegenüber akymr. ${ }^{*}$ alifn würde in seinen vokalen die normale entwicklung zeigen (vgl. kymr. Selyf aus lt. Salomo und mkymr. egit, nkymr. va. ëyt 'er geht' aus akymr. agit). Auffallend wäre nur der abfall des $-n$, den wir wohl ebenso zu beurteilen hätten, wie korn. scaff neben kymr. ysgafn 'leicht' (Pedersen I 167), falls man nicht eine verschiedene lat. grundlage vou singular- und pluralform annehmen will - wie das z. b. fiir die romanischen fortsetzungen von lat. vimen 'weide' geschehen muls: aital., prov., katal. vime, span. vimbre, portg. vime gehen auf den singular zurück, hingegeu bologn. vemna, piac. vïmna u. a. auf den plural vimina -, was vielleicht vorzuziehen ist, da auch das air. alamu 'alaun' die singularform alümen als grundlage verlangt. Schwierig ist allerdings nir. ailim (mit langem $i$ ) zu erklären, für das ich mir keinen andern ausweg wuifste als entlehnung ans dem Altbrittischen zu einer so frühen zeit, wo $f$ noch -m war, also aus abrit. *atimn, da direkte entlehnung aus lat. alimmen wegen des $\bar{\imath}$ statt ir. $\bar{u}$ unmöglich ist. Nkymr. alwm und ngäl. alm sind dagegen moderne lehnwörter aus dem nenengl. alum.

2) Lat. viola bedeutet nicht nur das 'veilchen', sondern auch verschiedene andere, angenehm dufteude blumen wie levkoje, goldlack und nachtriole. Das ae. hofe kann indes kaum etwas anderes sein als die 'gundelrebe' (Glechoma hederacea), die noch heute im Englischen hayhove oder ale-hoof heifst.

8) Die handschrift liest biscopwyrtel, nicht -wyrtil, wie Junius schreibt. Eine ähnliche glosse findet sich im Cleopatra-glossar (WW 416 ${ }^{\text {s): Gera- }}$ botane 'biscopwoyrt'. Mlat. Gerobotana, wie ähnliche formen in lat. glossaren (gerubutana Goetz III 612 ${ }^{45}$, girobotanin III $590^{23}, 624^{88}$, gerobotanis

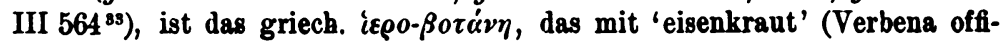


Calta . $¥$ Trifillon . cloefre .1)

W.-W. $134^{42}$

230 Crispa . Uictoriola . smerinzwyrt .2)

" $135^{1}$

cinalis) identifixiert wird. Das ae. biscoproyrtel wird indes kaum diese letztere pflanzen bedeuten können, wie denn auch im Brüsseler glossar (WW $301^{3}$ ) Hierobotanum mit ae. hratelwyrt d. i. ne. rattle-wort 'klapperschote' (Crotalaria) wiedergegeben ist. Vielmehr wird ae. biscop-woyrtel dasselbe bedeuten, wie das seo lasse biscop-royrt bei Flfric (ed. Zupitza $310^{15}$ ), in Londoner teil der Plantinus-glossen (WW 136 ${ }^{3}$ ) und im Durhamer pflanzenglossar (Leechd. III 300), nämlich das 'zehrkraut' (Betonica officinalis), - wohingegen ae. biscop-voyrt alle in in unserem glossar (nr. 196) für 'eibisch' steht. - Lat. verbena und sagmen, die in der handschrift ïber der zeile nachgetragen sind, bedeuten nicht eigentlich eine bestimmte pflanzenart, sondern verschiedene, zu sakralen zwecken verwandte pflanzen.

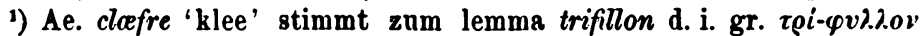
'klee'. Lt. caltha wird zumeist als 'ringelblume, dotterblume' (Calendula officinalis) orklärt, findet sich jedoch auch im Erfurter und Corpus-glossar (Sweet, OET. s. 50) mit 'rotem klee' (rede clabre bezw. reade clafre) und im Durhamer pflanzenglosøar (Leechd. III 300) mit vude-cleaure identifiziert.

2) Es läfst sich nicht sicher entscheiden, ob der schreiber smerinzuyrt (so las Junius) oder sinerinzwyrt geschrieben hat. Beides wäre jedenfalls, wie schon Varnhagen vorschlug, in simerinzwoyrt zu bessern. Denn vgl. in Elfrics glossar (ed. Zupitza $310^{12}=$ Napier, OEGl. 56, 383): malua crispa 'symerinzc-wyrt' (simarinzcwyrt), im Brüsseler sachglossar (WW $300^{32}$ ): Uiole [so die hdschr., nicht Uiola] 'simerinzwyrt', im Durhamer pflanzenglossar (Leechd. III 3(3): malua crispa 'smerig-vyrt' [lies simerinzwyrt] und in den Dresduer glossen (Anglia 24, 432; dazn H. Varnhagen, De glossis nounullis Auglicis, Erlanger Progr. 1902, 8. 9): maluam crispan 'simaringuuert' und accipe herbain simceringwuort. Danach wird auch das lat. crispa oben fïr malua crispa d. h. 'krause malve' stehen. - Lat. victoriola bedeutet als pflanzenname sonst meist den 'lorbeer' (belege bei Goetz VII 414), wenn auch andere gleichsetzungen, so z. b. mit ae. cneowholen 'mäusedorn' (WW 300"1 1 . Leechd. III 305, wo allerdings victoriale erscheint), vorkommen. Vielleicht ist daher victoriola verderbt aus uiola (vgl. die Brüsseler glosse oben), welches im altertum ja nicht nur das veilchen bezeichnet, sondern auch für andere, recht verschiedene blumen, wie hyazinthen, levkojen, nachtviole n. a., vorkommt. Die bedeutung von ae. symerinz-woyrt anzugeben, ist daher nicht ganz leicht; doch spricht die grölste wahrscheinlichkeit für die bedeutnng '(krause) malve' nnd nicht für 'veilchen', wie Hall ohne zusatz angibt. Etymologisch wüfste ich mir symerinz uur zu erklären als ableitung zu sumor 'sommer', ähnlich wie das ne. dial. summering (Wright, FDD), das einen früh-reifenden apfel bezeichnet. (Im Deutschen versteht man unter sommerwourz die weit verbreitete schmarotzergattung Orobanche.) - Völlig davon zu trennen ist der ae. pflanzenname sme(o)ru-vyrt (Ep.-Erf.-Corp. 1078; WW 296 ${ }^{18}, 457^{16}$; Leechd. III 305; Anglia 24, 432 u. ̈̈.), der für verschiedene pflanzen gebraucht zu sein scheint; vgl. NED unter smearwort. 
Gentauria . eordzealla .1)

W.-W. $135^{2}$

Strumus . \& uua lupina . niht-scada .2)

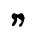

Ceutaura . cordzealla. . )

$135^{3}$

Saluia . fenfearn . ${ }^{3}$ )

[fehlt]

235 Collocasta . harewinta .4)

1) Ae. eorð-zealla, ne. earth-gall, ahd. ert-galla, nhd. erdgalle bedeuten 'tausendgiildenkraut' (Erythraea centaurium). Das lateinische lemma ist daher in beiden fällen in Centauria zu bessern (Junius liest fälschlich Centaurea und eor.yealle).

2) Lat. strumus bedentet bei Plinius und Pseudo-Apuleins eine nachtschattenart, und auch uva lupina wird in lateinischen glossaren (belege bei Goetz VII 388) wiederholt mit orov'yvos 'nachtschatten' identifiziert. Das nur hier belegte ae. niht-scada ist wohl mit Bosworth-Toller und Hall ${ }^{2}$ in niht-scadu zu bessern (vgl. ahd. naht-scato, as. naht-scado, mnd. nachtschade, mnl. nacht-schaduve).

3) Lat. salvia ist 'salbei'. Das altenglische fen-fearn kann aber der etymologie nach zu urteilen kaum diese pflanze bedeuten, sondern nur den sumpfigen boden verlangenden 'königsfarn' (Osmunda regalis).

4) Vgl. im Durhamer pflanzenglossar (Leechd. III 301): Carocasia 'hareminte' und in Ms. Laud. 567 (Leechd. III 330): 'Harminte' colosia. Dieses carocasia, colosia sowie unser obiges collocasta [so die hdschr.!]

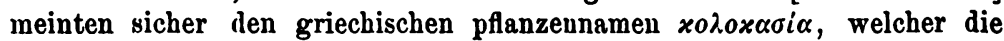
'indische wasserrose' (Nymphaea Nelumbo) bezeichnen soll. Das obige harewinta wird vou Cockayne, Bosworth-Toller und Hall 2 in harewirta gebessert. Aber abgesehen davon, dafs woyrta der plural sein milfste, der hier kaum sich rechtfertigen liefse, legt die analogie der Durhamer und der Oxforler pflauzenglosse eine besserung in haveminte näher. (Dals die endrokale in ihrer qualität in unseren glossen nicht mehr fest sind, haben wir schon mehrmals bemerkt, vgl. zu ur. 162, 180, 184, 215, 223, 232 . Und dafs ein schreiber den zweiten teil eines pflanzenuamens versehentlich mit $w$ begann, ist bei dem häutigen vorkommen der komposita mit wyrt psychologisch leicht verständlich.) Zur stütze dieser wortform läfst sich noch auf das ne. horemint verweisen, welches einmal in Th. Elyot's Castle of Helthe (1533) begegnet. Die ne. form gibt nns zugleich einen fingerzeig für die etymologie, dafs nämlich das wort von hara 'hase' zu trennen ist und ae. här 'weifslich' sich zugesellt. Ae. häre-minte, entstanden aus sèo häre minte, wird also vermutlich eine weifsliche minzenart bedeuten. - Eine ähnliche pflanzenart muls gemeint sein mit ae. hāre wyrt (Leechd. II $132^{9}, 156^{10}, 296^{25}, 344^{12}$; akkusativ pa häran wyrt II 156; me. ne. horewort s. NED, wo die ae. belege fehlen), welches nach Leechd. II 132 weifse blüten (hwñte blostman) hat: wahrscheinlich das 'filz- oder schimmelkrant' (Filago vulgaris). Das ähnlich gebildete ae. hār-hūne, hāre-hūne (me. horehoune, ne. horehound) bedeutet 'weifsen dorant' (Marrubium vilgare). Vgl. auch ne. dial. hoarwithy 'mehlbeerbanm' (Sorbns aria). 
Filex . fearn .1)

W.-W. $135^{6}$

Herba putida . mazba.$^{2}$ )

$135^{7}$

Cresco . kerse . ${ }^{3}$ )

Uermiculi . moeddre .4)

240 Filix arboratica . efenfearn.5)

Sinicia $\cdot 7$ senecion $\cdot$ zrundeswelze.$^{6}$ )

$\begin{array}{ll}" & 135^{7} \\ " & 135^{8} \\ " & 135^{9} \\ " & 135^{10} \\ " & 135^{11}\end{array}$

1) Die hschr. liest hier filex (nicht filix, Junius), in nr. 240 aber filix. Beide orthographien kommen frïh vor.

2) Vyl. oben s. 125 anmerk. 3.

3) Ein mlat. cresco 'kresse' erscheint auch in Elfrics glossar (ed. Zupitza $311^{\circ}$ ): cresco 'ccerse', in Batas erweiterung (Napier OEGl. 56, 414) sowie im Durhamer pflanzenglossar (Leechd. III 301): Cresco 'cerse'. Es ist vermutlich $\mathrm{zu}$ bessern in vlat. *crescio, welches als etymon für frz. cresson, prov. creiso, ital. crescione, engad. krašn von Körting vorausgesetzt wird. Anders Meyer-Lübke nr. 4770.)

4) Das lat. vermiculus, ursprtinglich 'würmchen' bedeutend, erscheint schon in der Vulgata (Exod. 35, 25) für die 'scharlachfarbe' gebraucht, wie sich bei Goetz II $351^{68}$ auch eine glosse vermicula. xóxxos tò $\beta \dot{c} \mu \mu c$ ('scharlach-farbstoff') findet. Ebendahin gehören die farbenglossen WW $491^{9}$ : wermiculo 'wealh-baso', WW $556^{19}$ (ca. 1250): uermiculum $i$. varance [frz.] $i$. wrotte [lies wrette, ae. wrette, vcratte, ahd. rezza 'färberröte', Anglia $30,249]$ und WW 618 ${ }^{43}$ : vermiculum 'vermyloun' (me.). Und dasselbe etymon verlangen frz. vermeil und seine romanischen verwandten (MeyerLübke 9230). Dagegen mufs oben ein pflanzenname gemeint sein, also vermiculus auf eine färberpflanze übertragen sein, wofür ich sonst keinen beleg kenne. - Ae. madere (ahd. matara, an. maðra, schwed. madra, dän. maure) entspricht dem me. mader, ne. madder, welches die 'färberröte' (Rubia tinctorum) bedeutet; und diese bedeutung wird hier auch für das Altenglische anzunehmen sein.

5) Das sonst nicht belegte arboratica ist sicher dasselbe wie lat. arborea 'baumähnlich'; vgl. die glosse (Goetz III $574^{27}$ ): Filix arborea . poli-

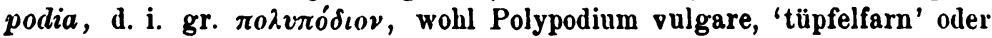
'edelsüfs'. Diese pflanze ist der beschreibung nach auch gemeint mit ae. efor-fearn im Herbarium Apuleii cap. 85 (Leechd. I 188: heo byd cenned on

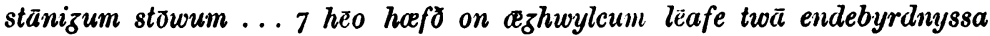
fazera pricena, 7 ba scinað swä zold). Daher wird auch das obige unverständliche efenfearn in eferfearn zu bessern sein, wie Junius stillschweigend schreibt. (Eine andere farnart scheint gemeint im Durhamer pflanzenglossar und in der Dresdener glosse: radiolum 'eofer-fearn' Angl. 24, 434; Leechd. III 304.)

b) Lat. senecio sowie ae. zrunde-swelze (ne. groundsel) sind gut bekannte wörter für 'kreuzwurz'. Sinicia (- so liest die handschrift, und nicht sintea, wie Junius schreibt -) und senecion sind auch sonst in lateinischen glossen vorkommende verstïınmelungen für senecio. 


\section{[fol. $4^{a}$ ]}

\section{[auf dem inneren rande links:]}

\section{Falsidicus . ł Falsiloquus . onsoðsazul . ${ }^{1}$ ) W.-W. $165^{21}$ Recompensatio . edlean. $\quad$ N16441}

1) Die handschrift bietet die regelrechte lateinische form falsidicus, nicht falcidicus, wie Junius vielleicht nur versehentlich schreibt. - Das uberlieferte onsoðsazul ist allerdings in unsoðsazul zu bessern, wie Junius stillschweigend einsetzt. Vertauschnng von on- und un- findet sich anch sonst (Sievers § 56 a. 1; Kluge, Grundr. ${ }^{2} 1$ 1058; Förster, Archiv CXVI 306 anm.; K. Glaeser, Lautlehre der Elfricschen Homilien in der hdsch. Vesp. D. XIV, Lpz. Diss. 1916, s. 64): so steht on- statt un-z. b. in onzelimp 'unpassend' (Tib. A. III bei Wulfstan ed. Napier $172^{17}$ ), onzemethāt 'nnermefsliche hitze' (Leechd. II $338^{24}$ ), onstydfullnise 'unfestigkeit' (Durhamer Rit. $192^{19}$ ), onnytt 'unnütz' (Stowe-Ps. 13, 4), onrihtwisnysse 'nngerechtigkeit' (allerdings für on unrihtwismesse, Stowe-Ps. 52, 2), onzefremming 'unrollkommenheit' (Regins- und Stowe-Pl. 138, 16), onzerois 'nngewils' (StowePsalter 50, 7), onræfniendlic 'nnerträglich' (Stowe-Ps. 123, 4), onbesmiten 'unbesudelt' (Vitelius- und Arundel-Ps. 17, 31), onbesmitynnys 'unbeflektheit' (Cambridge-Psalter ed. Wildhagen 17, 31 nnd OEGl. ed. Napier XI 52), onzescliznys 'unsesligkeit' (Cambr.-Ps. 13, 3), onbcestic 'nnpassend' (Defensor ed. Rhodes $33^{20}$ ), onzecoplice 'unpassend' (Defensor $80^{14}$ ), onzemet 'unermefslich' (WW 250 ${ }^{23}$ ), onzedered 'unbeschädigt' (OEGl. ed. Napier XI 28), omwiometen(d)lice ' unvergleichlich' (OEGI. XI 65), onfullfremednys 'unvollendetheit' (Cambr.-Ps. 138, 16), wohl anch onholede 'ungeheilt' (im Cott. Ms. für on unhale 'im unheil', Oros. IV 4). Umgekehrt steht un-

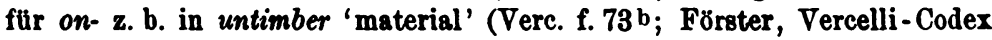
s. 177), unworizen 'enththllt' (Verc. 61 ; Förster s. $101^{\text {'}}$ ), uncyoig 'bewufst' (Elene 961). Bei dieser vertauschung wirken lautmechanische, semasiologische und psychologische grtinde zusammen. Einmal ist in betracht zu ziehen die neigung des Altenglischen, schwachtoniges $u$ uberoffen zu sprechen und in 0 ubergehen su laseen (Bülbring \& 364 u. 375). Zweitens berühren sich im bedentungsiuhalt das privative un- und das ursprünglich einen gegensatz bezeichnende on- ans älteren ond-, urgm. *and- 80 stark, dafs bei einer ganzen reihe von verben das ursprüngliche on- völlig von un- verdrängt ist: 80 z. b. bei ae. on-, unbindan 'aufbinden' (ne. unbind), onbregdan 'anfflechten' (ne. unbraid), on-, uncnyttan 'aufknüpfen' (ne. unknit), on-, undon 'offinen' (ne. undo), on-, unfealdan 'entfalten' (ne. unfold), on-, ungyrwan 'entkleiden', on-, ungyrdan 'entgïrten' (ne. ungird), on-, unlysan 'auflösen' (vgl. ne. unloose), on-, unlücan (me. unlouken, vgl. ne. unlock), onpennian 'entpferchen' (ne. unpen), on-, unsalan 'entseilen', on-, unscozan 'entschuhen' (ne. unshoe), on-, unsynizan 'entsündigen' (ne. va. unsin), on-, unspannan 'entspannen', untyzan 'aufbinden' (ne. untie), on-, untyman 'entzäunen', on-, unvindan 'entwinden' (ne. unvoind), on-, unworeon 'enthüllen', on-, unvoriðan 'aufdrehen'. Bei allen glossenbelegen 
Testimonium . zewitnes . $ł$ zecyðnes .

W.-W. $164^{40}$

245 Elegus . earminz. ${ }^{1}$ )

Balbus . stamer .2)

$161^{37}$

Catax . healt . ${ }^{3}$ )

Blesus . wlips .4)

Cetarius . hwoclhunta .

250 Surdus . $¥$ Surdaster . deaf.$^{5}$ )

Debilis . $¥$ eneruatus . lame . $\left.{ }^{6}\right)$

ist endlich mit der möglichkeit zu rechnen, dafs der schreiber das privative lat. in- gesondert als die lat. präposition in apperzipiert hat (vgl. Anglia Beibl. XII 356) und letztere mit ae. on wiedergab. Dafs so etwas wirklich vorkam, lehren uns eine reihe glossierungen, wie on iehtum für lt. inopibus 'den armen' (Defensor 53 ${ }^{10}$ ), on spornendum fet für inoffenso pede 'unbehelligten fufses' (Defensor $187^{\circ}$ ), on veze and on voceterizum für in invio et inaquoso (Stowe- und Eadwine-Ps. 62, 2; ähnlich Arnndel, Junins und Cambridge), on fullfremydnysse mine und sogar on mine fulfremednesse für lt. inperfectum meum 'meine unvollkommenheit' (Cambr.- u. Junius-Ps. 138, 16; ähnlich Eadwine). Dadurch, dafs ein solcher fehler vom kopisten bemerkt warde, konnten nun lesarten entstehen, wie on unvocterium für lat. inaquosa (Lambeth-Ps. 62, 2), on unnytte oder on unnyttenesse für lt. inutiles (Arundel- bezw. Eadwine-Ps. 13, 3), on unspede für inopiae (StowePs. 43, 27), onunuōsum für insipientibus (Stowe-Ps. 48, 21). Ans solchen glossen sind mehrfach unwörter in unsere lexika geraten, die zum teil noch von Hall ${ }^{2}$ (1915) beibehalten sind. Zu diesen zu streichenden wörtern gehören die adjektiva onceht 'arm' (Rhodes), onspornend 'nnstumbling' (Rhodes), onwateriz (B.-T., Hall), onunwis 'foolish' (B.-T.), und die substantiva onunsped 'indigence' (B.-T.) sowie ans anderen gründen (Archiv CXVI 306) auch onunwisdom 'folly' (B.-T. und Hall ${ }^{2}$ ). Vielleicht steht es ähnlich mit den bei B.-T. ohne beleg angeführten onzeðwcere nnd onwamme.

1) Ae. earming 'elender' ist nur eine verlegenheitserklärung für mlat.

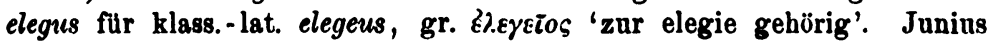
schreibt irrigerweise Plegus. Elfrics glossar bietet an der entsprechenden stelle das lemma miser (ed. Zupitza $304^{15}$ ).

2) Das $b$ von Balbus ist anscheinend aus $d$ gebessert.

3) Junins schreibt heolt. Die handschrift liest aber deutlich healt, obschon das $a$ etwas bauschig geraten ist.

-) Die handschrift liest dentlich volips, was Junius in plips verlesen hat. Lat. blaesus bedeutet sowohl 'lispelnd' als anch 'lallend' (wie ein betrunkener), also allgemein 'unartikuliert sprechend'. Diese allgemeinbedentung scheint anch dem ae. wlisp eigen gewesen $\mathrm{zn}$ sein.

•) Das ae. deaf scheint, wie nhd. taub, sowohl das lat. surdus 'stocktaub' wie lat. surdaster 'schwerhörig' zu umfassen.

b) Sowohl lat. debilis wie enervatus kann auf menschliche gliedmafsen angewendet 'gelähmt' bedeuten, so dafs die ae. glosse $\operatorname{lam}(a)$ 'lahm' $2 \mathbf{z}$ recht besteht. 


\author{
Strabus . scyleazede .2) \\ Pantamimus . zlizman .3) \\ Lippus . sureazede .4) \\ 255 Logotheta . zemotman .5) \\ Unimanus . anhende.
}

W.-W. $162^{2}$

$150^{19}$

$162^{3}$

" $164^{35}$

$7162^{4}$

2) Ae. scyl-eazede 'schieläugig' gehört zu ae. sceolh 'scheel' (WW $387^{29}, 508^{8}, 522^{7}$; dazu ae. sceol(h)ezi Ep.-Erf.-Corp. 981, WW $524^{19}$; vgl. ahd. scelah, mhd. schelch, nhd. scheel, dial. schelch, mnd. schel, mnl. nul. scheel, wfries. skel, nordfries. skellag [Schmidt-Petersen]; mit grammat. wechsel an. skjalgr; adän. skel, ndän. skelojet, nschwed. skelögd sind entlehnt ans dem Niederdeutschen). Die normalform des kompositums sollte daher scêol-ezzede lauten, wie auch in Ellfrics grammatik (ed. Zupitza $36^{12}$ ) in den meisten handschriften zu lesen steht. Die nebenform scyl-ę(a)zede, die auch sonst noch belegt ist (Elfric ed. Zupitza $304^{17}=$ scül-eizede WW $541^{23}$, Zupitza $36^{12}$ hs. DHJ, WW 157 $)$, zeigt einflufs des ae. verbums (be)scȳlan 'schielen' (Boet. 121 so, me. schülen Ancren R. 210, 212, ne. dial. shile, sheyle [Schottland, Cumberland, York]; vgl. ahd. scilehen. mhd. schilchen, nhd. schielen, mnd. schelen; mit gramm. wechsel an. skelgia 'schielängig werden', daraus ne. dial. skelly 'schielen').

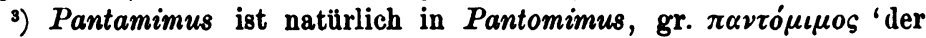
alles nachahmende', zu bessern, wie Junins stillschweigend schreibt.

4) Dem lat. lippus entsprechend bedentet auch ae. sūr-eazede (= mnd. sūr-ogede 'tiefäugig'; übertragen westfries. sür-eagede 'sauertöpfisch, unzufrieden'), ebenso wie ae. sür-ezze und as. surr-ogi, ahd. sür-ougi, mhd. sintöuge, an. sür-eygr, schwed. sur-ögd, dän. surejet, norw. suregd 'triefängig'. Denn, wie Talk-Torp richtig bemerken, bedeutete das urgm. *süro- urspritnglich den zustand einer säuernden flüssigkeit. Diese alte bedeutung zeigt sich noch in nhd. saurer boden, schwed.-dän. sur jord, schwed.-norw. sur ved 'fencht-fauliges holz', adän. sure oine und schwed. sura ögon 'triefende augen', schwed. sur ben, surbent 'schwärendes bein'; an. saurr 'fenchte erde', syra 'das sauer gewordene milchwasser'.

s) Das ae. zemot-man, welches sonst als übersetzung von lat. contionator erscheint (Elfric ed. Zupitza $301^{13}$; WW $371^{25}, 495^{11}$ ), wird gewöhnlich (Sweet, Hall2) mit 'redner' erklärt, wohl nur weil das lat. contionator im klassischen Latein 'versammlungsredner' bedentet. Im mittelalterlichen Latein wird aber contionator noch für 'versammlungsberufer und -anredner' gebraucht (Ducange und Liebermann, Ges. d. Ags. I 193). Und diese bedeutung wird, wie mir F. Liebermann freundlichst mitteilt, auch das ae. zemotman haben, das wir also mit 'versammlnngsvorsteher' tubersetzen müssen. In erster linie wird dabei an den vorsteher der hundertschaftsversammlung gedacht werden müssen, so dafs zemot-man mit ae. hundredes-man synonym wäre (vgl. Eadgars Gesetz über das Hundredgericht, ed. Liebermann I 193 u. III 132). Aber es könnte vielleicht auch an kleinere versammlungen, selbst dorfversammlungen ohne gericht, gedacht werden, für die allerdings das lat. logotheta dann nicht passen würde. 
Eger . ł egrotus . adliz .

W.-W. $162^{5}$

258 Paraclitus . bedrida .1)

Clinicus . hofrede .2)

1) Wenn man das offenbar der ganzen adjektivreihe zugrunde liegende Elfricsche glossar herbeizieht (ed. Zupitza $304^{19}$ : Paraclytus 'frofergast'. Paraliticus 'bedreda oððe se de paralysin haf $\partial$ '), sieht man, dal's hier der abschreiber zwei glossen in eine gezogen hat. $\mathrm{Zu}$ bed-rida sollte das lemma also heifsen Paraliticus. Das ae.bed-rida ist hier wie bei Elfric in dem verstärkten sinn 'chronisch (durch paralyse) an das bett gefesselt' gebraucht.

2) Als glosse zu lat. clinicus 'bettlägerich' (gr. $x \lambda \iota v \iota x o ́ s)$ ist das ae. hofrede von Bosworth-Toller, Hall ${ }^{2}$ und Sweet als hof-rede 'confined to the house' gedentet, indem man offenbar in dem zweiten bestandteile dasselbe rida sah wie in bed-rida. Formell betrachtet lälst sich hiegegen wenig einwenden; höchstens dafs die normalform dann als hof-rida, -reda anzusetzen wäre. In semasiologischer hinsicht aber erregt mir doch grölstes bedenken, dals der Angelsachse ein wort geprägt haben sollte für einen so eigenartigen krankheits- oder gesundheitszustand, für den keine moderue sprache, soweit ich sehe, es zu einer geläufigen worteinheit gebracht hat; nur die militärische dienstsprache kennt dafür die worte 'revierkrank' und 'zimmerkrank'. Und dieses bedenken wird noch vergrölsert, wenn man sich die primitivität der angelsächsischen heilkunst nnd die primitivität des angelsächsischen holzhauses mit seinem geringen schutz gegen atmosphärische einflüsse vor angen hält. Ich glaube daher, dais aus begrifflichen gründen die existenz eines ae. hof-reda 'ans haus gefesselt' abzulehnen ist. Nun existiert aber im Altenglischen das gut belegte adjektiv hoferede 'buckelig' (me. hoverede; and. hobarodi, mnd. hoverde; vgl. ahd. hovarohti) - zu ae. hof(e)r 'höcker' (ahd. hovar, andd. hobar, mnd. mnl. hover) -, wovon obiges hofrede eine nebenform ohne Srarabhaktivokal sein könnte. Die frage ist nur, wie wir sein erscheinen als glosse zI clinicus 'bettlägerig' rechtfertigen sollen. Dabei köunte einmal mit der moglichkeit gerechnet werden, dafs, wie bei der vorhergehenden glosse, das lemma gar nicht hierhergehörte - lat. clinicus pafst ohnehin besser zur vorhergehenden zeile - und dafs ursprünglich das lemma vielleicht gibbosus oder gibberosus lantete, was tatsächlich im Londoner teil der handschrift (WW 168 ${ }^{7}$ ) und in Elfrics glossar (ed. Zupitza 321 ${ }^{16}$ ) als lemma zn hoferede erscbeint. Zweitens ist in betracht zu ziehen; dafs ae. hofr nicht nur 'buckel' bedeutet, sondern, wie die glossen mit lat. tuber und struma zeigen, auch 'geschwulst, beule, skrophulöse anschwellung' und dafs dementsprechend das adjektiv hoferede nicht nur mit gibberosus glossiert ist, sondern auch mit lat. strumosus 'mit angeschwollenen drïsen behaftet' (WW $168^{2}, 337^{36}, 553^{22}$ ). Eine ähnliche bedeutnng dürfte anch in unserer obigen glosse vorliegen, etwa 'mit (pest-)beulen behaftet', was gut zu der umgebung von ulcerosus und leprosus passen würde. Da ein solcher zustand zu bettlägerigkeit führen kann, mag immerhin die zusammenstellung mit lat. clinicus angehen, ohne dafs ich deswegen mit Joh. Geldner,

Anglia. N. F. $\mathbf{X X I X}$. 
260 Ulcerosus . hreofla.

W.-W. $162^{9}$

Leprosus . licprowere . ')

Lunaticus . monapseoc .

Demoniacus . deofel-seoc .

Energuminus . zewitseoc .

265 Morbus . adl.

Pestis . cwyld . $\dashv$ lues . cwealm .

Amens . $¥$ Demens . zemendleas .

Rabidus . (ł) insanus . $200 d .2$ )

(R)abies . (w)odnys .2)

270 Incolumis . zesund.

Freneticus . se pe for sleaple awed.$^{3}$ )

[auf dem unteren rande:]

Lethargus . unzelimplice slapulnis .4)

Uigil . wacul $¥$ Uigilans .

Uigilia . wecen .5)

275 Peruigil . purhwacul.

(c) Weiter füllt die äufseren ränder von fol. $19^{b}-32^{b}$ (d. i. im Antwerpener teil fol. $4^{\mathrm{b}}-17^{\mathrm{b}}$ ), fortlaufend geschrieben, aber von dem ersten glossar und dèn randbemerkungen zum grundtext mehrfach unterbrochen, eine lateinische grammatische abhandlung, die sich selbst betitelt als Incipit

Ae. Krankheitsnamen II (1907) s. 34 auf grund dieser glosse eine verallgemeinerte bedeutung 'gebrechlich' für hof(e)rede annehmen möchte.

1) Ae. lic-proucere hat ebenso wie an. $l i k-p r a \vec{r}$ stets die verengte bedeutung 'mit aussatz (lepra) behaftet'; vgl. an. $\hbar \hat{k} k$ - $b r \bar{a}$ 'aussatz', aschwed. $\bar{l} k$ - thra - - sott.

2) Die eingeklammerten buchstaben stehen am anfang der zeile und sind jetzt fast ganz verblafst.

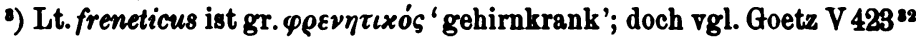
(Gregor, Dial. III 35): Phreneticus, insanus ob dolorem capitis, ad tempus qui multun vigilat. In der ae. glosse steht sleaple für slappleaste; denn die glosse ist entstanden aus Flfrics: Freneticus 'se de Jurh slapleaste āoet' (ed. Zupitza $305^{\mathrm{\theta}}$ ).

4) Lat. lethargus $=\mathrm{gr} . \lambda \dot{\eta} \vartheta \alpha \rho \gamma o \varsigma$ bedentet sowohl 'der schlafoüchtige' (ae. slāpol), wie 'die schlafsucht' (ae. slāpolness). In der ursprïnglichen fassung der glosse bei Elfric (ed. Znpitza $305^{7}$ : Lethargus $\&$ letargicus 'unzelimplice slapol') war das erstere gemeint. - Jnnins schreibt fălschlich slapfulnis. Das nur auf dieser falschen lesung beruhende wort ist aus unseren wörterblichern (Bosworth-Toller, Sweet, Hall ${ }^{2}$ ) zn streichen.

5) Ae. wečen 'das wachsein' ist eine abstraktbildung $z \mathrm{u}$ se. vacan (vgl. Kluge, Nom. stammbildungslehre § 150), wie ae. hengen (and. henginnia). 
editio Remigii super Donatum, Grammat(ic)um urbis Romę. Es handelt sich hier also um den Donat-kommentar des Benediktiners Remigius von Auxerre $(\dagger 908)$, den Fox, Remigii Autissiodori in artem Donati minorem commentarius (1902) herausgegeben hat.

(d) An diese abhandlung sich anschliefsend finden wir auf den äufseren rändern von fol. $33^{a}$-fol.? (d. i. im Antwerpener teil fol. $18^{\mathrm{a}}-19^{\text {verso }}$ und Londoner fragment fol. $16^{\mathrm{a}}-$ ?) das lateinische schulgespräch, welches unter dem namen Colloquium AElfrici ${ }^{1}$ ) bekannt ist. Unsere Plantinsche textfassung schliefst sich eng an die überlieferung in dem Cotton ms. Tiberius A. III (fol $60^{\mathrm{b}}-64^{\mathrm{b}}$ ) an, ${ }^{2}$ ) während die handschrift nr. 154 des St. John's College zu Oxford (fol. $204^{a}-221^{b}$ ) eine wesentlich erweiterte fassung bietet. Wie schon oben bemerkt, ist der schlufsteil (etwa ein drittel des ganzen) in dem Antwerpener teil nicht mehr vorhanden, doch tritt genau in die lücke die Londoner handschrift ein, die von fol. $16^{a}$ an den schlufs bringt. Soweit unser schulgespräch im Antwerpener teile steht, soll hier der text für eine künftige ausgabe bereit gestellt werden. ${ }^{3}$ )

1) Der text ist nach Tib. A. III herausgegeben bei Thorpe, Analecta Anglo-Saxonica, 1834 8. $101-118$, 2. anfl. 1868 s. 18-36, und bei WrightWulker, Vocabularies, 1884, s. 88-103. Über das verhältnis zur Oxforder fassung vergleiche Zupitza, Z. f. d. A. XXXI 32-45 nnd E. Schröder, ebenda XLI 283-299.

2) Danach ist Brandls angabe in der 'Altenglischen Literatur' (1908) s. 1107 sowie meine eigene im Archiv f. n. Spr. CXXI (1908) 39 zu verbessern.

2) Wenn Brandl s. 1131 neben dem obigen Colloquium AElfrici noch "eine ähnliche Locutio latina (hs. Christ Church Canterbury)" anführt, so berult das auf einem misverständnis einer anmerkung bei Cockayne I s. LVII a. 2. Cockayne meint nämlich, wie sein hinweis auf Wanleys Preface (s. b 2 verso) zeigt, nicht eine uns erhaltene handschrift, sondern nur einen eintrag in dem alten, um 1320 angelegten katalog, der jetzt in alle winde zerstreuten bibliothek des Chorherrnstiftes Christ Church in Canterbury (ed. M. R. James, The Ancient Libraries of Canterbury and Dover, Cambridge $1903,8.50$ ), wonach diese bibliothek einen codex besessen hat, der aufser anderem eine Locutio latina glosata anglice ad instruendos pueros enthielt. Was das für ein text gewesen ist, lärst sich natürlich nicht festlegen; möglicherweise war aber unser Colloquium Ellfrici damit gemeint. - Der im anschlufs daran von Brandl erwähnte schultext $O$ clerice, ne dempseris unquam diptycas lateri, der nach Brandl in derselben handschrift 
[D]: Nos pueri rogamus te, magister, ut doceas nos loqui Latialiter recte, quia idiote sumus et corrupte loquimur.

$\boldsymbol{R} .:$ Quid uultis loqui?

[D]: Quid curamus, quid loquimur ${ }^{1}$ ), nisi recta locutio sit et utilis, non anilis aut turpis?

M.: Uultis flagellari in discendo?

D.: Carius est nobis flagellari pro doctrina quam nescire. Sed scimus te mansuetum esse et nolle inferre plagas nobis, nisi cogaris a nobis.

M.: Interrogo te, quid mihi loqueris. Quid habes operis?

D.: Professus sum monachum, et psallam omni die septem sinaxos ${ }^{2}$ ) cum fratribus, et occupatus sum lectionibus et cantu; sed tamen uellem interim discere sermocinari Latina lingua.

M.: Quid sciunt isti tui socii?

D.: Alii sunt cantores $^{8}$ ), alii piscatores ${ }^{4}$ ), quidam aratores, alii opliones, quidam bubulci, quidam etiam uenatores, alii aucipes ${ }^{5}$ ), quidam mercatores, quidam sutores, quidam salinatores, quidam pistores, quidam autem coci. ${ }^{8}$ )

M.: Quid dicis tu, arator? Quo modo exerces opus turum?

D.: $O$ mi domine, nimium laboro. Ex-eo diluculo minando boues ad campum, et iungo eos ad aratrum. Non est tam aspera hiems, ut audeam latere domi pro timore domini mei; sed iunctis bobus et confirmato uomere et cultro aratro omni die debeo arare integrum agrum aut plus.

M.: Habes aliquem socium?

D.: Habeo quendan puerum minantem boues cum stimulo, que etiam ${ }^{2}$ ) raucus est pre frigore et clamatione.

M.: Quid amplius facis in die?

D.: Certe adhuc plus facio. Debeo impleve presepia boum feno et adaquare eos et fimum eorum portare foras.

M.: Magnus labor. ${ }^{8}$ )

D.: Etiam magnus labor est et fortis ${ }^{\circ}$ ), quia non sum liber.

[M.]: Quid dicis tu, opilio? Habes tu aliquem laborem?

R.: Habeo utique ${ }^{10}$ ). In primo mane surgo ") de meo lectulo, in manu baculum accipiens, aliquando discalciatus, et ") mino oues meas ad pascua et sto super eas in estu' ${ }^{12}$ ) et frigore cum canibus, ne lupi [fol. 18b] deuorent $e^{\mathrm{b}} \mathrm{s}^{13}$ ), et reduco eos ${ }^{13}$ ) ad caulas et mulgeo eos ${ }^{13}$ ) bis

stehen soll - in wahrheit findet er sich in St. John's College, Oxford, nr. $154-$, ist die glossierte fassung von des franzosischen Benediktinerabtes Abbo ( +1004 ) Clericorum decus (ed. Zupitza, ZfdA. 31, 4) und hat also mit etwaigem "Interesse der Angelsachsen für das Griechentum" wenig zu tun.

Varianten ans Tib. A. III, wo die von Thorpe beigefingten angaben der sprecher durchweg fehlen: 1) loquamur $\mathrm{T}$ 2) sinaxes $\mathrm{T}$ ?) cantores

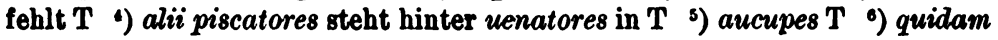
autem coci] loci $\mathrm{T}$ (was offenbar ans coci verderbt ist) ${ }^{7}$ ) etiammodo $\mathrm{T}$ s) $O, O$, magnus labor est $\mathrm{T}{ }^{9}$ ) et fortis fehlt $\mathrm{T}{ }^{10}$ ) Habeo utique] Etiam habeo $T{ }^{11}$ ) surgo bis discalciatus et fehlt $T{ }^{12}$ ) esto $T$ ") eas $T$ 
in die, et caulas eorum ${ }^{16}$ ) cotidie ${ }^{14 .}$ ) moueo. Caseum ${ }^{15}$ ) et butirum insuper ${ }^{16}$ ) facio; et fidelis sum domino meo.

[M.]: $O$ bubulce, quid operaris tu?

R.: O domine mi, multum laboro. Quando arator disiungit boues, ego duco eos ad pascua in campum ${ }^{17}$ ) et tota nocte sto super eos uigilando propter fures; et iterum mimo mane adsigno eos aratori bene pastos et adaquatos.

D. [lies M. $\left.{ }^{18}\right)$ ]: Est iste ex tuis sociis?

R. $\left.{ }^{19}\right)$ : Etiam est.

Int. ${ }^{20}$ ) [d. i. Interrogatio]: Scis tu aliquid?

R. ${ }^{21)}$ : Unam artem scio.

Int. $\left.{ }^{20}\right)$ : Qualem? ${ }^{22}$ )

R. ${ }^{21)}$ : Uenator sum.

Int. $\left.{ }^{20}\right)$ : Cuins?

R. ${ }^{21}$ ): Regis, sine ${ }^{23}$ ) ducis, aut alicuius principis. ${ }^{28}$ )

Int. $\left.{ }^{20}\right)$ : Quomodo exerces tuam artem?

R. $\left.{ }^{31}\right)$ : Plecto mihi retia et pono ea in loco apto et instigo canes meos, ut feras persequantur, usque quo perueniunt ad retia improuise et sic inretientur; et ego iugulo eos in retibus.

Int. $\left.{ }^{20}\right)$ : Nescis uenare nisi cum retibus?

R. ${ }^{21)}$ : Etiam sine retibus uenare possum.

[Int.] $\left.{ }^{20}\right)$ : Quomodo?

$\boldsymbol{R}^{21}$ ): Cum uelocibus canibus insequor feras.

Int. $\left.{ }^{20}\right)$ : Quales feras maxime capis? lepores.

$R^{21}$ ): Capio cernos et apros et dammas et capreos; aliquando uero ${ }^{24}$ )

Int. $\left.{ }^{20}\right)$ : Fuisti hodie in uenatione?

R. ${ }^{21}$ ): Non fui, quia dominicus dies est; sed heri fui cum multitudine hominum. ${ }^{25}$ )

Int. $\left.{ }^{20}\right)$ : Quid cepisti?

R. ${ }^{21): ~ D u o s ~ c e r u o s ~ e t ~ u n u m ~ a p r u m ~ t r i u m ~ a n n o r u m . ~}{ }^{20}$ )

Int. $\left.{ }^{20}\right)$ : Quomodo cepisti eos?

R. ${ }^{21}$ ): (eruos cepi in retia ${ }^{27}$ ) insequentibus canibus ${ }^{28}$ ); aprum autem ${ }^{20}$ ) iugulaui cum acuto gladio. ${ }^{30}$ )

Int. $\left.{ }^{20}\right)$ : Quomodo ausus finisti ${ }^{\text {s1) }}$ iugulare aprum?

$\boldsymbol{R}^{21}$ ): Canes perduxerunt cum ad me; ego autem ${ }^{32}$ ) e contra stans subito iugulaui eum.

[Int.] ${ }^{20}$ ): Ualde audax fuisti tunc. in siluis.

R. ${ }^{21}$ ): Non debet uenator formidolosus esse, quia uarie bestie morantur

Int. $\left.{ }^{20}\right)$ : Quid facis de tua uenatione?

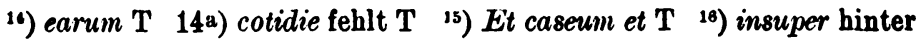
moweo in $\mathrm{T}{ }^{17}$ ) in campum fehlt $\mathrm{T}{ }^{18}$ ) $M$. WW ${ }^{19}$ ) $D$. WW ${ }^{20}$ ) $M$. WW ${ }^{21)} V$. WW ${ }^{22}$ ) Quale est? $T{ }^{23}$ ) siue ducis bis principis fehlt $T{ }^{24}$ ) aliquando uero] et aliquando $\mathrm{T}{ }^{25}$ ) cum multitudine hominum] in venatione $\mathrm{T}{ }^{20}$ ) trium annorum fehlt $\mathrm{T}{ }^{27}$ ) retibus $\mathrm{T}{ }^{28}$ ) insequentibus canibus fehlt $\mathrm{T}{ }^{20}$ ) et aprum $\mathrm{T}{ }^{30}$ ) cum acuto gladio fehlt $\mathrm{T}{ }^{31}$ ) fuisti ausus $\mathrm{T}{ }^{32}$ ) et ego $\mathrm{T}$ 
R. ${ }^{21}$ ): Ego do regi, quicquid capio, quia sum eius uenator. ${ }^{82}$ )

Int. $\left.{ }^{20}\right)$ : Quid dat ipse tibi, uel ${ }^{33}$ ) cuius honoris es inter tuos socios? ${ }^{33}$ )

R. ${ }^{21}$ ): Primum locum teneo in sua aula ${ }^{34}$ ); uestitum autem et uistum satis mihi tribuit. ${ }^{35}$ ) Aliquando uero anulum mihi aureum et armillam atque optimum equum concedit ${ }^{36}$ ), ut libentius artem meam exerceam.

[Int. $]^{20}$ ): Qualem artem scis tu?

R. ${ }^{39}$ ): Ego optimus sum piscator et ingeniosus. ${ }^{37}$ )

Int. ${ }^{20}$ ): Quid adquiris de tua arte?

R. ${ }^{39}$ ): Uictum cotidianum mihi et mee familie, et uestimenta pretiosa, pecuniam insuper non modicam. ${ }^{38}$ )

Int. $\left.{ }^{20}\right)$ : Quomodo capis pisces?

R. $\left.{ }^{39}\right)$ : Ascendo nauem et pono retia mea in amne, et hamum proicio et sportas et [f. 19a], quicquid ceperint, sumo.

[Int.] ${ }^{20}$ ): Quid, si pisces inmundi fuerint ? ${ }^{40}$ )

[R.]: Foras eos proicio; mundos autem mihi in escam sumo."1)

Int. ${ }^{20}$ ): Ubi uendis pisces tuos?

R. $\left.{ }^{88}\right)$ : In ciuitate.

Int. $\left.{ }^{20}\right)$ : Quis emit illos? uendere.

R. ${ }^{39}$ ): (iues ciuitatis illius. ${ }^{42}$ ) Non possum tot capere, quot possum

Int. $\left.{ }^{20}\right):$ Quales pisces capis?

R. $\left.{ }^{29}\right)$ : Anguillas, lucios, capitones, tructas ${ }^{43}$ ) et murenulas innumerabiles "6) et qualescunque in amne natant. ${ }^{45}$ )

Int. $\left.{ }^{20}\right)$ Cur non piscaris in mare $\left.{ }^{46}\right)$ ? ad mare.

R. ${ }^{89}$ ): Aliquando facio, sed raro, quia magnum nauigium mili est.

Int. $\left.{ }^{20}\right)$ : Quid capis in mare $\left.{ }^{46}\right)$ ?

$\boldsymbol{R}^{\mathrm{Bg}}$ ): Alleces, isicios, delfinos, sturias, ostreas, cancros ${ }^{47}$ ), musculas, polipedes et similia. ${ }^{48}$ )

Int. $\left.{ }^{20}\right)$ : Uis capere aliquem cetum?

R. ${ }^{\text {s9): Nolo. }}$

[Int.] $\left.{ }^{20}\right):$ Quare?

R. ${ }^{39}$ ): Quia periculosa res est capere cetum. Tutius enim est ire mihi ${ }^{49}$ ) ad amnem cum amoso) meo, quam ire cum multis nauibus in uenationem ballenę.

32) uenator eius $\mathrm{T}{ }^{\text {33) }}$ uel cuius bis socios fehlt $\mathrm{T}$ 34) Primum bis aula fehlt $\left.\mathrm{T}{ }^{25}\right)$ uestitum autem et uistum satis mihi tribuit] Uestit me bene et pascit $\mathrm{T}{ }^{88}$ ) Aliquando uero anulum mili aureum et armillam atque optimum equum concedit] aliquando dat mihi equum aut armillam $\mathrm{T}$ $\left.{ }^{87}\right)$ Ego sum piscator $\mathrm{T}{ }^{38}$ ) Uictum et uestitum et pecuniam $\mathrm{T}$

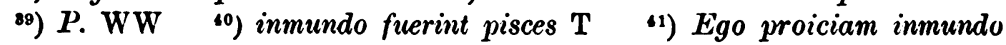
foras et sumo mihi mundos in escam $\mathrm{T}{ }^{42}$ ) Die hs. hat illos mit unterpungiertem (also getilgten) $o$ und iu darüber. - ciuitatis illius fehlt $T$ 4) Anguillas et lucios, menas et capitones, tructos $\mathrm{T}$ 4) murenulas innumerabiles] murenas $T{ }^{45}$ ) natant saliu $T{ }^{46}$ ) Von später hand geändert in mari ${ }^{47}$ ) et cancros $\mathrm{T}{ }^{48}$ ) polipedes] torniculi, neptigalli, platesia, et platissa et polipodes $\mathrm{T}{ }^{49}$ ) Tutius est milii ire $\mathrm{T}{ }^{50}$ ) amo (lies hamo)] homo $\mathrm{T}$ 
Int. $\left.{ }^{20}\right)$ : Cur sic?

R. ${ }^{39}$ ): Quia carius est mihi capere piscem, quem possum occidere, quam illum, quem ${ }^{51}$ ) non solum me, sed etiam meos socios uno ictu potest mergere aut mortificare.

[Int.] ${ }^{20}$ ): Et tamen multi capiunt cetos et euadunt maris ${ }^{52}$ ) pericula maximumque ${ }^{53}$ ) pretium inde adquirunt.

R. ${ }^{39}$ ): Uerum dicis, sed ego non audeo propter mentis meę ignauiam.

Int. $\left.{ }^{20}\right)$ : Quid dicis $t u$, a uceps? Qualiter nel ${ }^{54}$ ) quomodo decipis aues?

1R. ${ }^{55}$ ): Multis modis $\cos ^{58}$ decipio: aliquando retibus, aliquando laqueis, aliquando glutino, aliquando sibilo, aliquando accipitre, aliqnando decipula.

Int. $\left.{ }^{20}\right)$ : Habesne ${ }^{57}$ ) accipitrem?

R..$^{55}$ ): Habeo non solum unum, sed etiam quamplures. ${ }^{58}$ )

Int. $\left.{ }^{20}\right)$ : Scisne ${ }^{59}$ ) domitare eos?

R. $\left.{ }^{55}\right)$ : Utique, bene ${ }^{60}$ ) scio. Quid deberent mihi nisi scirem eos domitare. ${ }^{61}$ )

[Int.] ${ }^{62}$ ): Da milhi tunc ${ }^{63}$ ) unu $\mathrm{mn}$ ex illis. ${ }^{64}$ )

K. ${ }^{55}$ ): Dabo libenter, si mihi dederis ${ }^{65}$ ) unum uelocem canem.

Int. ${ }^{66}$ ): Qualem accipitrem uis habere: maiorem aut minorem? meliorem ant peiorem? ${ }^{67}$ )

$R .:$ Maiorem peto ac meliorem. ${ }^{68}$ )

Int. $\left.{ }^{20}\right)$ : Quomodo pascis tuos accipitres? ${ }^{69}$ )

R. ${ }^{55}$ ): Ipsi pascunt semet ipsas ${ }^{70}$ ) et me in hieme; et in ueve dimitto eos auolare in $\left.{ }^{11}\right)$ siluam; pullos autem eorum capio ${ }^{72}$ ) in autumno et domitare eos facio. ${ }^{78}$ )

Int. $\left.{ }^{20}\right)$ : Cur autem domitos permittis a te auolare? ${ }^{74}$ )

R. ${ }^{55}$ ): Quia eos $^{75}$ ) nolo pascere in estate, eo quod nimium comedunt.

[Int.] $\left.{ }^{20}\right)$ : Multi uer. ${ }^{76}$ ) pascunt domitos per ${ }^{77}$ ) estatem, ut iterum habeant paratos.

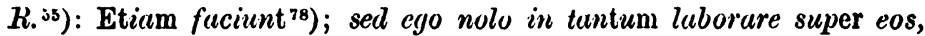
quia scio posse me leuiter alios ${ }^{79}$ ) capere.

[fol. 19b] Int. ${ }^{20}$ ): Quid dicis $t u$, mercator?

R. ${ }^{80}$ ): Ego dico, quod utilis sum regi eiusque conluterane $\left.{ }^{81}\right)$, ducibus et principibus $\left.{ }^{82}\right)$, omnique ${ }^{83}$ ) populo.

Int. $\left.{ }^{20}\right)$ : Quomodo? ${ }^{84}$ )

${ }^{51)}$ quam illum quem] qui $\mathrm{T} \quad{ }^{32}$ ) maris fehlt $\mathrm{T} \quad{ }^{53}$ ) et magnum $\mathrm{T}$ ${ }^{54)}$ Qualiter uel fehlt $\left.\mathrm{T}{ }^{{ }^{55}}\right) \mathrm{A}$. WW ${ }^{58}$ ) decipio anes $\mathrm{T}{ }^{57}$ ) Habes $\mathrm{T}$ ${ }^{68}$ ) Dafür: Habeo $\mathrm{T}{ }^{59}$ ) Scis $\mathrm{T}{ }^{60}$ ) Utique, bene] etiam $\mathrm{T}{ }^{61}$ ) domitare eos $\left.\mathrm{T} \quad{ }^{62}\right) V$. WW ${ }^{63}$ ) tunc fehlt $\mathrm{T}{ }^{64}$ ) ex illis] accipitrem $\mathrm{T}$

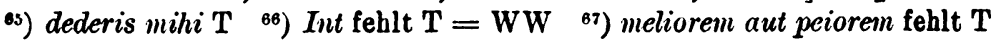
${ }^{68}$ ) Da mihi maiorem $\mathrm{T} \quad{ }^{69}$ ) accipitres tuos $\mathrm{T} \quad{ }^{70}$ ) semet ipsas] se $\mathrm{T}$ ${ }^{71}$ ) in] ad $\mathrm{T}{ }^{72}$ ) et capio mihi pullo $\mathrm{T}{ }^{73}$ ) domito eos $\mathrm{T}{ }^{74}$ ) Et cur permittis domitos auolare a te $\mathrm{T} \quad{ }^{75}$ ) eos hinter pascere $\mathrm{T}{ }^{76}$ ) Et multi $\mathrm{T}$ ${ }^{77)}$ super $\mathrm{T}{ }^{78}$ ) faciunt mit $a$ alls $i$ korrigiert; sis faciunt $\mathrm{T}{ }^{79}$ ) posse one leuiter alios] alios non solum unum sed etiam plures $\mathrm{T}{ }^{\text {so }}$ ) Mer. WW $\left.{ }^{81}\right)$ eiusque conlaterane] et $\mathrm{T}{ }^{82}$ ) principibus] diuitibus $\mathrm{T}{ }^{83}$ ) et omni $\mathrm{T}$ 8c) Et quomodo T 
R. ${ }^{80}$ ): Ego nauem ascendo cum meis mercibus ${ }^{85}$ ) et ultra marinas partes nauigo ${ }^{86}$ ) measque res uendo ${ }^{87}$ ) et pretiosas res, que in hac terra non nascuntur, emo ${ }^{88}$ ) et huc ${ }^{89}$ ) uobis adduco ${ }^{90}$ ) cum magno periculo super mare; et aliquando naufragium patior cum iactura omnium mearum rerum ${ }^{91}$ ) uix ui(uius euadens. ${ }^{92}$ )

[Int.] $\left.{ }^{20}\right)$ : Quid ${ }^{92 a}$ ) tu, sutor, utilitatis ${ }^{98}$ ) operaris nobis?

R.94): Est quidem ars mea uobis utilis ualde ${ }^{95}$ ) et necessaria.

Int. ${ }^{20}$ ): Quomodo?

R. ${ }^{94}$ ): Ego emo cutes et pelles easque preparo ${ }^{98}$ ) arte mea, et facio ex eis calciamenta diuersi generis, hoc sunt $\left.{ }^{97}\right)$ : subtulares $\left.{ }^{98}\right)$, ficones, caligas $^{99}$ ), et ocreas, utres, frenos ${ }^{100}$ ), falera, flascones, cassidilia $\left.{ }^{101}\right)$, calcaria, chamos $\left.{ }^{102}\right)$, peras, marsupia; et nemo uestrum uult hiemare $\langle e t\rangle^{103}$ ) equitare ${ }^{104}$ ) sine arte mea. ${ }^{105}$ )

Int. $\left.{ }^{20}\right)$ : $O$ salinator, refer nobis ${ }^{108}$ ), quid nobis proficit tua ars? ${ }^{107}$ )

R. ${ }^{24}$ ): Multum ars mea omnibns prodest ${ }^{108}$ ): nemo uestrum gaudio fruitur in prandio aut cena, nisi hospita ci fuerit ars mea. ${ }^{109}$ )

[Int.] ${ }^{20}$ ): Quomodo?

[R. $\left.{ }^{94}\right):$ Quis hominum dulcibus perfruitur cibis sine sapore salis? Quis replet cellaria sua siue prumptuaria ${ }^{110}$ ) sine arte mea? Ecce butirum omne et caseum perit uobis, nisi ego custos assim, qui nec saltem holeribus uestris dulciter ${ }^{111}$ ) sine me utimini.

(3) Das vorletzte blatt fol. 73 (= Plantinus fol. 48) enthält in fortlaufendem text ein kurzes lateinisches glossar ohne jede sachliche oder alphabetische ordnung. Auch dieses glossar, das ebenfalls um 1100 geschrieben sein mag, bietet zwei altenglische glossen, und zwar als ursprüngliche bestandteile des textes. Es sind dies die beiden glossen:

276 Insolentiam . for-2venednessa ${ }^{1}$ ) fol. $48^{\mathrm{b}}$

Passiuis . wiallese . zoretende ${ }^{2}$ ) fol. $48^{\mathrm{b}}$

${ }^{85)}$ ascendo nauem cum mercibus meis $\mathrm{T} \quad{ }^{80}$ ) nauigo vor ultra $\mathrm{T}$ $\left.{ }^{87}\right)$ et uendo meas res $\mathrm{T}{ }^{88}$ ) emo vor pretiosas $\mathrm{T}{ }^{88}$ ) huc über der zeile ${ }^{90}$ ) adduco uobis huc $\mathrm{T}$ (1) rerum mearum $\mathrm{T}{ }^{\text {92 }}$ ) In $\mathrm{T}$ folgen hier noch zwei fragen mit längeren antworten über des kaufmauns tätigkeit (=WW $94^{86}-97^{8}$ ) ${ }^{92 \times}$ ) quid hinter sutor $\mathrm{T}{ }^{93}$ ) utilitatis hinter nobis $\mathrm{T}{ }^{94}$ ) $\mathrm{S}$. WW $\left.{ }^{95}\right)$ utilis ualde uobis $\mathrm{T}{ }^{{ }^{96}}$ ) et preparo eas $\mathrm{T}{ }^{97}$ ) hoc sunt fehlt $\mathrm{T}{ }^{88}$ ) subtalares et $\mathrm{T}{ }^{90}$ ) coligas $\mathrm{T}{ }^{100}$ ) frenos et $\mathrm{T}{ }^{101}$ ) et casidilia $\mathrm{T}{ }^{102}$ ) et chamos, peras et $\mathrm{T}{ }^{103}$ ) statt dessen rasurstelle ${ }^{104}$ ) et equitare fehlt $\mathrm{T}{ }^{105}$ ) mea arte $\mathrm{T}{ }^{108}$ ) refer nobis fehlt $\mathrm{T}{ }^{107}$ ) ars tua $\mathrm{T}{ }^{108}$ ) prodest vor ars $\mathrm{T}$ ${ }^{109}$ ) ars mea hospita ei fuerit $\mathrm{T}{ }^{110}$ ) promptuaria $\mathrm{T}{ }^{111}$ ) dulciter fehlt $\mathrm{T}$.

1) Auf dieses in den wörterbüchern fehlende wort wies schon Zupitza im Archiv LXXIX 89 und nach ihm Napier, Contributions to 0. E. Lexicograpy 8. 25 hin. Man vgl. auch die Cleopatra-glosse insolentiam ' $p a$ forwenedan' (W.-W. $513^{85}$ ).

2) $\mathrm{Zu}$ lat. Passiuis ist jedenfalls oculis zu ergänzen, da das ae. zore- 
(4) Den schluls bildet auf fol. $73^{\mathrm{b}}-74^{\mathrm{a}}$ (= Plantinus fol. $48^{b}-49^{a}$ ) ein lateinischer brief an einen priester $A E l f$. (= Elfric ?), den Junius gleichfalls abgeschrieben hatte und der nach der handschrift hier folgen mag. Dieser brief scheint von derselben hand geschrieben, wie das lateinisch-altenglische glossar (siehe oben unter 2 b). Er war vermutlich als stilmuster gedacht - trotz seines reichlich gespreizten Lateins.

Facundissimo sacerdotum Ailf. philosophice documento discipline mente tenus delibuto, non cunctorum peripsema sincellitarum ${ }^{1}$ ), sic per caducam transire doxam, ut non ammittatur perpetua. Scimus Michahelem cum aliis supernorum ciuium uirtutibus presentie Dei semper adesse eosdemque diuina contemplari misteria. Et occulta Dei iudicia presenti sepe mundo eis adnuntiantibus reuelantur eorumdemque suffragio totius regitur machina cosmi et dininas indesinenter pulsant aures pro cunctorum piaculis populorum. Ita tu, sacerdos egregie 2 ., nostri regis consiliis obtutibus semper assistis et secreta eiusdem consilia a te non sunt abscondita, sed per tue industriam sapientie discernendo rimantur. Apud eundem uero multorum subuenis diuitum et inopum miseriis. Unde totis imploro nisibus tue serenitatem beniuolentię, ut per tui prudentiam consilii mihimet subuerias apud nostram uidelicet basilissam ${ }^{2}$ ), quatinus quoddam piscium uiuarium in uilla Niw. [wohl = at Niwan tune] sua misericordia milii indulgeat, ut meam a carne abstinentiam uiuendo defendere ualeam. Coram Deo testificor, quia die noctuque non sum immemor suę ipsius anime, sed in sacrarum sollempniis missarum psalmodiisque pecu[fol. 49a]liaribus eiusdem reminiscor. Et adhereat lingua mea faucibus meis, si non meminero teimet in orationibus apud Deum assiduis.

Perlege tamen et, que peto, perfice clemens et mihimet misero miseriis miserere misello, ut mihi sint pisces et nostre sint tibi misse. Si pisces

tende 'stierend' bedeutet. Für das bei Bosworth-Toller nicht belegte ae. jorettan 'stieren, starren' vergleiche die Aldhelm-glosse in Reg. 7. D. XXIV

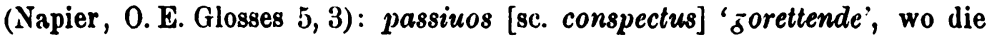
Aldhelm-glosse in Reg. 6. A. VI das einfache zoriende (uu zorian 'stieren') und die Brïsseler Aldhelın-glossen widzille zoretunze (verbalsubstantivum) lesen; Chrodegang - regel (Napier, Contributions 8. 34): vagis oculis 'zoretyndum eazum'; Elfric's Hom. I j30: pa eazan, pe nu ... zoretende hwearftliaj; Wulfstan 234 ${ }^{18}$ : Jat hine laerd se deofol, pat he stande and zorette and locize underbac ut. - Das davorstehende ae. widlese ist nicht ganz sicher zu erklären. In lichte der oben zitierten Aldhelmglosse betrachtet, scheint es eine ähnliche bildung mit ähnlicher bedeutnng wie ae. widzill(e), wīdzal (zu $z \bar{a} l$ 'geil'?) und widlāst (zu lāst 'fufsfpur') zu sein. Dann liefse sich der zweite bestandteil -lese wohl zu ae. løs 'die weide' stellen, und das ganze wort widles als 'weitweidend, umberschweifend' deuten. Widlose zoretende 'weitweidend starren' wäre schliefslich keine ubble übersetzung für passivis oculis.

1) D. i. mlat. symcellita 'mitmönch'.

2) D. i. $\beta \alpha \sigma i \lambda \iota \sigma \sigma \alpha$ 'königin'. 
aderunt, aderunt salmodia grata. Nuthus atque bonus multos adquirit amicos. Perfice uiuendo, ut moriendo uiuere possis. Einge namque Deus dicet tibi, serue fidelis: Si fratrem frater iunerit, tunc consolabuntur et capient pariter bona perpetualia semper.

(5) Vorgesetzt ist dem Antwerpener teile der handschrift ein einzelnes schutzblatt (fol. 1), auf welches vier verschiedene schreiber des 11. jahrhunderts lateinische verse eingetragen haben, von denen die drei ersten altenglische namen aufweisen.

(a) Das erste gedicht von vier zeilen, das mehrfach gänzlich verblafste oder abgeschabte stellen aufweist, erwähnt die heiligen frauen $A$ Ebeldripe $(\dagger 679)$ und $E a d g\langle y\rangle$ ( $(\dagger 984)$.

(b) Dann folgen von einem zweiten schreiber sechs hexameter, die den Angelsachsenkönig Eadweard den märtyrer († 978), den heiliggesprochenen Mercierkönig Coenclm (um 819) sowie den römischen märtyrer und heiligen Eustachius ( $† 118$ ?) erwähnen. Diese verse lauten folgendermaisen:

Altaris titulus profusus crismate huius.

Sanctifico almorum sub nomine christicolarum:

Cesaris Eadweardi, qui Christi corpore martyr;

Martyris Eustachii, domini qui sanguine testis;

Est athleta Dei fortis qui necne Kenelmi;

Istorum pia prex cunctos uniet huc uenientes.

(c) An dritter stelle folgen wiederum von anderer hand vier elegische distichen, die den am 16. November 1005 erfolgten tod ${ }^{1}$ ) des erzbischofs Flfric von Canterbury (9951005) beklagen. Dals wirklich dieser Elfric gemeint, beweilst die angabe des todestages in vers 7-8. Die schon von Junius kopierten und danach von Wright-Wülker mitgeteilten verse lauten folgendermalsen:

Pressulis hic redolent Allfrici lypsana summi,

Qui rector patrię perstitit Angligenę.

Inter pontifices rutilans ceu mystica lampas,

Defensor regni necne salus populi.

Heu nostram fera mors extinxit nempe lucernam,

Heu nostri cecidit fons quoque consilii.

Hunc sexta decimaque kalendas namque Decembris, Assumpsit Michahel seu dedit Emanuhel.

1) Vgl. W. G. Searle, Anglo-Saxon Bishops, Kings, and Nobles (Cambridge 1899) s. 11. 
(d) Zum schlufs setzt noch eine etwas rohe, ungeübte schreiberhand folgende rätselfrage in vier hexametern dahin:

Bis bine fiale caritatis nos uocitamur

Nosque duę natu maiores dicimur esse.

Si uos maiores nobis modo uultis adesse,

Non nos peiores similes tamen esse uidemur.

(6) Ebenso ist dem Londoner teile ein einzelnes blatt fol. 1 vorgeheftet, welches ein lateinisches gedicht in 49 distichen enthält, die ein armer priester französischer abstammung namens Herbert (v. 3) an einen günstiger gestellten amtsgenossen, den abt Wulfgar (v. 2), gerichtet hat. Dies erfahren wir aus dem anfange:

Summo pastori miserandum transfero carmen

Nunc, Vulfgare, tibi, qui pius es miseris;

Herbertusque vocor non dignus namque sacerdos;

Francia me genuit seu puerum docuit.

Das gedicht ist gedruckt von E. Dümmler im 'Neuen Archiv der Gesellschaft für ältere deutsche Geschichtskunde' X (1885) 351-353.

Über die herkunft der handschrift konnte ich nur folgendes ermitteln. Wie wir oben gehört, befindet sich heutzutage der hauptteil des manuskriptes in dem Musée Plantin-Moretus zu Antwerpen, d. h. dem 1876 von der Antwerpener stadtverwaltung angekauften altvlämischen patrizier-woln- und geschäftshause des berïhmten buchdruckers Christoph Plantin (1514-1589) und seines schwiegersolnnes und nachfolgers Johan Moerentorf oder Moretus ( $\dagger$ 1610). Da Christoph Plantin ein ausgesprochener bücher- und handschriften-liebhaber war, liegt von vornherein die vermutung nahe, dals die handschrift schon seiner sammlung angehört hat, vielleicht also zu jenen manuskripten gehörte, welche der alte Plantin von den unter Heinrich VIII. nach Antwerpen geflüchteten mitgliedern des All Soul's College in Oxford erhalten hat.1) Die erstere vermutung wird anf das trefflichste bestätigt durch ein noch

1) Ferd. Vanderhaeghen, Musée Plantin, notice sur la bibliothèque plantinienne (Gent 1875) s. 12 [mir unzugänglich]; Henri Stein, Les manuscripts du Mnsée Plantin-Moretus, Gent 1886 (= Messager des Sciences historiques de Belgique, bd. LX) s. 5. 
heute im museum befindliches, altes inventar der bibliothek Christoph Plantins, dem Index bibliothecae Plantini von 98 pergamentblättern, welcher im jahre 1592 (laut fol. $32^{\mathrm{b}}$ ) angelegt war und auf fol. 92-94 im ganzen 83 handschriften aufführt. Dort finden wir in der ersten gruppe der handschriften, den Manuscripti oratores varii generis $m$. f. (d. h. in kleinfolio), an fünfter stelle unsere handschrift verzeichnet als:

\section{Excerptiones ex Prisciano; in pergameno.1)}

Wir können daraus den schlufs ziehen, dals die handschrift sich schon seit dem ende des 16. jahrhunderts in der sammlung Plantin befand. Dazu stimmt, dafs in dem gleichfalls noch erhaltenem bücherinventar, das sein enkel Balthasar Moretus im jahre 1650 anlegen liefs, unter den 154 handschriften des Catalogus manuscriptorum bibliothecae Balthasaris Moreti in officina Plantiniana Antverpie unter nr. 69 gleichfalls wieder ein

Priscianus; parvo $f^{\circ}$, charactere mediocre vetustatis ${ }^{2}$ ) erscheint.

Dieser tatsache, dafs sowohl 1592 wie 1650 sich der Kodex im besitze der familie Plantin-Moretus nachweisen lälst, scheint nun allerdings die angabe $\mathrm{zu}$ widersprechen, dals Fr. Junius seine abschrift aus einem manuskripte des malers Rubens gemacht habe. So berichtet uns wenigstens Wanley (ex membranis Rubenii Antwerpiani) und noch deutlicher Wright-Wülker und Thompson. Vorsichtiger drückt sich Zupitza aus, indem er sagt, dafs die handschrift Junius "durch die freundlichkeit docti illius generosique Rubenii Antwerpiani zugänglich geworden war". Und dies wird sicherlich das richtige treffen. Offenbar liegt die sache so, dals Junius die handschrift von dem besitzer durch die vermittlung des malers P. P. Rubens geliehen erhalten hat, der nachweislich mit der familie Plantin-Moretus in enger beziehung stand und mit Junius möglicherweise anläIslich dessen geschichte der antiken malerei (De pictura veterum, Amsterdam 1637) bekannt geworden war. Wir sollten daher die bezeichnung 1886) 8. 6.

1) Henri Stein, Les Manuscripts du Musée Plantin-Moretus (Gent

2) H. Stein a. a. o. 8. 17 . 
"Rubens-glossen" endgültig aufgeben und sie fortab vielmehr "Plantin-glossen" nennen.

Die abschrift des Junius, die vor 1640 , dem todesjahre des malers Rubens, angefertigt sein muls, lehrt uns, dals zu anfang des 17. jahrhunderts das manuskript noch in seinem ursprünglichen, vollständigen zustande war. Wann jene 24 Londoner blätter daraus entwendet sind, lälst sich nicht mehr festellen. Jedoch mufs dies zwischen ca. 1640, dem todesjahre Ruben's und ca. 1880, dem ungefäliren datum des heutigen einbandes des Antwerpener teiles geschehen sein.

$\mathrm{Ob}$ die handschrift in England entstanden ist, oder, wie Thompson will, in Flandern oder Nordfrankreich, wird sich nicht so leicht entscheiden lassen. Es ist richtig, dals die schrift - trotz des gebrauches insularer zeichen für $z, f, r$ und gelegentlich auch $s$ bei altenglischen wörtern - durchaus fränkischen charakter zeigt. Aber dies ist auch für eine in England geschriebene handschrift um jene zeit nicht verwunderlich, da mit dem beginn des 11. jahrhunderts die fränkische minuskel auch in England zur herrschaft gelangt. Ähnlich steht es mit Thompsons hauptargument für die annahme eines nicht-englischen schreibers, daIs nämlich die altenglischen glossen fehler und namentlich buchstabenvertauschungen aufweisen. Zunächst beweist diese tatsache aber nur, dafs der kopist der englischen glossen, sei es aus flüchtigkeit oder aus ungeübtheit - die etwas rohe, ungelenke schrift spricht mehr für letzteres-D, schreibfehler gemacht hat und dals ihm das insulare alphabet vielleicht nicht mehr ganz geläufig war, zumal buchstabenvertauschungen ja auch sonst bei sicher in Fingland geschriebenen handschriften des 11. jahrhunderts sich zeigen. Daher scheint es mir, bis stärkere beweise dagegen gefunden werden, das geratenste anzunehmen, dals mindestens all jene zutaten, welche nach England weisen, nämlich das Colloquium Elfrici, der brief an Elfric, die vier gedichte mit englischen adressaten und die drei glossensammlungen, welche altenglische wörter enthalten, in England geschrieben sind und dafs demzufolge die handschrift am ende des 11. oder anfang des 12. jahrhunderts in England sich befand. Die handschrift kann dann sehr wohl zu jenen manuskripten gehört haben, die Christoph Plantin im 16. jahrhundert von nach Antwerpen gefliuchteten 
mitgliedern des All Soul's College zu Oxford erstanden haben soll (s. oben s. 155).

Aus dem vorstehenden dürfte hervorgehen, dafs eine neuausgabe der beiden bei Wright-Wülker gedruckten altenglischen glossare $\mathrm{nr}$. IV und $\mathrm{V}$ ein dringendes bedürfnis ist, da die dort zu grunde gelegte abschrift des Junius nicht nur zahlreiche lesefehler und auslassungen und umstellungen anfweist, sondern auch zwei völlig getrennte, zeitlich und inhaltlich verschiedene glossare miteinander vermischt hat.

\section{Verzeichnis der besprochenen ae. wörter.}

Nr. $1-22=$ s. $99-102 ;$ nr. $23-275=$ s. $104-146 ;$ nr. $276-277=$ s. 152 .

ädl krankheit 265

adliz krank 257

afen-zebed abendgebet (d. i. gebet

zur vesper) 28

after nach 34

almesse almosen 57

ar vor 35

aersc-hen s. ersc-hen

aroling 8. yroling

aesc-protu ochsenzunge? 205

apel-boren edelgeboren 67

azu elster 133

an ein 55

$\bar{a}$-hende einhändig 256

än-sweze harmonisch 37

àtor-lābe irgend eine als gegengift

angesehene pflanze 190

$\bar{a}$-2oedan toll werden 271

a-royrpan genesen 85

bed-rtda bettlügerig 258

betwux zwischen 3

biscop-wyrt eibisch 196

biscop-royrtel zehrkraut 228

blaze bleihe 16

blere 1. blässig, 2. kahl 160

bleri(a)-pyttel mänsebussard 160

brin-wyrt braunwurz 179

byčyan kaufen 74, 75

byrnete ringelgans 19

candel-twist lichtputzschere 10

capün (afrz.) kapann 156, 158

ceo dohle 125

cerse kresse 238 clcefre klee 229

clāte klette 194, 206, 209

clif klippe 166

clif-uyrt klette 194

cnēow-hole(n) mänsedorn 182

coc hahn 156

col-māse kohlmeise 161

cost franenminze 177

cran kranich 144

cräroe krthe 120

cucu lebendig 61

culfre tanbe 113

cū-sceote holz- oder ringeltaube $\mathbf{1 1 5}$

custure (afrz.) naht 21

cwealm volkssterben, pest 266

crogld das volkssterben, pest 266

cyčen küken 154

cyrfet kürbis 169

cyta weihe 121

cytel kessel 11

dead tod 63

deaf taub 250

déofol-seoc vom tenfel besessen 263

deore tener 73, 74

dite dill 199

docce ampfer 198

doppa (?) taucher 98 anm.

dopp-ened duckente, bläfshuhn 141

drysne schrecklich $\mathbf{7 6}$

eall-hälzunz völlige heiligung 51

eall-offrunz brandopfer 48

earminz elender, ungltickseliger 245

earn adler 89 
earn-géap seeadler 142

edcucian wiederbeleben 63

edlean vergeltung 243

edleanunz gegenzahlung 80

efne s. *elefne

efor-fearn tilpfelfarn 240

eft-sona wiederum 4 (s. 99)

*el(e)fne alann 226

elehtre lupine 219

embe-smēazunz auslegung 9 (s. 101)

ened ente 104, 141

enne-leac zwiebel 207

eorס-zealla tausendgüldenkraut 231 , 233

ersc-henn wachtel 132

faestīc fest 5 (s. 99)

fearn farnkrant 236

feferfuze fieberkrant, mutterkrant 192

feld-royrt enzian 201

fen-fearn königsfarn 234

tic- royrt? feigenwurz 220

fina specht 137

finol fenchel 174

fiscere königsfischer 153

folclic volkstümlich 50

forscrenčan beschränken 7 (s. 100)

for-8crenct niedergeschlagen 7 (8.100)

fordfaran sterben 64,65

forwenednesse einbildung 275 (s. 152)

fuzel vogel 98, 103, 105, 162

fuzel-doppa (?) taucher 98

zoers gras 189

zalluc schwarzwurz, wallwurz 176

zan (d)ra gänserich 102

$z \bar{a} r-\sec z$ ozean 164

zeac kuckuck 127

zeaces-sūre sanerklee 178

$z^{a} r-l e a c$ knoblauch 212

zearve schafgarbe 185

zecyðness zeugnis 244

zeznidan zu pulver reiben 79

zehälzian weihen 44

zehät gelöbnis 81

zehlyttrian klïren 52

zemengan mengen 53,83

zemot-man versammlungsvorsteher 255

zemynd-leas wahnsinnig 267 zeolu(w)-earte gelbe bachstelze(?) 146

zeolna, lies zeolıoa 'sichler'? 140

zerim zahl 13

zesund gesund 270

zesyllan übergeben 42

zepunzen vorgerïckt 12

zebware einträchtig 36

zewitness zengnis 244

zeroit-sēoc gemütskrank 264

ze-(z)yht angeschirrt 6 (s. 99)

zift-leod hochzeitlied 15

zifu gabe 58

zloedene schwertlilie 202

zlida königsweihe 139

zliz-man spielmann 253

zod gott 42, 44

zodes-lāc gottesopfer 41

zold-finc distelfink 109, 145, 150

zorettan stieren 276 (s. 152)

zos gans 100

उos-hafoc hühnerhabicht 99

Jrindan zu pulver zerreiben 82,84

zrunde-swelze kreuzkrant 241

zyčan anschirren 6 (s. 99)

zyld-daz festtag 51 anm.

zyldic kultisch 51

$\zeta \bar{y} b$-corn wolfsmilch 213

hafer-blate sumpfschnepfe 111

häre-minte weirse minze? 235

harewinta s. häre-minte

heals-wyrt hasenohr? 210

healt hinkend 247

heap schar 25

hearpe harfe 34, 35

hearp-sanz harfensang 33.

Vgl. hearpan-sang 34, 35

heze-suzze feldsperling 117

helde rainfarn 186

henn? henne 108

henne-belle bilsenkraut 195

hẽope hiefe, hagebutte 189

heor(o)t-clætre steinklee? 218

hice meise 147 anm.

hīce-mäse blaumeise(?) 147

hizere häher 126

(h)leomoc ehrenpreis 168

hliud laut 26

hofe gundelrebe 227 
hof(e)rede 1 . buckelig 2 mit pestbeulen behaftet 259

hraefn rabe 123, 124

hrāzra reiher 92

(h)ramesa bärenlauch 191

hreofla voller geschwüre 260

hroc saatkrähe 138

hulfestre regenpfeifer 134

hulu nufsschale 1 (s. 99)

hūsel hostie; kommunion 54

hwocl-hunta walfischjäger 249

hwerhwette garke 200

hwilpe regenpfeifer 134 anm.

hwit-leac zwiebel? 214

hyll-häma feldgrille 118

hyl-royrt polei 187

läc geschenk 56

lāc-sanz opfersang 39

lama lahme, schwache 251

lanz-ľfe langlebig 66

lār lehre 50

lāwerce lerche 110

leof lieb 70

lic-prowvere aussätziger 261

litie lilie 167

Tine-twoize hänfling 152

lof-sanz lobgesang 23

lufestice liebstöckel 181

luffenditc lieblich 163

madere färberröte 239

*mad-wyrt wiesenkönigin 215 anm.

mazen-leas kraftlos 14

mazpa kamille 173, 237

masse-lac melsopfer 38

maro möve 112

maneg mancher 9

māra gröfser 131

medu-royrt bienenkraut, melisse 215

mengan mengen 53

mer(e)ce wilde sellerie 190

mid mit 53

minte minze 225

monab-secoc dem mondwechsel unter-

worfen, epileptisch 262

mučž-woyrt beifuls 204

myrre myrrhe(nharz) 53

nähweeder keins von beiden 2 (8. 99)

näper keins von beiden 3 (s. 99) uepte katzenminze 175

nihte-gale nachtigall 96, 101

niht-hrafn nachtreiher 124

niht-scadu nachtschatten 232

offrunz opfer 40, 46

onsazunz opfer 45

oðठ oder 76

pāwa pfan 87

peopa mark 18 (8. 101)

pic-bred schweinemast? 17 (s.101)

popiz mohn 221, 222

por-leac porree 216

pyttel bussard 160 anm.

radinz (gottesdienstliche) lesung 30

reps responsorium 29

rinde-clifre blanspecht $140 \mathrm{anm}$.

rose rose 170

rudduc rotkelchen 107

rīde rante 193

riih haarig 76

rüma trennung 20 (8. 102)

ryze roggen 22 (s. 102)

sa-ebbunz see-rücktritt 165

saza anssage 8 (8. 101)

sam-sweze zusammenklingend,

harmonisch 32

sanz gesang $24,26,31,32,34-37,55$

sāwl-sceat seelenschatz 41

scealfr kormoran 97

scraf kormoran 140 anm.

scric misteldrossel 119

scyl-ęazede schielängig 252

seam saum 21 (s. 102)

sizel-hweorfa ringelblume(?) 183

sinzan singen 25

slappolniss schläfrigkeit, schlafsucht 272

slaple [ast] schlaflosigkeit 271

smerinz-wyrt s. symering-wyrt

smepian glätten 77

snīte schnepfe 143

sniounz (opfer-)schlachtung 47

sōlsece ringelblume? 183

spear-hafoc sperber 149

staer star 130, 131

stcern = stearn 129

stamor stotternd 246

stan-mereče petersilie 224 
stearn 1. seeschwalbe, 2. star 90, 129 stede stätte 163

storc storch 106

sund-corn körnersteinbrech 208

sür-ēazede triefäugig $2 \breve{54}$

sūðerne wudu eberraute 180

swalwe schwalbe 151

swan schwan 91,93

swertlinz grasmücke? kohlmeise? 94

syllan geben; verkaufen.74

symerinz-voyrt (krause) malve? 230

syndrig besondere 41

turtle turteltanbe 122

twā zwei 3

twezzen zwei $2 t$

penunz gottesdienst 27,43

peowdom gottesdienst 28

brēo drei 6

pri-lyfe dreiblatt, sauerklee 178

prosle schwarzdrossel 148

burh-lāð sehr verhafst 72

purh-wacol durchwachend, sehr wach-

sam 275

$\bar{u} f$ uhu 135

$\bar{u} h$ t-zebed gebet zur frühmette 27

üle eule 95

นท-aðel-boren unedel geboren 68

undeore billig $73^{\mathrm{b}}, 75$

unzelimp-tīc unziemend, übermärsig 272

unzeswe.ze 'nicht zusammenklingend' 31

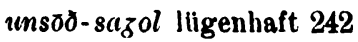

wäclīc weichlich; gering 69

wacol wachsam 273

wečen das wachsein 274

wealh-hafoc eine jagdfalkenart 159

wealh-wyrt alant 211 anm.

weal-wyrt zwerg-hollunder 211

vez-bræde wegerich 203

wid-løes weitweidend, umberschwei-

fend 277 (s. 152)

voizol weissagerisch 162

wilde wild 169, 171, 222

win wein 39,52

winn-zyrd weinrebe 171

win-tyfer trankopfer 49

wlips undeutlich sprechend (lispelnd;

lallend) 248

$w \bar{d} d$ wütig, toll 268

wodnys tollheit 269

wrenna zaunkönig 116, 147

voudu-cocc waldschnepfe 143

voudu-culfre holztaube 114

voudu-mereče wilde sellerie 223

wudu-rofe affodill 184

voulfes-camb kardendistel 217

uurp wert, preis 59

wur.oleas wertlos 60

wyrzan verfluchen 78

wyrznes verfluchung 81

voyrt kraut 188

wyrt-tūn arzneikräuter- und gemüse-

garten 172

ylfete schwan 86

yroling bachstelze 155

Berichtigungen.

S. 99, z. 26 lies stricti (statt sricti).

S. 131, z. 2 war docce kursiv zu drucken.

IseIPZIA.

Max Förster. 